AUTARQUIA ASSOCIADA À UNIVERSIDADE DE SÃO PAULO

MODELO COM QUALIDADES PSICOMÉTRICAS PARA AVALIAÇÃO DA CULTURA DE SEGURANÇA EM INSTALAÇÕES NUCLEARES

CLAUDIO SOUZA DO NASCIMENTO

Tese apresentada como parte dos requisitos para obtenção do Grau de Doutor em Ciências na Área de Tecnologia Nuclear - Reatores

Orientador:

Prof. Dr. Delvonei Alves de Andrade

Coorientador:

Prof. Dr. Roberto Navarro de Mesquita 
INSTITUTO DE PESQUISAS ENERGÉTICAS E NUCLEARES

Autarquia associada à Universidade de São Paulo

\title{
MODELO COM QUALIDADES PSICOMÉTRICAS PARA AVALIAÇÃO DA CULTURA DE SEGURANÇA EM INSTALAÇÕES NUCLEARES
}

CLAUDIO SOUZA DO NASCIMENTO

\author{
Tese apresentada como parte dos \\ requisitos para obtenção do Grau de \\ Doutor em Ciências na Área \\ de Tecnologia Nuclear - Reatores \\ Orientador: \\ Prof. Dr. Delvonei Alves de Andrade \\ Coorientador: \\ Prof. Dr. Roberto Navarro de Mesquita
}

Versão Corrigida

Versão Original disponível no IPEN

São Paulo

2015 


\section{Dedicatóría}

Este trabalho é dedicado à minha esposa cecilía "ín memoriam" com amor e gratidão por sua presença e compreensão das minhas ausências e pelo incessante apoio e incentívo em todos os momentos ao longo dessa jornada.

E aos meus filhos Priscila e caío, por sempre entenderem as minhas ausências e por estarem sempre presentes em todas as ocasiones, acredítando e confiando na superação desse desafio. 


\section{Agradecimentas}

Aa Prof. Dr. Deluanei agradeç imensamente pela competente arientaçãa deste trabalha. Atuon cam muita dedicaçãa e responsabilidade na canduç̃äa desse processa, em especial, na busca de apoia para a pesquisa, que sem a qual, este trabalho nãa seria passivel. Os seus conselhos e recomendaçäes faram fundamentais para a desenvoluimento deste trabalho. Sau muita grato aa $D_{r}$. Deluanci pela confiança depositada em mim e por sempre ter acreditada no men potencial, apesar dos problemas pessoais pelas quais passei nesse períada.

Aa Prof. Dr. Raberta coma coorientador deste trabalha pela atençãa $e$ apaia incondicional em tadas as atividades an longa desses anos. Agradeça, sobretuda, pela presteza e cordialidade cam que sempre me recebeu para tratar dos assuntos relacionados an trabaho e pela confianca depasitada em mim, desde a épaca da mestrada. O seu canhecimento e competência também foram essenciais para a realizaçãa deste trabalho.

Aos meus pais Claudia e Solange, as meus irmãas, irmäs, cunhados, cunhadas, sobrinhos e sobrinhas, aa meu gewro Fernando e à minha nora 
Déssica agradeça a todos profundamente par terem estado sempre ao men lada me apoianda e incentivanda e agradeça também pela compreensãa nos momentas de minha ausência.

Aa meu chefe e amiga Prof. Dr. Messias pela oportunidade de realizaçäa da pás-graduaçãa (mestrado e doutorada) e pela apoia e estímula em toda essa jornada. Nesses 13 anas de convivencicia a $D_{r}$. Messias muita me ensinou, contribuinda de forma determinante para men crescimento cientifica e intelectual.

Ao meu velho amigo Ramanata, companheira de trabalha há 30 anos e que muita me ajudou nas diversas etapas desta pesquisa, tanto na participaçãa de bancas examinadoras cama na contribuiçãa cam ideias de melhoria para a trabalho.

Aos meus amigos da CTMSP que, direta ou indiretamente, também colabararam para a realizaçãa deste trabalha. Agradeça em especial à Edicéia, amiga de trabalha há 30 anos, e ass amigos de sala Ten Mariana. Ten Ana Paula. Ten Saula. Ten Vinicios e Eliana par compartilharem comiga todos os momentos dessa trajetória. 
À valarasa contribuiçãa de tados as colaboradores da IPEN, CDTN, IEN, IRD, CRCN/CO, CRCN/NE e da CNEN-Sede pela atençãa e dedicaçãa na participaçãa da pesquisa, especialmente, as dirigentes desses institutas por disponibilizá-los para a avaliaçãa, que sem a qual. este trabalha mãa seria passível.

San muita agradecida também aas pesquisadores da USP, UFR,, CNEN-Sede, CDTN, IEN E IPEN que atuaram cama especialistas na ualidaçãa da instrumenta de pesquisa, pela presteza cam que aceitaram a encarga e pela dedicaçãa cam que desempenharam esse processa.

À Ora Patricia do IPEN, que além de atuar coma especialista na ualidaçãa da instrumenta de pesquisa, também prestan uma valiasa colabaraçãa nas revisães da 7ese. Sua dedicaçãa e seu esfarça proparcionaram significantes contribuiçöes para a trabalha. 


\title{
MODELO COM QUALIDADES PSICOMÉTRICAS PARA AVALIAÇÃO DA CULTURA DE SEGURANÇA EM INSTALAÇÕES NUCLEARES
}

\section{Claudio Souza do Nascimento}

\begin{abstract}
RESUMO
A operação segura e confiável de usinas nucleares não depende só da excelência técnica do projeto e construção, mas também das pessoas e da organização. Por essa razão, a importância dos fatores organizacionais nos mecanismos causais de acidentes tem sido reconhecida por uma série de organizações de pesquisas na Europa, EUA e Japão. Deficiências nesses fatores revelam fragilidades na cultura de segurança da organização. Uma preocupação básica na avaliação de uma cultura de segurança é garantir que os instrumentos de pesquisa sejam válidos e confiáveis. Nas áreas de saúde e de segurança do trabalho há uma série de instrumentos para avaliar a cultura de segurança, para os quais são apresentados estudos de suas proporiedades psicométricas (confiabilidade e validade), mas muito pouco com essas qualidades na área nuclear. No caso específico do Brasil, nenhum. Portanto, o principal objetivo deste trabalho foi desenvolver um modelo capaz de avaliar com medidas válidas e confiáveis a cultura de segurança de instalações nucleares. $\mathrm{O}$ instrumento de pesquisa foi desenvolvido com base em princípios psicométricos estabelecidos para pesquisas quantitativas e, portanto, foram realizadas a análise da confiabilidade e as validações de conteúdo, de face e de construto. $\mathrm{O}$ instrumento foi aplicado nos institutos de pesquisa da Comissão Nacional de Energia Nuclear (CNEN), obtendo-se um total de 226 questionários respondidos. Os resultados da pesquisa possibilitaram caracterizar demograficamente os respondentes e identificar muitos aspectos fortalecidos, mas também algumas fragilidades na cultura de segurança dos institutos avaliados. $\mathrm{O}$ instrumento apresentou boas evidências de confiabilidade com o coeficiente alpha de Cronbach de 0,95 para o instrumento como um todo. A validação de construto foi realizada por meio de uma análise fatorial utilizando-se a Análise de Componentes Principais (ACP) e rotação fatorial ortogonal Varimax. Os resultados da análise fatorial permitiram concluir que o instrumento possui boas evidências de validade de construto, mas também sugeriram alguns ajustes no caso de uma nova aplicação do instrumento.
\end{abstract}




\title{
MODEL WITH PSYCHOMETRIC QUALITY FOR SAFETY CULTURE ASSESSMENT IN NUCLEAR FACILITIES
}

\section{Claudio Souza do Nascimento}

\begin{abstract}
The safe and reliable operation of nuclear power plants does not depend only on technical excellence, but also it depends on people and on the organization. For this reason, the importance of organizational factors in causal mechanisms of accidents has been recognized by a number of research organizations in Europe, USA and Japan. Deficiencies in these factors reveal weaknesses in the organization's safety culture. A primary concern in evaluating a safety culture is to ensure that research instruments are valid and reliable. In the areas of occupational health and safety there are series of tools to evaluate the safety culture that present studies of its psychometric properties (reliability and validity), but very few of these qualities in the nuclear area. In the specific case of Brazil, none of these tools exist. Therefore, the main objective of this study is to develop a model to assess the safety culture in nuclear facilities with valid and reliable measures. The survey instrument was developed in accordance with the psychometric principles established for quantitative research and thus were held to analyze the reliability and validation of content, face and construct. The instrument was applied in the research institutes of the Brazilian Nuclear Energy National Commission (CNEN), yielding a total of 226 completed questionnaires answered. The survey results made it possible to characterize demographically the respondents and identify many strengthened aspects, but also some weaknesses in the safety culture of the evaluated institutions. The instrument showed good evidence of reliability with Cronbach's alpha coefficient 0,95 for the total instrument. The construct validation was performed by means of a factor analysis with Principal Component Analysis (PCA) extraction method and Varimax orthogonal factor rotation. Although factor analysis results have shown that the instrument has good evidence of construct validity, some adjustments in case of a new application of the instrument have also been suggested.
\end{abstract}




\section{SUMÁRIO}

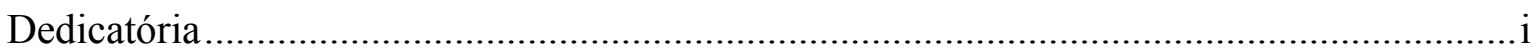

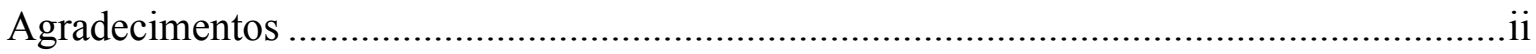

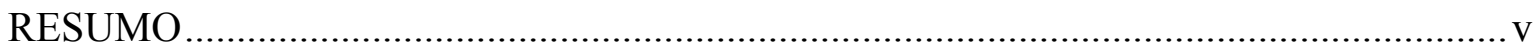

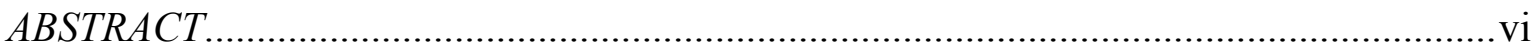

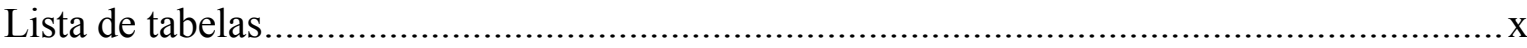

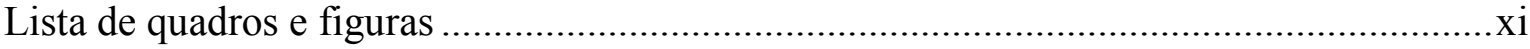

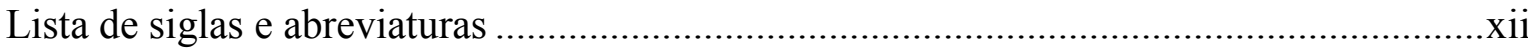

1 INTRODUÇÃ

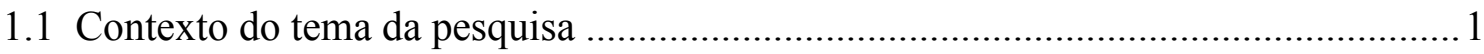

1.2 Relevância e contribuição original do trabalho ....................................................... 10

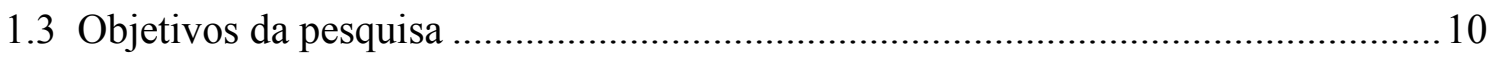

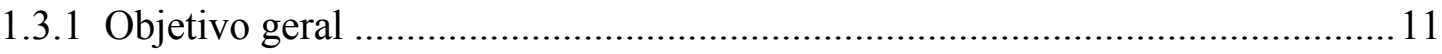

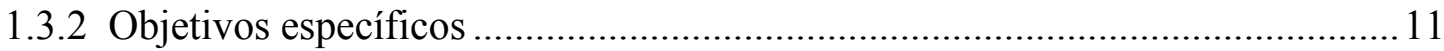

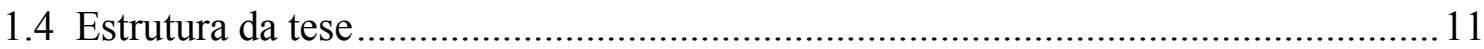

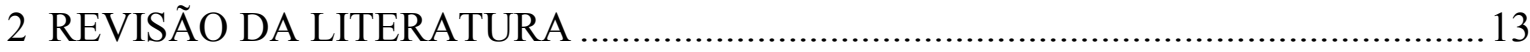

2.1 A visão contemporânea de modelos de acidentes .................................................... 13

2.2 A influência dos fatores humanos e organizacionais na gestão da segurança ........... 16

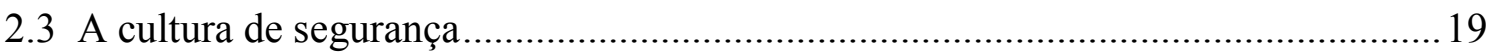

2.3.1 As definições da cultura de segurança .........................................................20

2.3.2 Cultura de segurança versus clima de segurança.......................................... 23

2.3.3 A influência da cultura nacional na cultura de segurança ...............................22

2.4 A dimensionalidade da cultura de segurança.......................................................24

2.5 As dimensões para uma cultura de segurança nuclear............................................ 30 


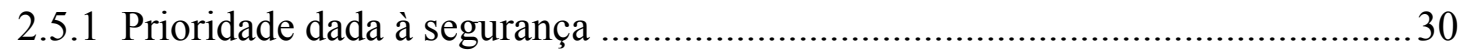

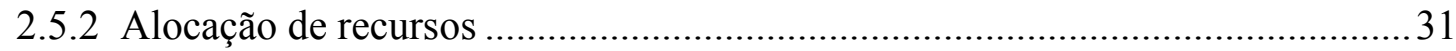

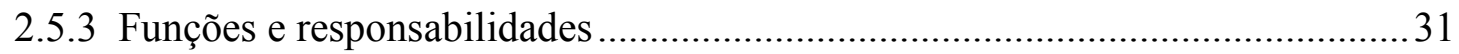

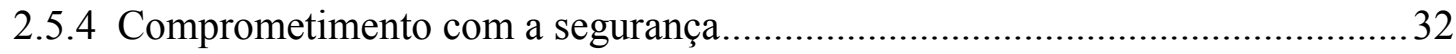

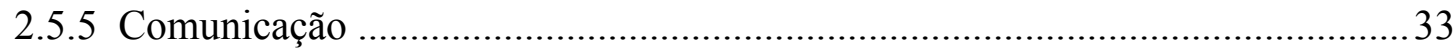

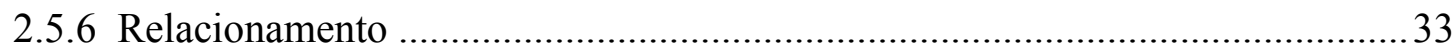

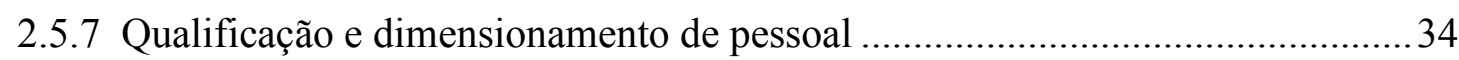

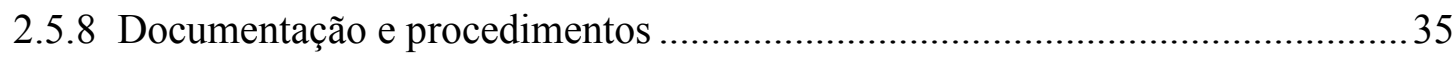

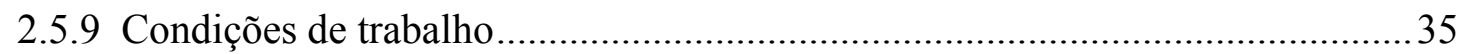

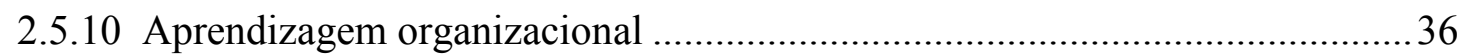

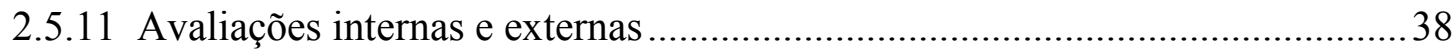

2.6 Uma revisão dos instrumentos de avaliação de cultura de segurança .......................39

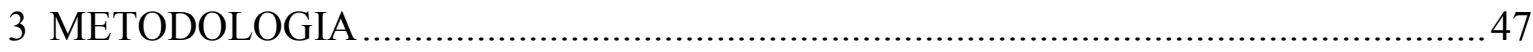

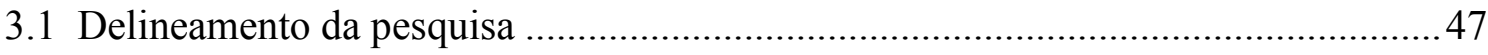

3.2 A modelagem de instrumentos de pesquisa .................................................... 48

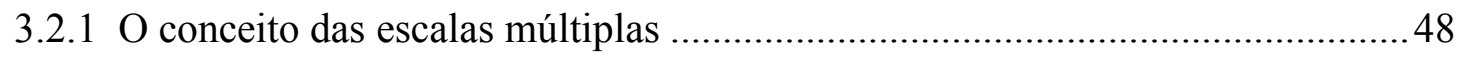

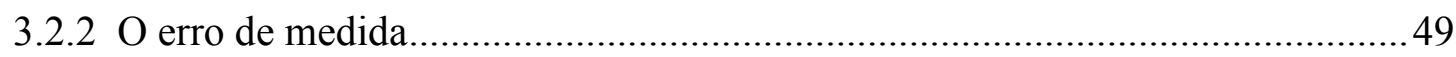

3.2.3 As propriedades psicométricas de instrumentos de pesquisa ..........................50

3.3 Concepção do modelo de mensuração da cultura de segurança ...............................5 54

3.3.1 Definição conceitual do modelo de mensuração ...............................................54

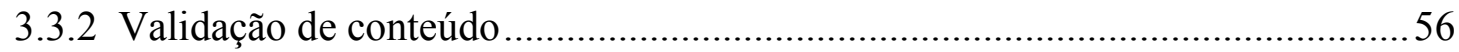

3.3.3 Validação de face (pré-teste) ..........................................................................59

3.3.4 Elaboração do instrumento de pesquisa (Questionário) ....................................62

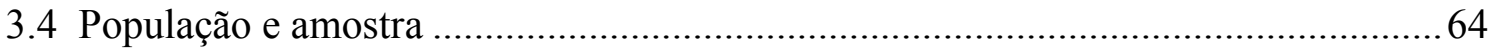

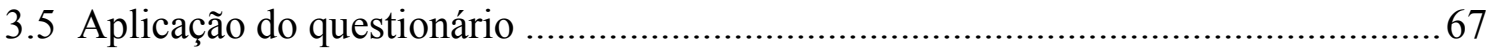


4 APRESENTAÇÃO E ANÁLISE DOS RESULTADOS DA PESQUISA .......................6

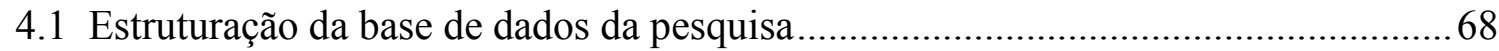

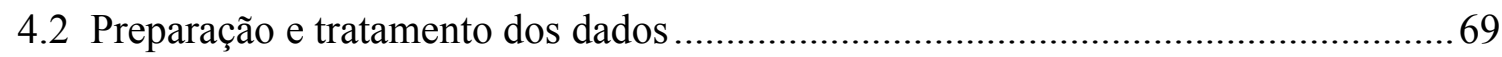

4.2.1 Análise e tratamento dos valores ausentes................................................... 70

4.2.2 Orientação positiva e negativa dos itens ........................................................ 73

4.2.3 Tratamento para as respostas "Não aplicável” .............................................. 75

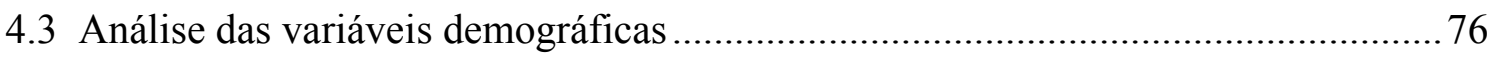

4.4 Análise dos indicadores de mensuração da cultura de segurança............................ 83

5 AVALIAÇÃO DAS PROPRIEDADES PSICOMÉTRICAS DO MODELO .................99

5.1 Análise da adequação do tamanho da amostra ....................................................... 94

5.2 Análise da confiabilidade do instrumento de pesquisa .......................................... 95

5.3 Validação de construto do instrumento de pesquisa ............................................. 101

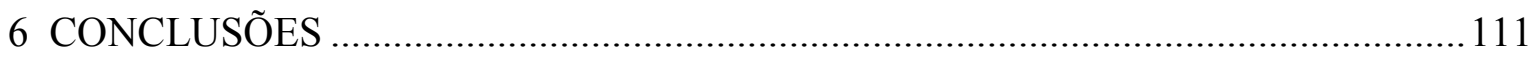

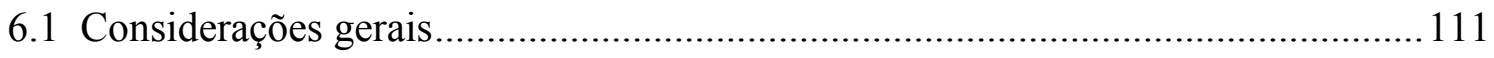

6.2 Limitações e sugestões para futuros desenvolvimentos ..................................... 115

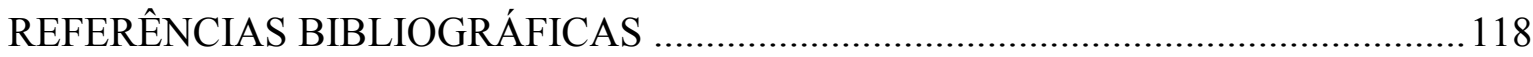

APÊNDICE A - Validação de conteúdo do instrumento de pesquisa ............................... 124

APÊNDICE B - Questionário de avaliação da cultura de segurança ................................ 125

APÊNDICE C - Distribuição de frequência das respostas ............................................... 148 


\section{Lista de tabelas}

Tabela 4.2-1 - Critérios para o tratamento de valores ausentes............................ 72

Tabela 4.2-2 - Processo de inversão da questão Q40............................................. 73

Tabela 4.2-3 - Distribuição de frequência da questão Q40 na forma invertida........ 74

Tabela 4.2-4 - Distribuição de frequência da questão Q40 na forma original......... 74

Tabela 4.2-5 - Classificação significativa de "Não aplicável"............................... 75

Tabela 4.3-1 - Caracterização da amostra por institutos da CNEN......................... 76

Tabela 4.3-2 - Caracterização da amostra pelo tempo de atividade na instituição... 77

Tabela 4.3-3 - Caracterização da amostra em relação à área de atuação................. 78

Tabela 4.3-4 - Caracterização da amostra em relação ao Cargo / Função............... 80

Tabela 4.3-5 - Caracterização da amostra em função da experiência nuclear.......... 81

Tabela 4.3-6 - Caracterização da amostra em relação à faixa etária....................... 82

Tabela 4.3-7 - Caracterização da amostra em relação à escolaridade...................... 83

Tabela 4.4-1 - Indicadores da dimensão D1. Prioridade dada à segurança............. 84

Tabela 4.4-2 - Indicadores da dimensão D2. Alocação de recursos....................... 85

Tabela 4.4-3 - Indicadores da dimensão D3. Funções e responsabilidades............. 86

Tabela 4.4-4 - Indicadores da dimensão D4. Comprometimento com a segurança. 87

Tabela 4.4-5 - Indicadores da dimensão D5. Comunicação e relacionamento........ 88

Tabela 4.4-6 - Indicadores da dimensão D6. Qualificação e dimensionamento de pessoal 89

Tabela 4.4-7 - Indicadores da dimensão D7. Documentação e procedimentos....... 89

Tabela 4.4-8 - Indicadores da dimensão D8. Condições de trabalho...................... 90

Tabela 4.4-9 - Indicadores da dimensão D9. Aprendizagem organizacional........... 92

Tabela 4.4-10 - Indicadores da dimensão D10. Avaliações internas e externas..... 93

Tabela 5.2-1 - Regras práticas de interpretação do Alfa de Cronbach...... 96

Tabela 5.2-2 - Coeficiente Alpha de Cronbach para cada dimensão..................... 97

Tabela 5.2-3 - Correlação item-total................................................................. 99

Tabela 5.3-1 - Análise da adequação da amostra.................................................... 104

Tabela 5.3-2 - Matriz fatorial não rotacionada................................................... 105

Tabela 5.3-3 - Matriz fatorial rotacionada (10 fatores)..................................... 106

Tabela 5.3-4 - Matriz fatorial rotacionada (9 fatores) ....................................... 108

Tabela 5.3-5 - Variância total explicada..................................................... 110 


\section{Lista de quadros e figuras}

Quadro 2.4-1 - Características e atributos da cultura de segurança (SCART)........ 29

Quadro 3.3-1 - Resultado das análises dos especialistas.................................... 58

Quadro 3.3-2 - Estrutura conceitual da cultura de segurança................................ 61

Figura 2.1-1 - Modelo de acidente do "queijo suíço"........................................... 14

Figura 3.2-1 - Confiabilidade versus Validade................................................... 53

Figura 4.2-1 - Estrutura de uma base de dados típica........................................ 70 


\section{Lista de siglas e abreviaturas}

\begin{tabular}{|c|c|}
\hline ABEN & Associação Brasileira de Energia Nuclear \\
\hline $\mathrm{ACP}$ & Análise de Componentes Principais \\
\hline $\mathrm{AIChE}$ & American Institute of Chemical Engineers \\
\hline $\mathrm{C} \& \mathrm{~T}$ & Ciência e Tecnologia \\
\hline CDTN & Centro de Desenvolvimento da Tecnologia Nuclear \\
\hline CNEN & Comissão Nacional de Energia Nuclear \\
\hline CRCN-CO & Centro Regional de Ciências Nucleares do Centro-Oeste \\
\hline CRCN-NE & Centro Regional de Ciências Nucleares do Nordeste \\
\hline HSE & Health and Safety Executive \\
\hline IAEA & International Atomic Energy Agency \\
\hline ICFTU & International Confederation of Free Trade Unions \\
\hline IEN & Instituto de Engenharia Nuclear \\
\hline INAC & International Nuclear Atlantic Conference \\
\hline INPO & Institute of Nuclear Power Operations \\
\hline INSAG & International Nuclear Safety Advisory Group \\
\hline IPEN & Instituto de Pesquisas Energéticas e Nucleares \\
\hline IRD & Instituto de Radioproteção e Dosimetria \\
\hline $\mathrm{KMO}$ & Kaiser Meyer Olkin \\
\hline MCTI & Ministério da Ciência, Tecnologia e Inovação \\
\hline NAS & National Academies of Sciences \\
\hline NEA & Nuclear Energy Agency \\
\hline $\mathrm{NRC}$ & Nuclear Regulatory Commission \\
\hline SPSS & Statistical Package for the Social Sciences \\
\hline TMI & Three Mile Island \\
\hline UFRJ & Universidade Federal do Rio de Janeiro \\
\hline USP & Universidade de São Paulo \\
\hline WANO & World Association of Nuclear Operators \\
\hline
\end{tabular}




\section{INTRODUÇÃO}

\subsection{Contexto do tema da pesquisa}

As preocupações com a segurança no mundo têm aumentado muito nos últimos anos, sobretudo, após uma série de grandes acidentes e incidentes em plantas nucleares, químicas e petroquímicas, como por exemplo, o acidente nuclear de Three Mile Island (USA) em 1979; o vazamento tóxico na planta química de Bhopal em 1984; o acidente nuclear de Chernobyl em 1986; o incêndio e explosão da plataforma offshore Piper Alpha (UK) em 1988; o acidente nuclear de Tokaimura em 1999 e o desastre em Fukushima em 2011.

Conforme apontam os principais relatórios publicados por instituições internacionais sobre as causas desses acidentes, foi marcante a contribuição dos fatores organizacionais e de vulnerabilidades na cultura de segurança para a sequência dos eventos.

De acordo com os relatórios NUREG-0585 (1979) e USNRC (1980), publicados pela U.S. Nuclear Regulatory Commission (NRC), o acidente na Unidade de Three Mile Island Unit 2 (TMI-2), ocorrido em 28 de março de 1979, apesar de ter sido o acidente mais grave na história das usinas nucleares dos EUA, não houve mortes ou ferimentos. Eventos tais como defeitos em equipamentos e problemas relacionados ao projeto e a erro humano levaram a uma fusão parcial do núcleo do reator TMI-2.

Em resumo, o acidente foi desencadeado da seguinte forma:

- As principais bombas de água de alimentação do sistema secundário pararam de funcionar;

- A pressão no sistema primário começou a aumentar e a válvula de alívio abriu;

- A válvula deveria ter fechado, automaticamente, quando a pressão diminuiu, mas isso não aconteceu;

- Não havia nenhum sinal claro nos painéis de que a válvula estava aberta;

- A água que vazou pela válvula presa na posição aberta causou um superaquecimento no núcleo do reator; 
- Não havia nenhum instrumento capaz de mostrar o nível do líquido de arrefecimento no núcleo;

- Os operadores não perceberam que a planta estava passando por um acidente de perda do refrigerante (Loss of Coolant Accident - LOCA);

- Aproximadamente metade do núcleo se fundiu durante os estágios iniciais do acidente.

Os relatórios apontam como causas principais do acidente os seguintes aspectos relacionados a fatores organizacionais:

- Respostas inadequadas a incidentes anteriores;

- Comunicação ineficaz;

- Supervisão e manutenção inadequadas;

- Ausência de supervisão administrativa;

- Erros de projeto das instalações e equipamentos;

- Erros na tomada de decisões;

- Baixa qualificação e capacitação dos operadores;

- Treinamento ineficiente para os operadores;

- Má concepção de Interface Homem-Máquina.

O relatório elaborado por WILLEY (2006), publicado pelo American Institute of Chemical Engineers (AIChE) e o relatório ICFTU (1985), publicado pela International Confederation of Free Trade Unions, ambos tratando das conclusões sobre o acidente em Bhopal na India em 1984, relataram que os eventos tiveram a seguinte sequência:

Em 2 de dezembro de 1984, às 11:00h, um operador da planta notou um pequeno vazamento do gás isocianato de metila e uma crescente pressão no interior do tanque de armazenamento. Por volta de 01:00h do dia 3 de dezembro, um forte barulho ecoou pela planta quando uma válvula de segurança liberou uma nuvem do gás isocianato de metila (mais de 40 toneladas do gás vazou). Poucas horas depois, as ruas de Bhopal estavam repletas de corpos humanos e animais mortos. Uma estimativa é de que 3.800 pessoas morreram imediatamente. 
Os relatórios revelaram que a causa fundamental estava relacionada a decisões gerenciais. Outros fatores organizacionais também estavam associados:

- Manutenção inadequada;

- Treinamento ineficiente;

- Erros em procedimentos;

- Comunicação ineficaz;

- Erros de projeto dos equipamentos;

- Má concepção de Interface Homem-Máquina.

Com relação ao acidente de Chernobyl, o relatório INSAG-7 (1992) que apresentou as conclusões sobre as suas causas, apontou que o acidente aconteceu da seguinte forma:

Em 26 de abril de 1986, o reator RBMK de número quatro da usina nuclear de Chernobyl, na Ucrânia, ficou fora de controle durante um teste em baixa potência, levando a uma explosão e incêndio que destruiu o prédio do reator e liberou grandes quantidades de radiação para a atmosfera. As medidas de segurança haviam sido ignoradas, de forma que o urânio combustível no reator superaqueceu e derreteu através das barreiras de proteção.

Os reatores RBMK, por natureza, não tinham uma estrutura de contenção, que é uma cúpula de concreto e aço projetada sobre o reator para conter a radiação no interior da planta em caso de acidente. Consequentemente, elementos radioativos incluindo plutônio, iodo, estrôncio e césio foram espalhados por uma vasta área. Além disso, os blocos de grafite utilizados como elemento moderador no RBMK pegaram fogo quando o ar entrou no núcleo do reator, o que contribuiu ainda mais para a emissão de materiais radioativos no ambiente.

Ainda conforme o relatório, os seguintes fatores contribuíram para a sua ocorrência:

- As normas de segurança em vigor na época em que a planta foi projetada não eram obedecidas; 
- Análise de segurança interna inadequada;

- A análise de segurança independente não recebeu a atenção suficiente;

- Troca de informações importantes sobre a segurança feita de forma inadequada e ineficaz, tanto entre operadores, como também entre operadores e pessoal de projetos;

- Os operadores nâo tinham um entendimento adequado dos aspectos de segurança da planta;

- Não obediência, por parte dos operadores, aos procedimentos operacionais e de teste.

Além desses fatores, o relatório destaca ainda a inexistência de uma cultura de segurança, tanto ao nível local como nacional. Observa também que a cultura de segurança deficiente, não era só na usina de Chernobyl, mas em todos os projetos nucleares soviéticos que existiam na época.

O Piper Alpha Case History, publicado pelo American Institute of Chemical Engineers (AIChE) no documento AIChE (2005), revela que em 6 de julho de 1988 a plataforma de petróleo Piper Alpha sofreu uma série de incêndios e explosões catastróficos. A plataforma tinha 226 pessoas a bordo no momento do evento, e dessas, 165 morreram. Além dessas pessoas, dois funcionários de resposta a emergências também morreram durante os esforços de resgate.

Em resumo, a sequência dos eventos foi desencadeada da seguinte forma:

- Uma liberação de hidrocarboneto leve ocorreu quando uma bomba foi reiniciada após a manutenção;

- Sem o conhecimento dos funcionários de operação, uma válvula de alívio na descarga da bomba tinha sido removida para manutenção e no lugar dela foi instalada uma flange de metal;

- Após o reinício da bomba, houve um vazamento pela flange produzindo uma nuvem de hidrocarboneto inflamável que, posteriormente, encontrou uma fonte de ignição; 
- Uma série de explosões ocorreu e os incêndios na plataforma enfraqueceram os dutos de gás natural, aumentando as explosões e os incêndios.

- A intensidade dos incêndios impediu os esforços de resgate dos operadores, tanto por helicóptero como por navio;

- Grande parte da tripulação na plataforma, conforme tinha sido treinada, se dirigiu para o alojamento para aguardar evacuação;

- Não foi feita nenhuma tentativa organizada de retirar as 81 pessoas do alojamento que morreram por inalação de fumaça, à espera de novas instruções que nunca vieram. A plataforma foi completamente destruída.

O relatório também ressalta que o acidente resultou, essencialmente, de uma acumulação de decisões gerenciais errôneas. Outros fatores associados aos eventos, que também contribuíram para o acidente, foram os seguintes:

- Erros de comunicação;

- Falta de supervisão e inspeção;

- Treinamento ineficiente;

- Falta de uma cultura de segurança sólida;

- Má concepção de interface homem-máquina;

- Manutenção inadequada.

O relatório aponta ainda que as deficiências, em sua grande maioria, estavam enraizadas na estrutura organizacional da instalação e na sua cultura de segurança e que eram comuns aos grandes segmentos da indústria de petróleo e gás naquela região.

Quanto ao acidente de Tokaimura, o relatório apresentado em IAEA (1999) descreve que em 30 de setembro de 1999 um acidente de criticalidade ocorreu na instalação de reprocessamento de combustível nuclear da companhia JCO em Tokaimura, Japão. A principal atividade da planta consistia em converter o urânio enriquecido isotopicamente, em dióxido de urânio combustível.

Uma solução de urânio enriquecido, em quantidade várias vezes maior do que o limite de massa especificado, foi colocada diretamente em um tanque de precipitação, 
ignorando o tanque de dissolução destinado a evitar a criticalidade. A fim de acelerar o processo, os operadores misturaram o óxido e o ácido nítrico em um recipiente de aço inoxidável em vez de usar o tanque de dissolução, levando, portanto, a um acidente de criticalidade.

Esta nova forma de operar seguia as instruções previstas no manual de operação da JCO, o qual não tinha sido aprovado pela Agência de Ciência e Tecnologia do Japão. De fato, após o processo de licenciamento nenhuma inspeção ou auditoria periódica havia sido realizada pela autoridade competente.

Ainda de acordo com o relatório, o acidente resultou, sobretudo, de erro humano e graves violações dos princípios de segurança, que juntos levaram ao evento de criticalidade. Os fatos decisivos para o acidente foram a utilização de procedimentos não aprovados e não autorizados e um "clima de pressão de tempo" para a realização das tarefas. Por fim, o documento concluiu que tais deficiências nas questões de segurança indicavam sérias fragilidades na cultura de segurança da instalação.

Com relação ao acidente de Fukushima em 2011, dois importantes relatórios chamam atenção para os problemas de fatores organizacionais e de cultura de segurança. De acordo com o relatório apresentado em INPO (2011), o pessoal da instalação respondeu ao acidente com coragem e resiliência e as suas ações com certeza reduziram a gravidade e a magnitude das liberações de materiais radioativos. No entanto, vários fatores relacionados com a gestão, projeto e operação da usina impediram o pessoal da planta de obter maior êxito e contribuíram para o agravamento geral do acidente.

De forma complementar, o relatório publicado em NAS (2014) aponta que foram significantes os problemas relacionados à cultura de segurança na instalação. Não houve um desenvolvimento e manutenção de uma forte cultura de segurança, com um comprometimento focado e sustentado por todas as partes envolvidas: os operadores na planta, a administração, o gerenciamento, os reguladores e o governo.

Há algum tempo existe um reconhecimento crescente de que a operação segura e confiável de usinas nucleares não depende só da excelência técnica do projeto e da 
construção, mas também das pessoas e da organização. Uma análise mais aprofundada dos cenários acidentais apresentados previamente revela que uma grande parte dos acidentes poderia ter sido evitada se a organização tivesse tomado as devidas precauções antes da sua ocorrência, sobretudo, uma atenção especial para os fatores humanos e, em particular, aos fatores organizacionais (Reason, 1997; Wilpert e Itoigawa, 2001).

Ainda de acordo com estes autores, a importância dos fatores organizacionais nos mecanismos causais de acidentes tem sido reconhecida por uma série de instituições de pesquisas na Europa, EUA e Japão. As autoridades regulatórias de segurança nesses países identificaram a necessidade de uma melhor compreensão dos fatores organizacionais, mas os esforços de pesquisa nessa área, porém, têm sido modestos.

A indústria nuclear e a NRC, explicitamente, reconheceram a importância dos fatores organizacionais e os de gerenciamento na segurança das instalações nucleares, logo após o acidente de Three Mile Island (NUREG-1756, 2002).

Nesse sentido, Zohar (1980), Reason (1998) e Sorenson (2002) alertam para o fato de que deficiências em fatores organizacionais revelam fragilidade na cultura de segurança da organização. Ainda de acordo com os autores, esses fatores correspondem aos atributos que determinam e caracterizam a cultura de segurança de uma organização.

O International Safety Advisory Group (INSAG), um grupo consultivo da International Atomic Energy Agency (IAEA) que foi encarregado de investigar o acidente Chernobyl, usou o termo "cultura de segurança fraca" para identificar os fatores organizacionais e de gerenciamento que conduziram àquele acidente.

Um dos objetivos fundamentais do projeto de uma instalação nuclear é que sua operação seja conduzida de forma segura, razão pela qual, cada aspecto da planta deve ser rigorosamente verificado e controlado por entidades reguladoras governamentais, a fim de garantir a segurança em todo o ciclo de vida da instalação. Esses aspectos incluem o projeto, a construção, o comissionamento, a operação experimental, a operação comercial, a manutenção, as alterações da planta, o gerenciamento dos resíduos radioativos e, finalmente, o descomissionamento da planta (IAEA, 2006). 
Por essa razão, a segurança nuclear começa já na concepção do projeto e o desafio principal é assegurar que as práticas de uma sólida cultura de segurança sejam aplicadas nessa fase para evitar tanto as deficiências latentes, como as imediatas. Em IAEA (2012) são apresentados os princípios da cultura de segurança durante as fases préoperacionais para as instalações e fornecedores.

Conforme revelam Wilpert e Itoigawa (2001), prevalece um consenso por parte da comunidade internacional de energia nuclear de que uma sólida cultura de segurança nuclear deve ser adotada universalmente: pela alta administração das organizações que operam as usinas nucleares; por indivíduos que trabalham nas plantas; pelos órgãos reguladores e por outras organizações que elaboram as políticas de energia nuclear. $\mathrm{Na}$ verdade, este compromisso com a segurança é uma prioridade internacional, como evidenciado por alguns tratados sobre segurança nuclear.

Muitas organizações na tentativa de reduzir acidentes e os custos correspondentes, têm desenvolvido esforços para avaliar e promover uma cultura de segurança sólida. Há muitos estudos propondo modelos para avaliar a cultura de segurança ou verificar se as medidas de segurança mudaram ao longo do tempo em uma organização (Sorenson, 2002).

Segundo Guldenmund (2010), o interesse na avaliação da cultura de segurança resultou em uma proliferação de instrumentos com essa finalidade, a maioria sob a forma de questionários de auto-avaliação, administrados em diferentes setores. Entretanto, observa o autor que enquanto a importância do conceito clima ou cultura de segurança é enfatizada pela maioria dos trabalhos, muito pouco tem sido feito com relação aos estudos das propriedades psicométricas (confiabilidade e validade) dos instrumentos de pesquisa.

Na mesma linha de pensamento, Mkrtchyan e Turcanu (2012) ressaltam que estão disponíveis na literatura internacional uma série de instrumentos para avaliar a cultura de segurança, sobretudo, na área nuclear, nas indústrias de produção e construção e na área de saúde, mas a maioria apresenta dados limitados de sua confiabilidade e validade. 
Ainda de acordo com os autores, uma preocupação básica na avaliação de uma cultura de segurança é garantir que os instrumentos de pesquisa sejam válidos e confiáveis, ou seja, que eles meçam o que pretendem medir e que produzam resultados semelhantes em medidas repetidas. Essa opinião também é compartilhada por Williams (2008).

No caso específico do Brasil, existe uma quantidade significante de instrumentos de avaliação de cultura de segurança com essas qualidades psicométricas nas áreas de saúde (hospitais) e em segurança do trabalho, no caso das petroquímicas e das plataformas petrolíferas. No entanto, não foi identificado nenhum instrumento na área nuclear, existindo, assim, uma grande lacuna nesse sentido.

É importante ressaltar que instrumentos de avaliação de cultura de segurança, com evidências de confiabilidade e de validade decorrentes da aplicação em outro país, não podem ser empregados diretamente no Brasil, devido, especialmente, às diferenças culturais entre o país de origem do instrumento e o Brasil. Nesse aspecto, o TECDOC1321 (2002) esclarece que problemas e soluções para a cultura de segurança de uma instalação podem variar de país para país em razão das diferenças nas culturas nacionais.

De forma complementar, no TECDOC-1329 (2002) afirma-se que as variações em culturas nacionais implicam que uma boa abordagem para melhorar a cultura de segurança em um país pode não ser a melhor opção em outro. Ainda conforme observado em IAEA (1998), as características de uma cultura nacional podem ampliar ou atenuar os problemas associados aos atributos da cultura de segurança na organização.

Cada organização é única em termos de sua história, sua cultura organizacional e seus funcionários e é por essa razão que muitas organizações optam por realizar a sua própria avaliação (self-assessment) da cultura de segurança (TECDOC-1321, 2002).

Weidmer (1994) também alerta para o fato de que há outras implicações na aplicação de um instrumento de pesquisa desenvolvido em outra cultura, destacando-se entre elas: problemas de equivalência na tradução, diferenças nas questões culturais com o país de origem, a equivalência conceitual, além das variações étnicas no vocabulário. 
No entanto, conforme orientam Sekaran (2003), Weidmer (1994) e Cha et al. (2007), na hipótese de se optar pelo emprego de um instrumento de pesquisa desenvolvido em outro país, seria necessário submetê-lo a um processo de tradução e adaptação transcultural com a finalidade de obter a equivalência entre o instrumento original e a versão adaptada. Neste caso, após serem contornadas todas as implicações mencionadas anteriormente, haveria a necessidade de um novo processo de análise da confiabilidade e de validação do instrumento. Existem alguns trabalhos na área de saúde desenvolvidos por meio desse processo, dentre os quais se destacam Carvalho (2011), Reis et al. (2012) e Costa (2013).

\subsection{Relevância e contribuição original do trabalho}

Observa-se que há uma lacuna, tanto no campo acadêmico como no técnicocientífico, de instrumentos com evidências de confiabilidade e de validade para a avaliação da cultura de segurança em instalações nucleares no Brasil.

Instrumentos de avaliação que tenham sido elaborados, aplicados e validados em outros países não são de pronto emprego no Brasil em razão de implicações culturais.

Portanto, este trabalho supre essa lacuna e contribui de forma original ao estado da arte em avaliação da segurança, pois disponibiliza um instrumento de pesquisa capaz de obter medidas válidas e confiáveis da cultura da segurança em instalações nucleares brasileiras.

A originalidade do trabalho da mesma forma advém das expressões linguísticas empregadas nas escalas de mensuração do instrumento de pesquisa. São termos apropriados para captar as atitudes, opiniões e percepções dos respondentes com relação à segurança na organização.

\subsection{Objetivos da pesquisa}

Realizada a introdução contextual do tema e apresentadas a relevância e a contribuição original da tese, definem-se, então, os objetivos que orientaram o presente trabalho. 


\subsubsection{Objetivo geral}

Desenvolver um modelo capaz de avaliar com medidas válidas e confiáveis a cultura de segurança em instalações nucleares.

\subsubsection{Objetivos específicos}

\section{Objetivo específico 1}

Elaborar um instrumento de coleta de dados e aplicá-lo nos institutos de pesquisas da Comissão Nacional de Energia Nuclear (CNEN). A aplicação deste instrumento tem o propósito de identificar áreas de solidez ou de fragilidades na cultura de segurança dessas organizações e de obter os dados necessários para a avaliação de suas propriedades psicométricas.

\section{Objetivo específico 2}

Proceder à avaliação das propriedades psicométricas do modelo por meio da análise da confiabilidade e das validações de conteúdo, de face e de construto do instrumento de pesquisa.

\subsection{Estrutura da tese}

Esta tese está organizada em seis capítulos. Neste capítulo é realizada a introdução do trabalho contextualizando o tema da pesquisa, apresentando a relevância e a contribuição original do trabalho e definindo os seus objetivos.

No Capítulo 2 é realizada uma revisão da literatura relacionada ao tema da pesquisa com foco na fundamentação teórica de modelos de acidentes, fatores organizacionais e cultura de segurança na área nuclear. Nesse capítulo também é apresentado o resultado de uma busca na literatura por trabalhos em avaliação de cultura de segurança. 
A metodologia empregada para que os objetivos propostos fossem atingidos é desenvolvida no Capítulo 3. Inicialmente é apresentado o delineamento da pesquisa. $\mathrm{Na}$ seção seguinte é realizado um embasamento teórico acerca dos conceitos de modelagem de instrumentos de pesquisa, que são o alicerce deste trabalho. Na sequência, são desenvolvidas as etapas de concepção do modelo de mensuração da cultura de segurança, com destaque para a validação de conteúdo, a validação de face e a elaboração e aplicação do instrumento de pesquisa.

No Capítulo 4 são apresentados e analisados os resultados obtidos com a pesquisa. É também realizado nesse capítulo a preparação e o tratamento dos dados como medidas preliminares para a avaliação das propriedades psicométricas.

Os estudos realizados das propriedades psicométricas do instrumento de pesquisa (confiabilidade e validade de construto) são apresentados no Capítulo 5.

Por fim, no Capítulo 6 são apresentadas as conclusões finais do trabalho, as limitações verificadas no desenvolvimento do modelo e as recomendações para futuros desenvolvimentos. 


\section{REVISÃO DA LITERATURA}

Este capítulo tem por finalidade apresentar o resultado de uma ampla pesquisa realizada na literatura, nacional e internacional, em busca de trabalhos que representassem o estado da arte em fatores organizacionais e cultura de segurança, sobretudo, aqueles aplicados à área nuclear.

\subsection{A visão contemporânea de modelos de acidentes}

Nos últimos 20 anos houve mudanças significativas nos modelos de acidentes, com evoluções nos métodos e objetivos da análise. Como exemplo, o Modelo Epidemiológico proposto por Hollnagel (2002), como o próprio nome sugere, descreve um acidente em analogia com uma doença, ou seja, como o resultado de uma combinação de fatores, em que alguns se manifestam e outros são latentes e, num dado momento, se juntam para a ocorrência do acidente. Essas condições têm muitas origens: falta de normas, procedimentos incompletos, mensagens contraditórias, pressões de produção, indefinição de responsabilidades, treinamento inadequado, falta de manutenção, tecnologia deficiente e assim por diante.

Essa visão inicial de acidentes, como o resultado natural de uma série de eventos ou circunstâncias que invariavelmente ocorrem em uma ordem fixa e lógica, está pouco a pouco sendo substituída por uma visão sistêmica, segundo a qual os acidentes resultam de um alinhamento de condições e ocorrências, cada qual sendo necessária, mas nenhuma por si só suficiente.

Por esse novo modelo, os acidentes em sistemas complexos ocorrem através da acumulação de múltiplos fatores. Reason (1997) desenvolveu um modelo baseado na metáfora do queijo suíço, no qual sugere que múltiplos contribuidores (os furos nas fatias do queijo) devem estar alinhados para que qualquer evento adverso ocorra, conforme ilustrado na Figura 2.1-1. 


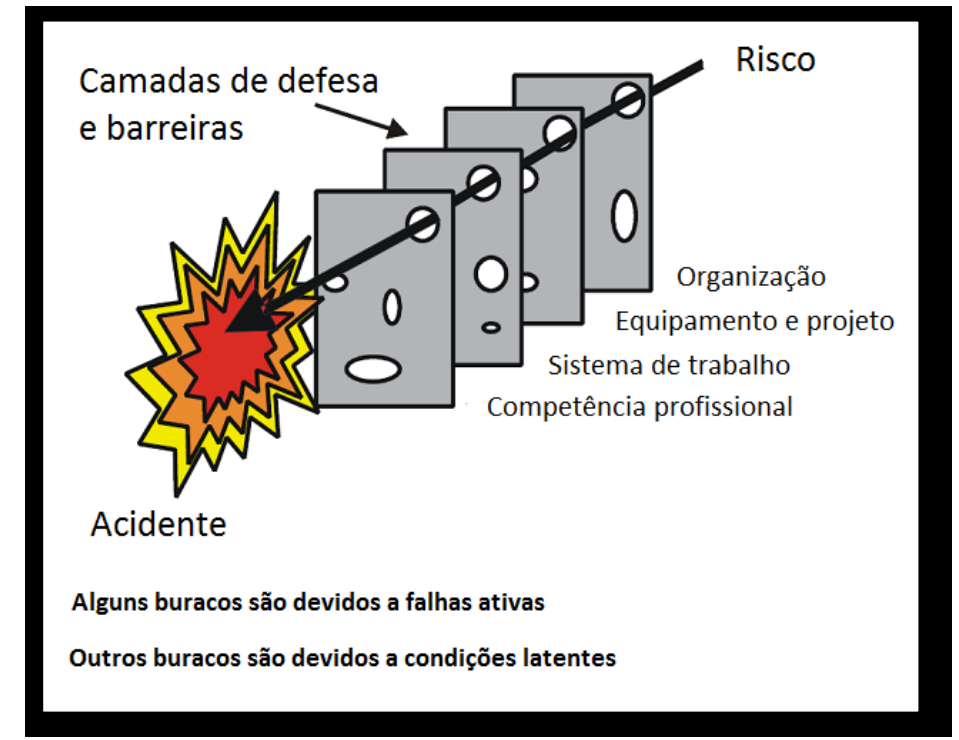

Fonte: Adaptado de (Reason, 1997)

Figura 2.1-1 - Modelo de acidente do "queijo suíço"

As fatias do queijo representam as defesas e as barreiras contra os acidentes. Os furos no queijo representam as falhas nessas defesas. Algumas falhas são devidas a erros humanos, enquanto outras são causadas por condições latentes (Reason, 1997).

Na Figura 2.1-1 está sendo mostrado que para cada risco existente há várias camadas de proteção (representadas pelas fatias do queijo) que impedem que o risco resulte em um acidente. No entanto, se as camadas de proteção falharem um acidente poderá acontecer.

Reason (1997) sugere que as fatias do queijo são como discos girando em torno de um eixo horizontal e que as falhas nas defesas estão, constantemente, se movendo em cada fatia do queijo e estão se abrindo e fechando. Quando as falhas se alinham, o erro (seta) pode penetrar as defesas e ocorrer um acidente.

Defesas, barreiras e salvaguardas ocupam uma posição-chave na abordagem sistêmica. Em geral os sistemas de alta tecnologia têm muitas camadas de defesa: algumas são projetadas como, por exemplo, alarmes, barreiras físicas e desligamentos automáticos; outras dependem de pessoas como, por exemplo, operadores da sala de controle e técnicos 
de manutenção; e outras, ainda dependem de procedimentos e controles administrativos. Sua função é proteger as vítimas potenciais e patrimônios de riscos locais. Geralmente, elas fazem isso de forma muito eficaz, mas existem sempre os pontos fracos.

Reason (1997) ainda cita que em um mundo ideal, cada camada de defesa estaria intacta (sem os furos). Na realidade, porém, elas são mais como as fatias do queijo suíço, tendo muitas falhas. Embora diferentemente do queijo, essas falhas estão continuamente se abrindo, fechando e mudando a sua localização. A presença de uma falha em qualquer "fatia" normalmente não causa um mau resultado. Normalmente, isso só pode acontecer quando as falhas em muitas camadas, momentaneamente, se alinham para permitir uma trajetória de oportunidade de acidente, trazendo os riscos em contato prejudicial com as vítimas.

As falhas nas defesas surgem por duas razões: erros ativos e condições latentes. Quase todos os acontecimentos adversos envolvem uma combinação destes dois conjuntos de fatores.

Os erros ativos são os atos inseguros cometidos por pessoas que estão em contato direto com o sistema. Eles tomam uma variedade de formas: deslizes, lapsos, erros e violação de procedimentos. Elas têm um impacto direto e, normalmente, são de curta duração sobre a integridade das defesas.

Condições latentes são os inevitáveis "elementos patogênicos" dentro do sistema. Elas decorrem de decisões tomadas por projetistas, construtores, autores de procedimentos e pela alta gerência. Todas estas decisões estratégicas têm o potencial para introduzir "elementos patogênicos" no sistema. Condições latentes podem traduzir-se em um erro provocado pelas condições locais de trabalho, como por exemplo, pressão do tempo para a produção, falta de pessoal, equipamentos inadequados, fadiga, inexperiência do operador, alarmes e indicadores não confiáveis, procedimentos impraticáveis, deficiências de projeto e construção, criando duradouras falhas ou pontos fracos na defesa. Condições latentes, como o termo sugere, podem estar dormentes dentro do sistema por muitos anos antes de se combinarem com as falhas ativas e disparadores locais para criar uma oportunidade de acidente (Reason, 1997). 
Ao contrário de falhas ativas, cujas formas de ocorrência são muitas vezes difíceis de se prever, condições latentes podem ser identificadas e corrigidas antes de um evento adverso acontecer. São precursoras potenciais de acidentes e incidentes e se inserem no campo de estudos da engenharia de fatores humanos. Conforme discorre Hollnagel (2002), "não se pode mudar a condição humana, mas pode-se mudar as condições sob as quais os seres humanos trabalham".

\subsection{A influência dos fatores humanos e organizacionais na gestão da segurança}

A história da energia nuclear ilustra uma mudança de ênfase nas questões de segurança, notadamente, de questões técnicas para fatores humanos e questões mais amplas ligadas à organização e gestão.

Conforme destaca Alexander (2004), a NRC começou a tratar formalmente os fatores humanos como uma importante questão de segurança após o acidente de Three Mile Island em 1979. No seu relatório de investigação pós-acidente, a NRC concluiu que um grande contribuinte para acidentes nucleares sempre foi negligenciado. Uma importante conclusão a que se chegou é que "as principais deficiências na segurança dos reatores comerciais hoje não são problemas de equipamento, são problemas de gestão". O relatório também reconheceu que a própria NRC tinha, praticamente, ignorado áreas como treinamento de operadores, engenharia de fatores humanos e supervisão dos seus licenciados.

Conforme ressalta Ponte Junior (2014), os erros humanos e suas consequências são influenciados diretamente pelo projeto para fatores humanos do empreendimento tecnológico como um todo. Os fatores humanos podem aumentar ou diminuir a possibilidade de o homem cometer erros, ou seja, o erro humano pode ou não acontecer dependendo dos fatores humanos considerados no projeto do empreendimento tecnológico.

Compartilhando da mesma opinião, Reason (1990) defende que o erro humano, pela própria natureza, é fortemente influenciado por fatores humanos, 
sobretudo os fatores organizacionais tornando a ocorrência de um erro mais ou menos provável.

Ainda de acordo com Ponte Junior (2014), uma análise do erro humano e a sua influência sobre a ocorrência de acidentes permitem perceber o quão é importante investir em engenharia de fatores humanos. O ideal é projetar sistemas de segurança que contemplem mecanismos de proteção contra o erro humano, a partir de uma análise dos fatores humanos estabelecidos pelo projeto.

Charlton e O’Brien (2002) também são de opinião que uma operação confiável e com segurança, em processos baseados em tecnologia de risco, não depende somente de fatores técnicos relacionados aos processos, mas em especial, de questões relacionadas a fatores humanos. Para melhorar a segurança e, portanto, reduzir eventos indesejáveis é necessário que os equipamentos, operações, processos e ambiente de trabalho sejam compatíveis com as capacidades físicas e cognitivas do homem, bem como de suas limitações.

A definição clássica de fatores humanos é o estudo científico da interação entre o homem e a máquina. Porém, uma definição mais abrangente é a proposta pela agência inglesa Health and Safety Executive em HSG48 (2007):

\begin{abstract}
"Os fatores humanos podem ser definidos com base em aspectos ambientais, organizacionais, do trabalho e das características humanas e individuais, que influenciam o comportamento no trabalho de uma forma que afeta a saúde e a segurança. As características humanas compreendem as considerações biomédicas, psicológicas e psicossociais do indivíduo" (HSG48, 2007).
\end{abstract}

Esta definição inclui três aspectos inter-relacionados que devem ser considerados: o trabalho, o indivíduo e a organização.

$\underline{\mathrm{O} \text { trabalho }}$ inclui áreas como a natureza da tarefa, a carga de trabalho, o ambiente de trabalho, o projeto das telas dos painéis e dos controles, e os procedimentos. As tarefas devem ser concebidas de acordo com os princípios ergonômicos, levando em 
conta as limitações do homem. Isso inclui adequar a função às limitações físicas e mentais das pessoas.

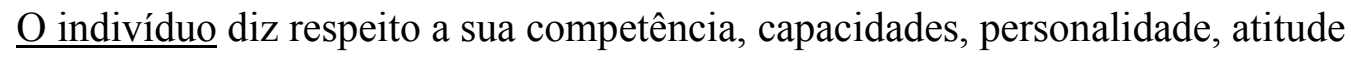
e percepção de riscos. As características individuais influenciam o comportamento de forma complexa. Algumas características, tais como a personalidade, são fixas; outras como a capacidade e as atitudes, podem mudar ou ser melhoradas. Os aspectos mentais incluem requisitos de tomada de decisões, de percepção e atenção.

A organização considera os métodos de trabalho, a cultura organizacional, os recursos, a comunicação e a liderança. Esses fatores, conhecidos como fatores organizacionais, são muitas vezes negligenciados durante a programação das atividades, mas têm uma influência significativa no comportamento individual e em grupo.

As intervenções em fatores humanos não são eficazes se considerarem estes aspectos isoladamente. Os fatores humanos podem e devem ser incluídos num sistema de gestão de segurança, de forma adequada, e podem, assim, serem analisados de forma semelhante a qualquer outro sistema de controle de riscos.

As questões de segurança precisam de uma abordagem multidisciplinar, com a participação de diferentes especialistas e grupos profissionais. É essencial que estas questões não sejam tratadas de forma isolada, mas sim, integradas. Como exemplo, o planejamento e implementação de uma modificação na planta, ou a investigação de um acidente, são ações que, normalmente, exigem consideração dos aspectos técnicos, fatores humanos (sobretudo os organizacionais), de uma forma coordenada e integrada (IAEA, 1998).

A experiência tem demonstrado que, quando o foco principal em uma instalação recai sobre os aspectos técnicos, o cronograma do projeto e o orçamento, certamente, atenção insuficiente está sendo dada aos aspectos humanos e organizacionais.

$\mathrm{Na}$ mesma linha de pensamento, Wilpert e Itoigawa (2001) ressaltam que a gestão da segurança para ser eficiente deve ser exercida baseada em uma profunda 
compreensão das interações entre o desempenho técnico e organizacional. As investigações de incidentes e acidentes demonstram claramente a importância dos fatores organizacionais como iniciadores dos eventos e como aspectos que podem tornar as consequências dos acidentes ainda piores.

Ainda nesse sentido, em AIChE (2007) é observado que a consideração do fator humano, sobretudo os fatores organizacionais, é um aspecto essencial na gestão da segurança do processo, pelo fato de ser uma disciplina amplamente reconhecida de tratamento das interações entre as pessoas, a instalação e seu sistema de gestão.

\subsection{A cultura de segurança}

A fim de entender cultura de segurança, é necessário ter uma visão sobre o conceito de cultura. O primeiro passo é a obtenção de uma apreciação da cultura no seu sentido mais lato.

A cultura é como uma lente que através da qual se percebe o mundo. Ela molda a forma de como se vê o mundo. Há uma tendência natural de usar a própria cultura como um ponto de referência para avaliar as outras. A cultura é para a sociedade o que a memória é para o indivíduo. Ela inclui tradições e compreende a forma de como as pessoas aprenderam a olhar para o seu ambiente e para si mesmos e as suas suposições sobre como o mundo é e como as pessoas devem agir (TECDOC-1329, 2002).

As definições de cultura variam em complexidade. Uma das mais simples é: "A maneira que fazemos as coisas por aqui". Embora simples, esta definição não é de uso muito prático para qualquer pessoa interessada em estudar uma cultura. Talvez a definição mais inclusiva seja: "A cultura é a parte do ambiente constituída pelo homen".

Atualmente uma das definições mais aceitas de cultura é a dada por Edgar Schein e é a adotada em TECDOC-1329 (2002):

"A cultura é um padrão de suposições básicas - criadas, descobertas ou desenvolvidas por um determinado grupo - de como ele aprende 
a lidar com seus problemas de adaptação externa (como sobreviver) e de integração interna (como permanecer juntos), que têm evoluído ao longo do tempo e são transmitidos de geração para geração".

\subsubsection{As definições da cultura de segurança}

A indústria nuclear e a NRC reconheceram, explicitamente, a importância dos fatores organizacionais e de gerenciamento para a segurança das instalações nucleares logo após o acidente de Three Mile Island (TMI) em 1979. Seguindo o acidente de Chernobyl em 1986, o INSAG introduziu o termo "cultura de segurança" para indicar os fatores organizacionais e os de gerenciamento que eram importantes para a segurança.

Conforme observa Alexander (2004), o INSAG, um grupo de assessoria do Diretor-Geral da IAEA, afirmou no seu relatório pós-acidente que a atitude de gerenciamento contribuiu significamente para a cadeia de eventos que levaram ao acidente.

Dessa forma, a definição original de cultura de segurança foi dada pela IAEA, em sua Safety Series No 75-INSAG-4, como:

"O conjunto de características e atitudes de organizações e indivíduos, o qual estabelece que uma prioridade absoluta seja dada à segurança nuclear de modo que esta receba a atenção garantida pelo seu significado" (INSAG-4, 1991).

Como a definição de cultura de segurança está relacionada com as atitudes pessoais e hábitos de pensamento, bem como ao estilo de organização, a INSAG-4 sugere que essas questões são normalmente intangíveis, mas que, no entanto, tais características levam a manifestações tangíveis. Neste caso, um requisito essencial é o desenvolvimento de meios para utilizar as manifestações tangíveis para testar o que está subjacente.

A cultura de segurança exige que todas as tarefas importantes para a segurança sejam realizadas corretamente, com a precaução devida, com o conhecimento necessário, com discernimento e um bom senso de responsabilidade. É considerada como tendo duas componentes principais: o ambiente criado, dentro do qual o pessoal trabalha, a atitude e a resposta dos indivíduos a esse ambiente (INSAG-4, 1991). 
O termo "cultura de segurança" se refere a uma questão muito ampla, o empenho pessoal e a responsabilidade de todos os indivíduos envolvidos em qualquer atividade que tenha influência sobre a segurança das organizações. O ponto de partida para todas as ações necessárias às questões de segurança é da alta administração das organizações. As políticas estabelecidas e implementadas asseguram as práticas corretas com o reconhecimento de sua importância, não apenas nas práticas em si, mas também no ambiente de consciência pela segurança que é criado.

Linhas claras de responsabilidade e de comunicação são estabelecidas; procedimentos sólidos são desenvolvidos; a estrita observância a esses procedimentos é exigida; revisões internas das atividades relacionadas com a segurança são realizadas e, acima de tudo, formação e treinamento de pessoal são implementados.

De forma ainda mais abrangente, a cultura de segurança é definida em HSG65 (2008) como:

\begin{abstract}
"O produto de valores individuais e de grupo, atitudes, percepções, competências e padrões de comportamento que determinam o comprometimento, o estilo e a proficiência da gestão da segurança e da saúde em uma organização. Organizações com uma cultura de segurança sólida são caracterizadas por comunicação fundada na confiança mútua, por percepções compartilhadas da importância da segurança, e pela eficácia das medidas preventivas" (HSG65, 2008).
\end{abstract}

Guldenmund (2000) define a cultura de segurança como:

"Aqueles aspectos da cultura organizacional que têm impacto sobre as atitudes e o comportamento relacionados ao aumento ou à diminuição dos riscos" (Guldenmund, 2000).

Cooper (2000) diferencia "cultura" e "cultura de segurança" como:

"Cultura é o produto das múltiplas interações entre as pessoas (psicológica), o trabalho (comportamental) e a organização (situacional); enquanto que a cultura de segurança é o grau observável do esforço pelo qual todos os membros da organização 
direcionam a sua atenção e ações para melhorar a segurança de forma diária" (Cooper, 2000).

Na visão de Ponte Junior (2014) a cultura de segurança é a combinação de compromissos e atitudes, nas organizações e indivíduos, que estabelecem como prioridade absoluta que os assuntos relacionados com a segurança recebam atenção certa no tempo certo. $\mathrm{O}$ autor ainda ressalta que atenção certa significa não apenas seguir normas, estabelecer controles, fazer inspeções, fazer o melhor treinamento ou utilizar os melhores recursos disponíveis de segurança, mas sim a atitude na medida exata para evitar o acidente. $\mathrm{O}$ tempo certo significa não apenas prontidão, dedicação permanente, cuidado constante, verificação redundante ou aperfeiçoamento contínuo nas melhores práticas de segurança, mas sim, a atitude no momento exato no qual um acidente pode ser evitado.

Em sentido amplo, a cultura de segurança é uma fusão de valores, padrões, costumes e de comportamento. Estes aspectos conduzem a uma abordagem disciplinada para o aprimoramento da segurança para além das exigências legislativas e regulamentares (Zohar, 1980).

O documento TECDOC-1329 (2002) destaca que para se desenvolver uma cultura de segurança, é importante reconhecer que ela se refere às pessoas, a sua organização e às suas interações. Aspectos humanos a considerar abrangem comportamentos e atitudes das pessoas envolvidas, isso também inclui as percepções formadas a partir de influências e experiências passadas.

Portanto, a cultura de segurança é inerente aos pensamentos e ações de todos os indivíduos e em todos os níveis da organização. A liderança exercida pela alta gerência é muito importante. Todas as considerações de segurança são afetadas por pontos comuns de convicção, atitudes, de comportamento e traços culturais, intimamente ligados a um sistema de valores e padrões compartilhados (IAEA, 1998).

É importante ressaltar que todas as definições são plausíveis para efeito deste trabalho, mas que não se adotou nenhuma em especial. Isso porque o requisito fundamental para a concepção deste modelo é o estudo da dimensionalidade da cultura de segurança. 


\subsubsection{Cultura de segurança versus clima de segurança}

As pesquisas evidenciam alguma confusão e inconsistências na literatura sobre o uso dos termos clima de segurança e cultura de segurança. Uma forma simples de abordar essa questão é a proposta por Cooper (2000). Segundo o autor, o termo cultura de segurança pode ser usado para se referir aos aspectos comportamentais "o que as pessoas fazem" e aos aspectos conjunturais da empresa "o que a organização tem". O termo clima de segurança deve ser usado para se referir às características psicológicas dos funcionários, ou seja, "o que as pessoas sentem", correspondendo aos valores, atitudes e percepções dos funcionários em relação à segurança dentro de uma organização.

Guldenmund (2010) ressalta que enquanto a cultura de segurança representa atitudes de longo prazo, as convicções e as formas de como as pessoas se comportam, o clima de segurança representa um instantâneo do estado atual desses fatores em qualquer momento. Assim, o clima de segurança é algo que uma organização "tem" em um determinado momento. $\mathrm{O}$ autor ainda observa que o uso do termo clima de segurança apareceu antes da utilização do termo cultura de segurança na literatura.

\subsubsection{A influência da cultura nacional na cultura de segurança}

No estabelecimento de uma sólida cultura de segurança, atenção especial deve ser dada à cultura nacional. Em alguns países pode até haver diferenças significativas entre culturas regionais. As características da cultura nacional podem ampliar ou atenuar os fatores associados à cultura de segurança (IAEA, 1998).

A consciência de diferenças significativas na cultura nacional é importante no caso de projetos multinacionais. Há organizações que realizam negócios em uma base global e têm plantas e instalações localizadas em muitos países do mundo. Em um contrato turnkey internacional, por exemplo, o fornecedor poderia adotar a sua própria cultura nacional para o projeto e para a estrutura documental do empreendimento. Essa cultura "importada" pode não ser totalmente compatível com a cultura local onde o empreendimento será instalado e qualquer incompatibilidade poderia ter consequências potencialmente negativas para o futuro desempenho da segurança na instalação. 
Um princípio fundamental que serve de base para uma sólida cultura de segurança é o respeito à saúde humana, à segurança e ao bem-estar, o que é totalmente compatível com os valores estruturais de todas as culturas nacionais. A cultura nacional não deve ser vista como um impedimento para o estabelecimento de uma cultura de segurança. Ser sensível às suas características permite tirar proveito dos pontos fortes culturais e trabalhar com, e não contra, o fluxo de ricas e diversas correntes culturais do mundo (IAEA, 1998).

\subsection{A dimensionalidade da cultura de segurança}

Conforme aponta Guldenmund (2010), como regra geral os construtos científicos sociais são multidimensionais. Por exemplo, um construto como a inteligência pode ser evidenciado não só pelo desempenho em determinados testes de aritmética, mas também em tarefas de visão espacial ou em certos exercícios de linguagem.

A cultura e o clima de segurança têm sido caracterizados como sistemas multidimensionais. Técnicas de análise, como por exemplo a análise fatorial, produzem tais dimensões quando elas são usadas para avaliar os resultados de uma pesquisa. Essas dimensões são o resultado das tendências inter e intra-respondentes para analisar determinadas questões de uma forma similar.

Quando se discute acerca dos aspectos que compreendem uma cultura de segurança - a sua dimensionalidade - surge um grande problema com relação à terminologia empregada pelos diversos autores e pesquisadores nessa área. Nesse sentido Alexander (2004) ressalta que os pesquisadores, a indústria nuclear e os reguladores utilizam indistintamente os seguintes termos: indicadores, princípios, traços, características, componentes, dimensões, domínios, atributos, fatores, ou uma combinação deles, quando descrevem os vários aspectos de uma cultura de segurança.

A terminologia empregada para esses aspectos também varia consideravelmente entre as organizações na área nuclear, mesmo quando elas se referem aos mesmos aspectos da cultura de segurança. Por exemplo, o INPO e a World Association of Nuclear Operators (WANO) se referem a princípios; o Health and Safety Executive 
(HSE), a indicadores; a NRC, a componentes; e a IAEA, a características, atributos ou a fatores organizacionais.

Para efeito deste trabalho, observando o que sugerem Castro et al. (2013), será adotado o termo dimensão. Em seu trabalho os autores salientam que esse termo está de acordo com a terminologia psicométrica e também reflete a natureza multidimensional que é assumida pela cultura de segurança.

Em sua pesquisa, Williams (2008) também observa que não existe um consenso entre os diferentes autores e pesquisadores com relação às dimensões que compõem o conceito cultura de segurança, ou seja, a sua dimensionalidade. Entretanto, há sempre um pequeno grupo de dimensões que aparecem com mais frequência.

O trabalho pioneiro na identificação das dimensões que caracterizam uma cultura de segurança foi proposto por Zohar (1980). O autor concluiu que as seguintes dimensões determinavam uma cultura de segurança.

- A importância dada aos treinamentos em saúde e segurança;

- As atitudes da gerência para com a segurança;

- Promoção de bons resultados relacionados à segurança;

- Nível de risco no local de trabalho;

- Influência do trabalho exigido com relação à segurança;

- Nível das equipes de segurança na organização;

- Comprometimento com a segurança na organização.

Lee (1998) propôs um modelo com base em nove domínios (dimensões) da cultura de segurança:

- Comprometimento da administração;

- Procedimentos de segurança;

- Percepção de risco;

- Satisfação no trabalho;

- Normas de segurança; 
- Participação;

- Treinamento;

- Controles;

- Projeto da planta.

Cooper (2000) propôs um modelo baseado em três componentes principais: as pessoas, que diz respeito ao clima de segurança (percepções e atitudes); comportamento, relacionado com a segurança; e organização, que compreende o sistema de gestão da segurança.

Cox e Cheyne (2000) apresentaram em seu trabalho nove dimensões que melhor representariam uma cultura de segurança:

- Adequação de pessoal para segurança;

- Ambiente de trabalho;

- Atitude de melhoria;

- Comprometimento da administração;

- Comunicação;

- Condições de trabalho;

- Normas e procedimentos de segurança;

- Percepção de risco;

- Prioridade dada à segurança;

Diaz-Cabrera et al. (2007) em seu trabalho propuseram um grupo de sete dimensões que representam várias práticas organizacionais e seus valores subjacentes:

- Conteúdo dos programas de treinamento;

- Sistemas de relatórios de incidentes e acidentes;

- Regras e procedimentos de segurança;

- Estratégias de avaliação de desempenho e promoção da segurança;

- Padrão de motivação do empregado;

- Sistemas de informação;

- Comunicação e estilos de liderança. 
Os autores ainda enfatizam que essas sete dimensões são componentes centrais da cultura de segurança nas organizações.

A busca por um consenso nas dimensões para uma cultura de segurança sólida nas organizações nucleares tem sido o tema de uma série de publicações da IAEA. Os trabalhos mais significativos com esse propósito foram: TECDOC-1329 (2002), TECDOC1321 (2002) e SCART (2008).

A IAEA por meio do TECDOC-1321 (2002) afirma que existem certos fatores organizacionais que devem ser considerados quando se propõem soluções para os problemas de cultura de segurança. A importância de um determinado fator varia de acordo com a natureza do problema. Alguns fatores são de grande alcance no seu efeito potencial. Os seguintes fatores organizacionais foram identificados, pelo grupo de trabalho que discutiu essa questão, como sendo especialmente importantes quando se busca soluções para os problemas de cultura de segurança.

- Atitude de melhoria contínua;

- Canais de comunicação eficazes;

- Comprometimento da administração com a segurança;

- Sistema de planejamento eficaz;

- Adequação dos recursos;

- Habilidades e competências;

- Influências externas.

Com base em resultados de pesquisas, nas lições aprendidas com as falhas organizacionais e na colaboração internacional de especialistas em segurança, a IAEA publicou o TECDOC-1329 (2002), identificando as seguintes características (dimensões) de cultura de segurança que devem ser consideradas nas avaliações:

- Comprometimento da alta direção com a segurança;

- Liderança visível;

- Abordagem sistemática da segurança;

- Auto-avaliação; 
- Ausência de conflitos segurança versus produção;

- Relação com os reguladores e outros grupos externos;

- Perspectiva proativa e de longo prazo;

- Gerenciamento de mudanças;

- Qualidade da documentação e procedimentos;

- Conformidade com as normas e procedimentos;

- Pessoal suficiente e competente;

- Atitude de questionamento dos funcionários;

- A integração homem, tecnologia e organização;

- Funções, responsabilidades e obrigações claras;

- Motivação e satisfação no trabalho;

- O envolvimento de todos os colaboradores;

- Boas condições de trabalho, relacionadas com a pressão do tempo, a carga de trabalho e o estresse;

- Medição do desempenho da segurança;

- Alocação adequada de recursos;

- A colaboração e trabalho em equipe;

- Tratamento de conflitos;

- Relação entre gerentes e funcionários;

- O processo de trabalho;

- Arrumação e limpeza;

- Alta prioridade dada à segurança;

- Comunicação aberta;

- Aprendizagem organizacional;

Como resultado de um trabalho mais abrangente da IAEA, foi publicado o SCART (2008). O documento identifica uma estrutura com base em cinco características principais de cultura de segurança, especificadas por um conjunto de 37 atributos, conforme apresentada no Quadro 2.4-1. 
Quadro 2.4-1 - Características e atributos da cultura de segurança (SCART)

\begin{tabular}{|c|c|}
\hline Características & Atributos \\
\hline $\begin{array}{l}\text { (A) } \\
\text { A segurança é } \\
\text { um valor } \\
\text { claramente } \\
\text { reconhecido }\end{array}$ & $\begin{array}{l}\text { A.1. A alta prioridade dada à segurança é mostrada na documentação, comunicação e } \\
\text { tomada de decisão } \\
\text { A.2. A segurança é uma considerações primordial na alocação de recursos } \\
\text { A.3. A importancia estratégica da segurança se reflete no plano de negócios } \\
\text { A.4. As pessoas estão convencidas que a segurança e a produção andam de mãos dadas } \\
\text { A.5. Uma abordagem pró-ativa e de longo prazo para as questões de segurança é mostrada } \\
\text { nas tomadas de decisão } \\
\text { A.6. Um comportamento consciente de Segurança socialmente aceito e apoiado (formal e } \\
\text { informalmente) }\end{array}$ \\
\hline $\begin{array}{l}\text { (B) } \\
\text { A liderança para } \\
\text { a segurança é } \\
\text { clara }\end{array}$ & $\begin{array}{l}\text { B.1. A alta administração está claramente comprometida com a segurança } \\
\text { B.2. O comprometimento com a segurança é evidente em todos os níveis gerenciais } \\
\text { B.3. Existe uma liderança visível mostrando o envolvimento da administração em } \\
\text { atividades relacionadas com a segurança } \\
\text { B.4. Habilidades de liderança são sistematicamente desenvolvidas } \\
\text { B.5. A administração assegura que existem pessoas competentes suficientes } \\
\text { B.6. A Administração busca o envolvimento ativo das pessoas na melhoria da segurança } \\
\text { B.7. Questões de Segurança são consideradas nos processos de gestão de mudanças } \\
\text { B.8. A administração mostra um esforço contínuo para obter uma comunicação boa e aberta } \\
\text { em toda a organização } \\
\text { B.9. A administração tem a capacidade de resolver conflitos quando necessário } \\
\text { B.10. As relações entre os gestores e as pessoas são construídas na confiança }\end{array}$ \\
\hline $\begin{array}{c}\text { (C) } \\
\text { A } \\
\text { responsabilidade } \\
\text { pela segurança é } \\
\text { clara }\end{array}$ & $\begin{array}{l}\text { C.1. Existe uma relação apropriada com o órgão regulador, o que garante que a a } \\
\text { responsabilidade pela segurança permanece com o titular da licença } \\
\text { C.2. Funções e responsabilidades estão claramente definidas e compreendidas } \\
\text { C.3. Há um alto nível de conformidade com os regulamentos e procedimentos } \\
\text { C.4. A administração delega responsabilidade com a autoridade apropriada } \\
\text { C.5. "Propriedade" pela segurança é evidente em todos os níveis organizacionais e para } \\
\text { todas as pessoas }\end{array}$ \\
\hline $\begin{array}{l}\text { (D) } \\
\text { A segurança é } \\
\text { integrada em } \\
\text { todas as } \\
\text { atividades }\end{array}$ & $\begin{array}{l}\text { D.1. A confiança permeia na organização } \\
\text { D.2. A consideração de todos os tipos de segurança, incluindo a segurança industrial, } \\
\text { ambiental e física é evidente } \\
\text { D.3. A qualidade da documentação e procedimentos é boa } \\
\text { D.4. A qualidade dos processos, desde o planejamento até a execução e revisão, é boa } \\
\text { D.5. As pessoas têm o conhecimento e a compreensão necessária dos processos de trabalho } \\
\text { D.6. Os fatores que afetam a motivação pelo trabalho e a satisfação no trabalho são } \\
\text { considerados } \\
\text { D.7. Boas condições de trabalho existem em termos de pressão do tempo, carga de trabalho } \\
\text { e estresse } \\
\text { D.8. A cooperação e o trabalho em equipe estão presentes } \\
\text { D.9. As condições de limpeza e dos materiais refletem o compromisso com a excelência }\end{array}$ \\
\hline $\begin{array}{c}(\mathrm{E}) \\
\text { A segurança é } \\
\text { direcionada ao } \\
\text { aprendizado }\end{array}$ & $\begin{array}{l}\text { E.1. Uma atitude de questionamento prevalece em todos os níveis organizacionais } \\
\text { E.2. Os relatórios de desvios e erros são incentivados } \\
\text { E.3. As avaliações internas e externas, incluindo a auto-avaliação, são realizadas } \\
\text { E.4. A experiência organizacional e operacional (interna e externa à a instalação) são } \\
\text { utilizadas } \\
\text { E.5. A aprendizagem é facilitada pela capacidade de reconhecer e diagnosticar desvios e de } \\
\text { implementar e monitorar ações corretivas } \\
\text { E.6. Indicadores de desempenho de segurança são desenvolvidos, avaliados e colocados } \\
\text { em prática } \\
\text { E.7. Existe um desenvolvimento sistemático de competências individuais }\end{array}$ \\
\hline
\end{tabular}




\subsection{As dimensões para uma cultura de segurança nuclear}

Conforme observado na seção anterior, as dimensões que compreendem uma cultura de segurança variam significativamente de um autor para outro. Por conseguinte, foram selecionadas como determinantes para uma cultura de segurança na área nuclear aquelas referenciadas com maior frequência nos trabalhos analisados, conforme elucidadas a seguir.

\subsubsection{Prioridade dada à segurança}

De acordo com Ponte Junior (2014), o desenvolvimento de uma cultura de segurança requer a priorização dos assuntos relacionados à segurança. Não é possível desenvolver cultura de segurança quando é permitido que outros assuntos protelem a atenção que deve ser dada aos assuntos relacionados com a segurança.

Conforme apresentado em TECDOC-1329 (2002), uma das formas de se evidenciar que a segurança tem prioridade em uma instalação é pela ausência de conflitos entre a segurança e a produção. Não haverá conflitos se a segurança for uma verdadeira prioridade. Sempre que questões de segurança surgem durante o trabalho, as atividades devem parar temporariamente para uma avaliação e para a resolução de eventuais problemas. Os trabalhadores não devem improvisar sem avaliar as consequências e nem assumir riscos para ganhar tempo ou para atingir alguma meta de produção. Ainda conforme o documento, muitas organizações afirmam que a segurança é prioridade máxima, mas as suas ações e comportamentos nem sempre confirmam este valor na prática.

Quando a segurança é uma prioridade na instalação, os operadores são treinados para interromper o processo quando em dúvida se pode continuar a operar seguramente. Nesse caso, também se observa na política de segurança declarada pela organização que a segurança tem prioridade sobre a produção.

Outra forma de verificar a prioridade dada à segurança na instalação é pela crescente quantidade de violações. Violações são desvios conscientes de regras, como por exemplo, 'atalhos" no processo que fornecem uma visão direta da cultura de segurança de uma organização. Todas as violações devem ser investigadas a fundo para determinar a 
causa raiz. Onde as violações estão em número crescente, pode ser um indicador de um gerenciamento indiferente, ou seja, aquele que raramente pune violações ou que não recompensa quem não as comete. Violações não devem ser confundidas com os erros causados por deslizes ou lapsos que são desvios não intencionais (TECDOC-1321, 2002).

\subsubsection{Alocação de recursos}

De acordo com NEA (1999), essa característica diz respeito a alocar, distribuir e monitorar os recursos financeiros, humanos e técnicos para apoiar as atividades estabelecidas pelas metas. Se a alocação de recursos é inadequada, a segurança será prejudicada. Essa característica é especialmente importante em períodos de orçamentos reduzidos, em que poderia haver ênfase da operação econômica em detrimento da operação segura.

A inadequação da alocação de recursos pode se revelar sob a falta de pessoal qualificado e experiente, aumento do uso de contratados em funções organizacionais chaves, por longos períodos de tempo, e de repetidos pedidos aos reguladores para dispensas de exigências regulamentares. Ao considerar a alocação de recursos, deve ser dada atenção tanto na quantidade como na qualidade dos recursos, e se a alocação é por curto ou longo prazo (TECDOC-1329, 2002).

Para uma alocação apropriada de recursos é recomendado em TECDOC-1329 (2002) que deve ser dada atenção para as necessidades de recursos de trabalho rotineiro e não rotineiro. Paradas de engenharia para manutenção, por exemplo, muitas vezes têm necessidades de recursos mais elevados do que o previsto. A adequação de recursos deve ser considerada em um amplo contexto, devendo incluir habilidades, conhecimento e experiência.

\subsubsection{Funções e responsabilidades}

Em uma cultura de segurança sólida, a alta administração garante que as funções, as responsabilidades e a autoridade delegada aos executivos (gerentes seniores e gerentes corporativos) estão claramente definidas, compreendidas e documentadas. Eles, 
por sua vez, devem delegar responsabilidades e autoridade de forma apropriada (NUREG$2165,2014)$.

De forma semelhante, é recomendado em TECDOC-1329 (2002) que, em se tratando de segurança, é importante que os documentos com as descrições dos cargos definam funções e responsabilidades claramente. Essa atribuição de responsabilidades indica que as metas a atingir são estabelecidas, o progresso avaliado e que há consequências para o não cumprimento das metas.

\subsubsection{Comprometimento com a segurança}

O comprometimento com a segurança pela alta administração talvez seja a característica mais importante de uma cultura de segurança, porque se não estiver presente, inibirá seriamente o desenvolvimento de uma cultura de segurança sólida. A alta administração tem de demonstrar seu compromisso pelo seu comportamento, atitude para a segurança e pela alocação adequada de recursos, incluindo o tempo destinado para tratar de questões de segurança (TECDOC-1329, 2002).

$\mathrm{Na}$ opinião de Alexander (2004) se todos os níveis de gerenciamento estão verdadeiramente comprometidos com a segurança, todas as outras características da cultura de segurança vêm naturalmente. Um comprometimento com a segurança significa que a segurança é uma prioridade absoluta e que não há conflito entre a segurança e a produção. Nenhum risco para a segurança deve ser tomado com o intuito de manter a instalação em funcionamento.

Uma gestão comprometida terá uma abordagem conservadora para a segurança, particularmente, no caso de instalações que possuem reatores. A energia nuclear é reconhecida como sendo diferente de outras fontes de energia convencionais, e os riscos associados devem ser levados em consideração nas tomadas das decisões.

O comprometimento com a segurança inclui, sobretudo, a alocação dos recursos necessários para garantir a segurança, seja financeiro, tempo, pessoal, ou a própria atenção da administração. Esse compromisso também fica evidenciado pela observância às normas e regulamentos. 


\subsubsection{Comunicação}

A Comunicação conforme definida em NEA (1999), é um processo pelo qual a informação é trocada, tanto formal como informalmente, de forma escrita ou verbal, dentro ou fora dos limites organizacionais. É um sistema que compreende o fluxo de informações entre a organização e outras entidades (reguladores e prestadores de serviços); entre os diferentes níveis da organização, tanto vertical (entre a gerência e os empregados) como horizontal (entre os diferentes departamentos) e o fluxo intra-organizacional que é a comunicação dentro dos grupos e entre os membros do grupo.

Conforme observado em TECDOC-1321 (2002), um aspecto que pode evidenciar uma boa comunicação na instalação é a "verificação de pronto" para a operação ou para a manutenção. Alguns incidentes ocorrem com frequência na partida da planta após a parada de manutenção, ou quando a planta não está devidamente preparada pelos operadores para o trabalho da manutenção planejada. A existência de um processo sistemático para a preparação da planta para a partida, ou para a manutenção, é um indicador de que atenção está sendo dada a este importante aspecto de segurança. O processo deve incluir verificações pré e pós-manutenção por parte dos operadores e do pessoal da manutenção. A eficácia desses controles é um indicador da qualidade do relacionamento entre a operação e a manutenção.

Uma organização com a intenção de desenvolver ou melhorar a sua cultura de segurança deve garantir que a informação seja efetivamente transmitida por toda a organização, como também para as partes externas interessadas, incluindo os reguladores. Sistemas de informação computadorizados têm um papel importante a desempenhar na melhoria da comunicação dentro de uma organização (TECDOC-1321 (2002).

Outra consideração importante, apresentada por Alexander (2004), é que a comunicação deve ser aberta e transparente e a sua eficácia monitorada.

\subsubsection{Relacionamento}

Como bem delineado na NUREG-2165 (2014) essa característica da cultura de segurança compreende o relacionamento com reguladores ou outros grupos externos e o 
relacionamento entre gerentes e empregados. No primeiro caso, deve haver um respeito mútuo entre os membros da organização e os reguladores ou outros grupos externos. Compartilhar planos de longo prazo com os reguladores podem ajudar a aumentar a confiança e permitir que o regulador possa se preparar de forma mais eficaz para as demandas de trabalhos futuros. O relacionamento deve ser caracterizado pela confiança mútua e de abertura na comunicação.

Com relaçao a gerentes e empregados, deve haver uma relação aberta e de respeito mútuo entre os gestores e os colaboradores. Algumas organizações podem ser mais hierárquicas do que outras, mas a hierarquia não deve impedir o respeito mútuo.

\subsubsection{Qualificação e dimensionamento de pessoal}

Uma equipe competente e em quantidade suficiente de pessoas é outro indicativo de uma cultura de segurança sólida. Os funcionários enfrentam riscos adicionais se forem em número insuficiente para a tarefa, ou se eles não possuírem as habilidades necessárias. Tanto a quantidade, como também a qualidade da equipe, são importantes. $\mathrm{O}$ conhecimento técnico é a base para um pessoal competente e deve ser um processo contínuo (Alexander, 2004).

De acordo com a orientação apresentada em TECDOC-1321 (2002), o trabalho com impacto potencial na segurança só deve ser realizado por pessoas devidamente qualificadas e experientes. Isso é especialmente importante na indústria nuclear. Em geral, as habilidades e competências são especificadas em perfis profissionais que são baseadas na análise das tarefas a serem realizadas por uma pessoa. A falta de perfis profissionais adequados indica a ausência de uma abordagem sistemática dentro da organização. Habilidades e competências se estendem para além do domínio técnico e incluem comunicação, liderança e outras habilidades interpessoais.

Uma abordagem sistemática para o treinamento é particularmente importante. As organizações precisam dedicar os recursos suficientes para o treinamento a fim de garantir o desempenho eficaz da segurança. As necessidades de treinamento para funções e tarefas devem ser identificadas e os critérios de competência especificados. A programação deve incluir treinamento em cultura de segurança, principalmente, para os gestores e 
operadores. Adicionalmente, deve haver uma revisão periódica da aplicabilidade dos cursos. O treinamento deve ser dado durante toda a vida do funcionário na organização (TECDOC-1321, 2002).

\subsubsection{Documentação e procedimentos}

De acordo com a NUREG-2165 (2014), a organização deve criar e manter a documentação completa, precisa e atualizada.

Conforme recomendado em TECDOC-1329 (2002), a documentação e os procedimentos em geral devem ser abrangentes e de fácil entendimento. A responsabilidade pela preparação da documentação e pela sua revisão deve ser clara. A documentação deverá ser utilizada tanto em treinamento como no trabalho. A documentação relativa ao processo na organização deve ser de fácil compreensão não só do próprio processo de trabalho, mas também a forma como ele interage com outros processos.

Os documentos e procedimentos que não são regularmente atualizados e revisados podem se tornar inválidos, e possivelmente resultar em consequências para a segurança. A preparação, emissão e atualização dos procedimentos devem estar sujeitas ao controle da qualidade. Indicadores de fraqueza nesse aspecto são a falta de um processo sistemático de análise dos procedimentos e a falta de definição da responsabilidade pela revisão (TECDOC-1321, 2002).

\subsubsection{Condições de trabalho}

Conforme preconizado em TECDOC-1329 (2002), as condições de trabalho no que diz respeito à pressão do tempo para realizar as tarefas, carga de trabalho e estresse são características importantíssimas para a segurança em uma instalação nuclear. A segurança pode ser comprometida se os funcionários estão sobrecarregados de trabalho. Seu estado de alerta para problemas de segurança diminuirá.

De acordo com a orientação em HSG48 (2007), o ritmo de trabalho muito rápido, ou mesmo muito lento, pode resultar em fadiga para o executante e movimentos 
repetitivos podem resultar em lesões para os mesmos. Trabalhar com prazos irreais pode resultar em estresse psicológico ou em acidentes. Programação de trabalho que exige longas horas de atividades, ou o trabalho noturno, pode resultar em fadiga e proporcionar a ocorrência de erros e acidentes. Ainda de acordo com o documento, os fatores ambientais como iluminação, ruído, ventilação e umidade relativa do ar devem estar em níveis para o máximo conforto do trabalhador. O excesso de ruído, vibração e os extremos de temperatura pode resultar em estresse físico.

Padrões insatisfatórios na arrumação e limpeza geralmente indicam uma gestão desinteressada e uma força de trabalho pouco motivada e que tem pouco orgulho em seu ambiente de trabalho. Esses pontos fracos geralmente se estendem para o domínio da segurança e indicam fragilidades na cultura de segurança. Bons padrões de arrumação e limpeza têm provado pela experiência ser um indicador extremamente confiável da cultura de uma organização (TECDOC-1321, 2002).

O comportamento dos funcionários será fortemente influenciado por sua motivação e satisfação no trabalho. Estas refletirão a qualidade da liderança e a atenção ao planejamento do trabalho em uma organização. Questões motivacionais são complexas e uma assistência especializada pode ser necessária (TECDOC-1329, 2002).

\subsubsection{Aprendizagem organizacional}

Alexander (2004) esclarece que uma cultura de aprendizagem significa simplesmente um desejo de melhorar e uma vontade de aprender com os outros. Cada problema ou erro é uma oportunidade para aprender. Uma planta com uma cultura de aprendizagem é proativa e vai buscar a experiência de outras plantas.

Conforme documentado em NEA (1999), trata-se de uma característica de cultura de segurança que compreende:

- O feedback da experiência operacional;

- Comportamento proativo em vez de reativo;

- Transformação do conhecimento indivídual tácito em conhecimento organizacional explícito; 
- Atitude de questionamento;

- Promoção de uma compreensão comum dos processos e das responsabilidades;

- Aprender com questões genéricas;

- Identificação e resolução de problemas;

- Auto-avaliação periódica;

- Capacidade e vontade de aprender;

- Melhoria continua.

A indústria nuclear é um setor que tem se esforçado para compartilhar experiências internacionalmente. Podem surgir problemas quando as organizações se tornam complacentes e se concentram no sucesso do passado. Elas ficam relutantes em investir na construção de novas competências para o futuro (TECDOC-1329, 2002).

Ainda coforme observado em TECDOC-1329 (2002), a repetição de um problema geralmente indica que a causa fundamental (ou as causas) não foi devidamente identificada. Uma análise sistemática em profundidade de incidentes e acidentes é indispensável quando lições devem ser aprendidas e as causas identificadas. As causas podem ser técnicas, ou relacionadas a fatores humanos, cultura organizacional, processos, procedimentos, equipamentos ou ao próprio ambiente.

A experiência tem mostrado que os fatores humanos e as questões da cultura de segurança desempenham um papel importante em muitos eventos que têm consequências na segurança. A análise de causa raiz permite que a complexidade de eventos seja melhor compreendida. Um sinal positivo de que a atenção está sendo dada à análise sistemática de eventos é que os funcionários que realizam essas análises estejam sendo treinados nesse sentido (TECDOC-1329, 2002).

Na opinião de Ponte Junior (2014), o desenvolvimento de uma cultura de segurança requer visão multidisciplinar dos acidentes. Os cenários acidentais se apresentam como situações adversas com características multidisciplinares relacionadas com as consequências da imprevisibilidade de determinados fatos e os relacionados com falhas de equipamentos, de procedimentos, falhas comportamentais, falhas de gerenciamento entre outras. 
De acordo com a orientação encontrada em TECDOC-1321 (2002), qualquer aumento significativo no número de ações corretivas que não tenham sido implementadas dentro do tempo planejado é um dos sinais mais evidentes de fragilidades na cultura de segurança. É um sinal de que não está sendo dada à segurança a prioridade que merece. Atenção deve ser dada tanto ao número de ações corretivas que tenham excedido a data de implementação original como à dimensão do atraso.

Com relação à atitude de melhoria contínua, a recomendação em TECDOC1321 (2002) é que não importa quão bem uma organização está desempenhando no momento, ela sempre precisa considerar como poderia melhorar ainda mais. A ausência dessa atitude se revela sob a forma de inércia organizacional. Por outro lado, o seu desenvolvimento é fortemente dependente da liderança, do comprometimento da alta administração e do envolvimento dos trabalhadores no processo de aprendizagem e aperfeiçoamento.

\subsubsection{Avaliações internas e externas}

Dentre as avaliações internas que podem ser realizadas em uma organização, a mais eficaz é a auto-avaliação, conforme salientado em IAEA (1999). O documento define a auto-avaliação (self-assessment) como um processo estruturado através do qual os indivíduos, os grupos e o gerenciamento, dentro de uma organização, avaliam a eficácia de sua própria segurança operacional em relação às expectativas de desempenho predeterminadas. Entretanto o documento alerta para o fato de que um programa de autoavaliação só é completo quando as ações corretivas tiverem sido implementadas e sua adequação confirmada.

O propósito e os benefícios de uma auto-avaliação são claros: promover a melhoria do desempenho da segurança através do envolvimento direto do pessoal na análise crítica, e aprimoramento de suas próprias atividades e resultados do trabalho.

Como bem observado em TECDOC-1329 (2002) a falta de um processo de auto-valiação é um importante indicador de fragilidade na cultura de segurança da organização. Na falta dessas avaliações a organização ficará cega às deficiências nas atitudes e comportamentos de segurança e não vai conhecer as causas de muitos eventos. É 
improvável que uma organização adote uma filosofia de melhoria contínua se ela não realiza auto-avaliação.

O processo de auto-avaliação em conjunto com outras formas de avaliação interna e externa é um fator essencial para se alcançar as expectativas de desempenho global, bem como manter e reforçar a cultura de segurança da organização.

Todas as formas de avaliação, como as avaliações independentes, as avaliações externas, as avaliações por parte do órgão regulador e as auto-avaliações, juntamente com o feedback da experiência operacional, são métodos para a identificação de problemas, e se constituem em um valoroso input para o processo de ação corretiva.

É importante ressaltar que um processo de avaliação só é completo com a devida divulgação dos resultados. É essencial que uma organização meça o seu desempenho de segurança e comunique os resultados e as tendências para todos os seus funcionários.

\subsection{Uma revisão dos instrumentos de avaliação de cultura de segurança}

Realizou-se uma ampla pesquisa na literatura nacional e internacional, com o intuito de identificar trabalhos em avaliação de cultura de segurança no domínio nuclear.

No âmbito nacional foram identificados os seguintes trabalhos: Oliveira e Saxena (2003), Obadia (2004), Neto et al. (2007), Martins (2008), Neto et al. (2009) e Pereira (2011), conforme apresentados a seguir.

No trabalho realizado por Obadia (2004) foi desenvolvido um sistema de gestão para organizações que lidam com tecnologia perigosa em que a segurança representa um fator crítico para a excelência organizacional. O sistema consiste de um processo de gestão baseado no Modelo de Excelência do Prêmio Nacional da Qualidade ao qual a cultura de segurança da organização é integrada segundo uma abordagem adaptativa e a segurança é incorporada como uma dimensão estratégica da excelência. O sistema de gestão adaptativo foi inicialmente desenvolvido de maneira teórica e complementado por meio de um estudo de caso realizado no Instituto de Engenharia Nuclear (IEN) que é 
uma unidade de pesquisa e desenvolvimento tecnológico da Comissão Nacional de Energia Nuclear (CNEN).

O instrumento de coleta de dados foi constituído de introdução, glossário, 7 questões relacionadas a informações pessoais e 70 afirmativas, redigidas de forma positiva e negativa, referentes a 22 fatores organizacionais avaliados. A pesquisa permitiu concluir que o índice médio da cultura de segurança do IEN sofreu um aprimoramento correspondente a três pontos percentuais, passando de $62 \%$ para $65 \%$, no período de 2001 a 2003, o que representou uma variação positiva na sua classificação, de regular para satisfatória.

No Instituto de Pesquisas Energéticas e Nucleares (IPEN), também pertencente à $\mathrm{CNEN}$, foram identificados mais cinco trabalhos relacionados à avaliação de cultura de segurança. No primeiro, Oliveira e Saxena (2003) realizaram uma pesquisa com os funcionários do reator de pesquisas IEA-R1 para avaliar o estado atual da cultura de segurança na instalação. A pesquisa avaliou as principais dimensões da cultura de segurança baseadas na atitude, opinião e na percepção dos funcionários do reator com relação à segurança. $\mathrm{O}$ instrumento de pesquisa utilizado foi um questionário quantitativo composto por 42 questões. Essas questões foram distribuídas por 14 dimensões que apresentavam diferentes aspectos da cultura de segurança.

O questionário foi respondido por 34 funcionários, envolvendo apenas parte da equipe do Reator, sobretudo aqueles que trabalhavam na operação, manutenção e radioproteção.

Foram realizadas análises estatísticas para estimar os parâmetros das respostas dos questionários e obter o nível de satisfação dos funcionários em relação às dimensões de cultura de segurança definidas.

A Pesquisa identificou algumas dimensões da cultura de segurança, consideradas como adequadas para a realização das atividades na instalação: motivação e satisfação no trabalho, noções de prevenção de riscos, a atitude dos funcionários em relação à segurança, compromisso e responsabilidade dos funcionários, conflito da 
segurança com a produção e as condições de trabalho em relação à segurança. Por outro lado, a pesquisa também identificou como inadequadas as seguintes dimensões: conformidade com as normas e procedimentos, prioridade dada às questões de segurança, treinamento, comunicação, documentação e procedimentos, comprometimento da alta direção com a segurança e gerenciamneto da segurança.

No segundo trabalho identificado no IPEN, Neto et al. (2007) apresentaram um estudo que consistiu na elaboração e implementação de um plano de ação visando a melhoria da cultura de segurança na organização, em decorrência das dimensões não adequadas identificados por Oliveira e Saxena (2003) no trabalho anterior apresentado.

Esse plano de ação foi apresentado em um workshop no qual a maior parte dos funcionários do reator estavam presentes. Nesse workshop os principais conceitos de cultura de segurança e os resultados das avaliações mencionadas foram apresentados e discutidos amplamente entre os participantes, resultando na identificação dos pontos fortes, fracos e de consenso para uma cultura de segurança eficaz na organização.

O trabalho realizado por Martins (2008) foi o terceiro trabalho desenvolvido no IPEN. Seus objetivos foram avaliar o grau de aderência de uma instalação nuclear aos atributos de cultura de segurança considerados pela IAEA e estudar os fatores humanos e as possíveis causas que podem ocasionar um erro humano para a ocorrência de incidentes, acidentes e exposições de trabalhadores. A avaliação contou com o apoio de um grupo de operadores do reator de pesquisa IEA-R1, localizado no IPEN CNEN/SP. Os dados foram coletados através da aplicação de dois questionários. O primeiro foi elaborado a partir dos atributos de cultura de segurança considerados pela IAEA. O segundo considerou fatores individuais e situacionais que compõem categorias classificadas como podendo afetar as pessoas no ambiente de trabalho.

Assim, os valores obtidos indicaram que, segundo a percepção dos trabalhadores, a instalação pesquisada atende parcialmente aos atributos de cultura de segurança propostos e que fatores mediatos necessitam de atuação direta nas necessidades do grupo e do indivíduo. A pesquisa também mostrou que é necessário ter uma unidade de 
planejamento e organização, que seja realmente efetiva, tanto para as questões da saúde física e psicológica, como também, para a segurança no trabalho.

Com base nos resultados obtidos, também foi realizado o cálculo de confiabilidade utilizando a estimativa alfa de Cronbach. A metodologia demonstrou um bom grau de confiabilidade.

Apesar de o instrumento ter sido elaborado com base em atributos utilizados para avaliar cultura de segurança, o propósito da avaliação era o de medir e avaliar o aspecto comportamental do fator humano, ou seja, as características subjetivas e intangíveis referentes às percepções e reações das pessoas.

No quarto trabalho desenvolvido no IPEN, Neto et al. (2009) descreveram as características principais de uma base de conhecimento em cultura de segurança, desenvolvida no IPEN. O principal objetivo desta base é organizar as informações sobre cultura de segurança encontradas na literatura e torná-las disponível para pesquisadores e profissionais em segurança. Os pesquisadores concluíram em seu trabalho que, apesar de a base de dados ainda não ser profunda e abrangente o suficiente para os fins pretendidos, ela pode ser de grande ajuda, tanto para os pesquisadores e profissionais que estão começando na área, como também para aqueles mais experientes obterem as informações de interesse.

Já o último trabalho identificado no IPEN teve um enfoque um pouco diferente dos anteriores. A pesquisa realizada por Pereira (2011) teve como objetivo identificar os atores da rede de relacionamentos que exercem maior influência no comportamento de segurança. Para isso, o autor buscou na literatura estudos de abordagens teóricas e práticas, que utilizassem conceitos sócio-antropológicos. Foi dada preferência para trabalhos com enfoque na área nuclear, que possuíssem questionários de cultura de segurança, devidamente testados e avaliados por métodos estatísticos. Com base nos trabalhos encontrados, o autor realizou uma pesquisa no âmbito do IPEN para um mapeamento das redes sociais de compartilhamento de ideias. Dessa forma, o autor aplicou um questionário para mapear as crenças dos atores com significativo grau de influência, obtido a partir do levantamento das redes de influências. Os resultados mostraram que a metodologia 
desenvolvida permite a identificação das redes sociais mais relevantes com influência na formação da cultura de segurança do IPEN.

Apesar desses trabalhos identificados na literatura nacional serem iniciativas importantes na avaliação de cultura de segurança no domínio nuclear, verificou-se que não foram previstos para os instrumentos de pesquisa, estudos de suas propriedades psicométricas - análise da confiabilidade e validação. Excetua-se o trabalho trabalho desenvolvido por Martins (2008) que realizou um estudo da confiabilidade.

Como observação, vale ressaltar que Pereira (2011) em sua revisão bibliográfica também chegou à mesma conclusão, ou seja, não conseguiu identificar no domínio nacional instrumentos de avaliação de cultura de segurança, aplicados à área nuclear, que possuíssem evidências de avaliação de suas propriedades psicométricas. $\mathrm{O}$ autor acrescenta que, embora tenha encontrado vários questionários de avaliação de cultura de segurança na área nuclear, nenhum apresentava evidências de confiabilidade e de validade.

De acordo com Mkrtchyan e Turcanu (2012), uma preocupação básica na avaliação de uma cultura de segurança é garantir que os instrumentos de pesquisa sejam válidos e confiáveis, ou seja, meçam o que pretendem medir e produzam resultados semelhantes em medidas repetidas. Hair Jr. et al. (2010) afirmam que a evidência de validade oferece a segurança de que as medidas obtidas de uma amostra representam o verdadeiro parâmetro que caracteriza a população.

Ainda com relação à necessidade de validação, Williams (2008) ressalta que os resultados têm que ser válidos para serem considerados adequados, significativos e úteis. $\mathrm{Na}$ verdade, afirma ainda o autor, a validade é um dos conceitos mais importantes da pesquisa de opinião e, sem ela, tem-se resultados sem sentido e um desperdicio de tempo, energia e dinheiro.

Com relação a outros segmentos no Brasil (área não nuclear), a quantidade de instrumentos de avaliação de cultura de segurança, com propriedades psicométricas avaliadas é significante. Observou-se uma predominância nas áreas de saúde (hospitais e 
instituições de ensino), segurança do trabalho (petroquímicas e plataformas petrolíferas) e em quantidade menor, a aviação. Dentre os trabalhos identificados, destacam-se: Gonçalves (2007), Pontes (2008), Filho (2011), Carvalho (2011), Massoco (2012), Batalha (2012), Reis et al. (2012) e Costa (2013).

No âmbito internacional foi realizada uma pesquisa mais restrita, pois se buscou identificar apenas instrumentos de avaliação de cultura de segurança, aplicados à área nuclear, que possuíssem evidências de avaliação de suas propriedades psicométricas. Com essas qualidades foram encontrados apenas quatro trabalhos: Lee (1998), Lee e Harrison (2000), Morrow (2012) e Castro et al. (2013) que são apresentados a seguir.

Lee (1998) realizou uma pesquisa das atitudes de segurança na instalação de reprocessamento de combustível nuclear em Cumbria, Inglaterra. Foi aplicado um questionário de 172 itens a 5.296 participantes, com a finalidade de determinar as suas convicções, atitudes e valores relevantes para a segurança. As questões abrangeram nove domínios (dimensões) da cultura de segurança: comprometimento da administração, procedimentos de segurança, percepção de risco, satisfação no trabalho, normas de segurança, participação, treinamento, controle e projeto da planta. O instrumento foi submetido a uma análise fatorial pelo método de Análise de Componentes Principais. Inicialmente foram extraídos 38 fatores, mas em uma análise fatorial posterior os fatores foram reduzidos para 19 e os itens, para 81. O autor realizou também uma estatística descritiva, analisando os dados por subgrupos relevantes, ou seja, sexo, idade, tempo de serviço, turnos e tipo de trabalho.

Lee e Harrison (2000) desenvolveram um questionário de 120 itens, abrangendo oito domínios de cultura de segurança, aplicando-o em três centrais nucleares. Para a validação de construto, realizou uma análise fatorial pelo método Análise de Componentes Principais (ACP), que resultou em 28 fatores. As diferenças por sexo, idade, turnos e áreas de trabalho também foram analisadas. Os efeitos dos fatores analisados sobre a cultura de segurança também foram explorados, como por exemplo, o papel da segurança no trabalho em equipe, o estilo de gestão e a pressão do tempo no trabalho, em detrimento da segurança. 
Os principais objetivos do estudo proposto por Morrow (2012) foram analisar os fatores que compreendem o conceito de cultura de segurança na indústria nuclear, avaliar o grau em que eles se alinhavam com as características apresentadas na política de segurança da NRC e verificar as relações entre os resultados da pesquisa com outras medidas de desempenho de segurança, mantidos pelo Institute for Nuclear Power Operations (INPO) e pela própria NRC.

O instrumento de pesquisa foi composto por 110 itens. O estudo também incluiu questões demográficas para que os respondentes indicassem a sua planta, grupo de trabalho (por exemplo, operação, manutenção, engenharia), e o vínculo de trabalho (permanente ou contratado).

Em linhas gerais, o instrumento de pesquisa da cultura de segurança demonstrou boas propriedades psicométricas por meio da análise da confiabilidade e da validação de conteúdo e de construto. Os resultados da análise fatorial apresentaram correspondência razoável entre a maioria dos fatores abordados na pesquisa e as características da declaração de política da NRC.

O trabalho apresentado por Castro et al. (2013) consistiu em uma primeira iniciativa de validar o modelo de cultura de segurança proposto pela IAEA em SCART (2008). Esse modelo, composto por cinco características especificadas por 37 atributos, é muito referenciado em instrumentos de avaliação de cultura de segurança. A pesquisa de Castro et al. (2013) foi realizada em três estudos independentes e complementares. No primeiro, 290 alunos foram empregados para realizar a validação de face do modelo. No segundo, 48 especialistas em comportamento organizacional realizaram a validação de conteúdo. No terceiro, 468 trabalhadores de uma usina nuclear espanhola participaram diretamente da pesquisa, o que proporcionou dados para realizar a análise da confiabilidade e a validação de construto do intrumento. Os resultados dos estudos sugerem que vários atributos do modelo não estão relacionados com as dimensões correspondentes e que uma estrutura unidimensional se ajustaria melhor aos dados, do que as cinco dimensões propostas pela IAEA. Além disso, o modelo da IAEA não apresentou boas evidências de validade de conteúdo e de face. 
Por ocasião dessa revisão na literatura internacional, outros instrumentos de avaliação de cultura de segurança, aplicados à área nuclear, foram identificados, porém, não abordavam as questões de validade e de confiabilidade.

A fim de complementar a revisão na literatura internacional, pesquisou-se também junto a reguladores internacionais, por trabalhos nesse sentido. Foram identificados vários documentos, publicados pela IAEA, tratando da questão da avaliação de cultura de segurança em instalações nucleares, como por exemplo, INSAG-4 (1991), TECDOC-1125 (1999), INSAG-15 (2002), TECDOC-1321 (2002) e SCART (2008). Esses documentos fornecem valorosas diretrizes sobre os atributos da cultura de segurança que devem ser avaliados e sugerem algumas questões. No entanto, não abordam formas de quantificar os resultados e nem de tratamento estatísticos para os dados. 


\section{METODOLOGIA}

Este capítulo apresenta os métodos empregados para que os objetivos propostos para esse trabalho fossem atingidos.

\subsection{Delineamento da pesquisa}

A metodologia estabelecida para a realização deste trabalho obedeceu às seguintes etapas:

1. Ampla revisão da literatura;

2. Definição conceitual do modelo de mensuração;

3. Operacionalização dos construtos;

4. Elaboração do instrumento preliminar de coleta de dados (Questionário);

5. Mapeamento de especialistas;

6. Validação de conteúdo do instrumento;

7. Validação de face do instrumento (pré-teste);

8. Definição da estrutura conceitual da cultura de segurança;

9. Elaboração do instrumento de pesquisa definitivo (Questionário);

10. Identificação da população e amostra;

11. Aplicação do Questionário;

12. Consolidação e organização dos dados;

13. Preparação e tratamento dos dados

14. Análise das variáveis demográficas;

15. Análise dos indicadores de mensuração das dimensões;

16. Análise da adequação do tamanho da amostra;

17. Análise da confiabilidade do instrumento;

18. Validação de construto do instrumento;

19. Consolidação do modelo.

A etapa 1 foi apresentada no Capítulo 2; as etapas 2 a 11, neste capítulo; as etapas 12 a 15, no Capítulo 4 e as etapas 16 a 19, no Capítulo 5. 


\subsection{A modelagem de instrumentos de pesquisa}

Esta seção tem o propósito de apresentar em linhas gerais os aspectos teóricos das ferramentas e métodos utilizados para modelar e implementar instrumentos de pesquisa.

\subsubsection{O conceito das escalas múltiplas}

Escalas múltiplas na definição de Hair Jr. et al. (2010) é o método de combinação de diversas variáveis, que medem o mesmo conceito (construto) em uma única variável, na tentativa de aumentar a confiabilidade da medida. Essa forma de mensuração, denominada medida multivariada, consiste no emprego de duas ou mais variáveis como indicadores de uma única medida composta.

O indicador é o valor observado usado como uma medida única ou parte de uma medida combinada para mensurar um construto. Diversos indicadores, como por exemplo, as questões de um questionário, são, então, combinados para formar um escore único (escala múltipla), que representa o construto (conceito).

De acordo com Devellis (2003), construto é um conceito latente que pode ser definido em termos teóricos, mas não pode ser medido diretamente, ou seja, não há uma resposta única que forneça total e perfeitamente a medida do conceito. Um construto pode ser definido em diversos graus de especificidade, variando de conceitos muito limitados até aqueles mais complexos ou abstratos, como por exemplo, inteligência ou emoções. Malhotra (2006) cita como exemplo a área de marketing em que a atitude de uma pessoa em relação a um produto não pode ser medida precisamente a ponto de não haver incerteza, mas fazendose várias perguntas podem-se avaliar muitos aspectos da atitude dessa pessoa. Em combinação, as respostas a tais questões fornecem uma medida razoavelmente precisa do construto atitude.

O uso de múltiplos indicadores permite, então, representar os múltiplos aspectos de um construto para se obter uma perspectiva mais ampla do mesmo. A premissa básica é que respostas múltiplas refletem a resposta "verdadeira" com maior precisão do que uma única resposta (Hair Jr. et al., 2010). 
Ainda de acordo com Devellis (2003) as escalas múltiplas são amplamente utilizadas em ciências sociais para medir não apenas atitudes, como também opinião, personalidade, estado emocional, necessidades pessoais, dentre outras. $\mathrm{O}$ seu processo de construção tem fundamentos teóricos e empíricos em diversas disciplinas, incluindo a teoria psicométrica, a sociologia e o marketing.

Por fim, complementando os enunciados anteriores, Hair Jr. et al. (2010) acrescentam que as escalas múltiplas, um dos desenvolvimentos recentes em metodologia de pesquisas, estão encontrando aplicação crescente em pesquisa aplicada e gerencial também. A habilidade da escala múltipla de representar conceitos complexos em uma única medida e ainda reduzir erros de medida a torna uma valiosa ferramenta em qualquer análise multivariada. A análise fatorial fornece ao pesquisador uma avaliação empírica das inter-relações entre variáveis, essencial na formação do fundamento conceitual e empírico de uma escala múltipla.

O desenvolvimento de uma escala de múltiplos indicadores envolve os seguintes passos:

1. Conhecer os aspectos teóricos acerca do conceito em estudo: revisão da literatura;

2. Definir teoricamente o conceito em estudo: identificação dos construtos (dimensões) individuais;

3. Desenvolver uma lista de potenciais indicadores de mensuração que correspondam aos construtos: operacionalização dos construtos;

4. Avaliar quão bem os indicadores correspondem aos construtos em estudo: validação de conteúdo e de face;

5. Elaborar o questionário (instrumento): questões para os indicadores de mensuração.

\subsubsection{O erro de medida}

A utilização da escala múltipla é um meio de minimizar consideravelmente o erro de medida inerente a qualquer variável mensurada. 
Conforme esclarece Trochim (2006), erro de medida é o grau com que os valores observados não são representativos dos valores "reais". Tais erros surgem a partir de várias fontes: distração e estresse do respondente, variações nas condições do teste, erro do respondente em fornecer informações precisas e assim por diante.

A escala múltipla reduz o erro de medida utilizando indicadores múltiplos, pois com a resposta média ou típica de um conjunto de variáveis relacionadas, o erro de medida, que poderia ocorrer em uma única questão, é reduzido.

Quando se estima o erro presente em qualquer medida, deve-se levar em conta uma característica muito importante do instrumento: as suas propriedades psicométricas, ou seja, a validade e a confiabilidade das medidas.

\subsubsection{As propriedades psicométricas de instrumentos de pesquisa}

\section{$\underline{\text { A psicometria }}$}

Nas palavras de Pasquali (2009) a psicometria fundamenta-se na teoria da medida em ciências para explicar o sentido que têm as respostas dadas pelos sujeitos a uma série de tarefas, tipicamente chamadas de itens, e propor técnicas de medida dos processos mentais. Ainda de acordo com o autor, é o ramo da psicologia que lida com o desenvolvimento, administração e interpretação de testes quantitativos para a medição de variáveis psicológicas.

A psicometria é conjunto de técnicas utilizadas para mensurar, de forma adequada e comprovada experimentalmente, um conjunto ou uma gama de comportamentos que se deseja conhecer melhor. É uma área da Psicologia que faz o vínculo entre as ciências exatas e a Psicologia (Devellis, 2003).

Com relação ao domínio da psicometria, Devellis (2003) observa que o seu impacto nas ciências sociais transcendeu as suas origens de medição da percepção e das habilidades intelectuais. A psicometria tem sido considerada como um paradigma metodológico por três razões: o uso generalizado das definições psicométricas de 
confiabilidade e de validade, o uso disseminado da análise fatorial em pesquisa de ciências sociais e a adoção de métodos psicométricos para o desenvolvimento das escalas múltiplas.

A aplicabilidade dos conceitos e métodos psicométricos para a medição de fenômenos psicológicos e sociais em instrumentos de pesquisa é antiga, mas só recentemente, com o aumento da capacidade de processamento dos computadores para realizar análises multivariadas de dados, seu emprego se tornou mais frequente. Essas análises (multivariadas) se referem a todas as técnicas estatísticas que simultaneamente analisam múltiplas medidas sobre indivíduos ou objetos sob investigação.

A qualidade das medidas obtidas por um instrumento de pesquisa é determinada pela análise de suas propriedades psicométricas. Essas análises visam obter as evidências de confiabilidade e de validade do instrumento (Devellis, 2003; Sekaran, 2003; Hair Jr. et al., 2010; Hinkin, 2011).

\section{$\underline{\text { A confiabilidade }}$}

Como bem observado por Trochim (2006) a confiabilidade está relacionada com a qualidade da medição. Em seu sentido mais amplo, a confiabilidade é a consistência ou a repetibilidade das medidas, ou seja, a medida é considerada confiável, se ela fornecer o mesmo resultado repetidamente, assumindo, no entanto, que o que estamos medindo não esteja mudando. É o grau com que a variável observada mede o valor "verdadeiro" e o quanto está "livre de erro".

Na mesma linha de pensamento Hair Jr. et al. (2010) definem a confiabilidade como a medida do grau de consistência entre as medidas de uma variável e Malhotra (2006), por sua vez, observa que a confiabilidade mostra até que ponto uma escala produz resultados consistentes se as medidas forem tomadas repetidamente.

Devellis (2003) aponta que a confiabilidade de um questionário significa que se ele for aplicado em dois diferentes momentos, a uma mesma população, serão obtidos resultados semelhantes, desde que não tenha havido mudanças significativas no perfil da população durante o lapso de tempo entre as duas aplicações. 
De forma complementar aos enunciados anteriores, Sekaran (2003) explica que a confiabilidade de uma medida indica o grau com que ela está livre de erros aleatórios e, portanto, garante uma medição consistente através do tempo e entre os vários itens no instrumento.

$\underline{\text { A validade }}$

De acordo com Hair Jr. et al. (2010), validade é o grau com que uma medida, ou um conjunto de medidas, representa corretamente aquilo que se pretende medir, ou seja, o conceito de estudo, o construto. É também o grau com que se está livre de qualquer erro sistemático ou não aleatório.

De a acordo com Sekaran (2003) existem vários métodos para se avaliar a qualidade dos dados obtidos em uma pesquisa, mas não há um consenso em sua denominação. Entretanto, com relação à validade, a maioria dos autores, como por exemplo, Devellis (2003), Netemeyer et al. (2003) e Malhotra (2006) a dividem em três principais categorias: validade de conteúdo, validade de face e validade de construto.

\section{Confiabilidade versus Validade}

A validade se refere a quão bem o conceito é definido pelas medidas, ao passo que a confiabilidade se refere à consistência das medidas. A confiabilidade é diferente da validade no sentido de que não se relaciona com o que deveria ser medido, mas com o modo como é medido (Trochim, 2006; Hair Jr. et al., 2010).

Na mesma linha de pensamento, Sekaran (2003) ressaltando as diferenças entre confiabilidade e validade, esclarece que a primeira testa como consistentemente um instrumento de medição mede o conceito; e a segunda, quão bem o instrumento mede o conceito que se pretende medir. Em outras palavras, a validade está preocupada com o fato de medirmos o conceito certo, e a confiabilidade com a estabilidade e a consistência das medidas. 
Uma forma bastante elucidativa encontrada na literatura para ilustrar a relação entre a confiabilidade e a validade é a metáfora do "alvo" proposta por Trochim (2006), como apresentado na Figura 3.2-1.

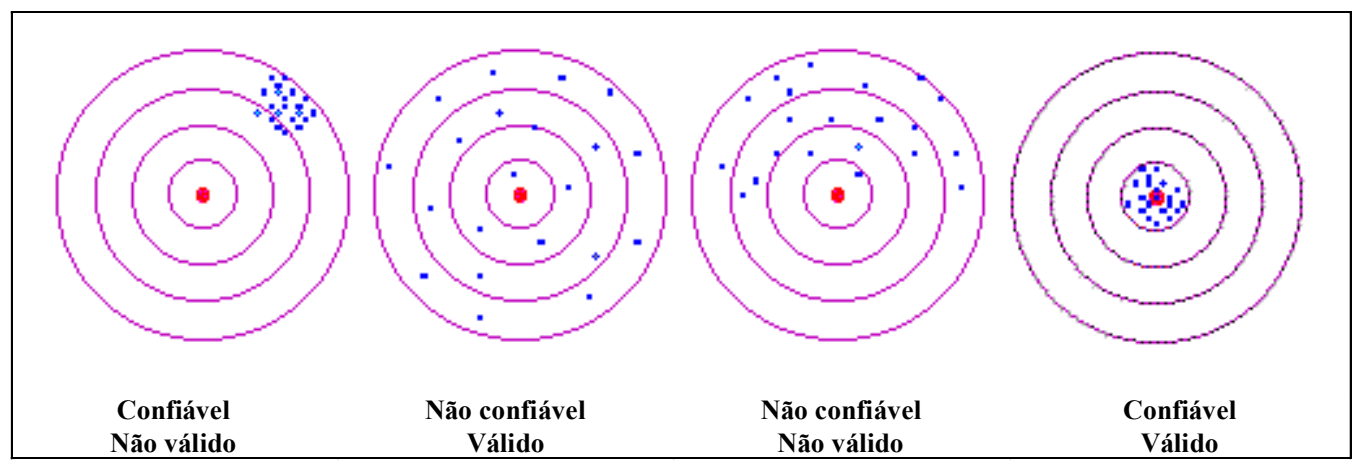

Fonte: Adaptado de Trochim (2006)

Figura 3.2-1 - Confiabilidade versus Validade

$\mathrm{Na}$ figura o centro do alvo seria o construto que se pretende medir e cada tiro no alvo a resposta de um respondente. Uma medição perfeita do conceito, por exemplo para um respondente, seria um ponto no centro do alvo.

Como se observa nessa figura existem quatro situações possíveis. Na primeira, os tiros (as respostas dos respondentes) estão acertando o alvo de forma consistente, mas estão afastados do centro do alvo, ou seja, está se medindo, consistentemente, o valor errado. Neste caso, a medida é confiável, mas não válida. Na segunda, são mostrados os pontos espalhados aleatoriamente ao redor do alvo. Neste caso, as respostas não são consistentes, mas estão certas, porque uma média do grupo se aproximaria do centro do alvo. Neste caso, as medidas são válidas mas não confiáveis. Na terceira situação, os pontos não estão agrupados (não consistentes) e estão afastados do centro do alvo, ou seja, medidas não válidas e não confiáveis. $\mathrm{Na}$ última situação, os pontos estão agrupados (consistentes) e no centro do alvo (valor certo), ou seja, medidas válidas e confiáveis.

Por fim, ressalta-se que neste trabalho são avaliadas as seguintes propriedades psicométricas do instrumento de pesquisa: 
- Validação de conteúdo, neste capítulo;

- Validação de face, neste capítulo;

- Análise da confiabilidade, no Capítulo 5;

- Validação de construto, no Capítulo 5.

\subsection{Concepção do modelo de mensuração da cultura de segurança}

A Concepção do modelo de mensuração da cultura de segurança teve como base o conceito das escalas múltiplas.

\subsubsection{Definição conceitual do modelo de mensuração}

Nas palavras de Hair Jr. et al. (2010) a definição conceitual é o ponto de partida para criar qualquer escala múltipla. Consiste em especificar a base teórica para a escala múltipla definindo a variável abstrata a ser representada, em termos aplicáveis ao contexto de pesquisa. As definições teóricas são baseadas em pesquisa prévia da literatura que define o caráter e a natureza da variável.

A definição conceitual possibilita que um conceito em estudo (variável abstrata) seja mensurado através da definição dos seus construtos individuais e pela seleção de itens indicadores para operacionalizá-los.

De acordo com Devellis (2003), para que as medidas de construtos tenham relevância nas ciências sociais, o construto deve ser fundamentado por meio de uma estruturação teórica. Definir claramente um construto, suas faces e domínios, é o passo mais importante no processo de desenvolvimento de uma escala múltipa.

Conforme defende Sekaran (2003), a mensuração de opinião, atitude ou percepção se torna muito complexa devido à natureza subjetiva dessas medidas. Uma das formas de se medir essas variáveis é reduzir a noção abstrata da variável para características e comportamentos observáveis. Este processo é chamado de operacionalização do construto. 
Operacionalizar um construto, ou defini-lo operacionalmente a fim de torná-lo mensurável, consiste em traduzir os seus aspectos comportamentais em elementos observáveis e mensuráveis denominados indicadores (Netemeyer et al., 2003).

A definição dos construtos e a geração dos itens (indicadores) para a sua mensuração devem ser precedidas por uma ampla revisão da literatura. Conforme verificado no Capítulo 2, foram identificados vários trabalhos importantes relacionados aos aspectos teóricos e empíricos de uma cultura de segurança, os quais foram utilizados como base para a definição conceitual do modelo de mensuração proposto para este trabalho. No entanto, observou-se que não existe um consenso entre os autores da terminologia empregada como também de quais aspectos que melhor determinam uma cultura de segurança.

Por conseguinte, como já fora mencionado, foi adotado o termo dimensão para designar os aspectos da cultura de segurança, o qual substituirá a expressão construto nas próximas etapas. Com relação às dimensões que melhor determinam uma cultura de segurança, optou-se para a definição conceitual do modelo por eleger aquelas que foram mais referenciadas pelos autores, dentre os quais se destacam: Zohar (1980), INSAG-4 (1991), TECDOC-943 (1995), IAEA (1998), Reason (1998), Cooper (2000), Wilpert e Itoigawa (2001), TECDOC-1329 (2002), NUREG-1756 (2002), Sorenson (2002), SCART (2008) e Zohar (2010).

Dessa forma, um modelo de mensuração da cultura de segurança preliminar foi definido conceitualmente por meio de 12 dimensões, conforme descritas a seguir:

- D1. Prioridade dada à segurança;

- D2. Alocação de recursos;

- D3. Funções e responsabilidades;

- D4. Comprometimento com a segurança;

- D5. Qualificação e dimensionamento de pessoal;

- D6. Comunicação;

- D7. Relacionamento com superiores e reguladores;

- D8. Exequibilidade dos processos; 
- D9. Documentação e procedimentos;

- D10. Condições de trabalho;

- D11. Cultura de aprendizagem organizacional;

- D12. Avaliações internas e externas.

Com base em INSAG-4 (1991), TECDOC-943 (1995), Reason (1998), TECDOC-1125 (1999), TECDOC-1321 (2002), INSAG-15 (2002), Stanton et al. (2005), AIChE (2007), SCART (2008), IAEA (2009) e IAEA (2010) foram operacionalizadas essas 12 dimensões por meio de 62 indicadores de mensuração. Na determinação dos indicadores procurou-se abranger tanto quanto possível o domínio de definição de cada dimensão.

A partir dos 62 indicadores propostos para mensurar as 12 dimensões do modelo, foi elaborada uma versão preliminar do instrumento de coleta de dados, do tipo questionário, composto por 75 questões para os indicadores de mensuração.

Com relação à quantidade dos itens da escala (questões), observou-se a recomendação dada por Devellis (2003) de que, o ideal é iniciar uma escala com um número de questões superior à quantidade pretendida para a escala definitiva. Isso porque poderá haver redução do número de questões em virtude dos processos de validação de conteúdo e de validação de face.

\subsubsection{Validação de conteúdo}

Conforme esclarecem Hair Jr. et al. (2010), a validade de conteúdo se refere ao grau de correspondência entre os itens selecionados para constituir a escala múltipla e a sua definição conceitual. Seguindo a mesma linha de pensamento, Hinkin (2011) e Sekaran (2003) afirmam que essa forma de validade avalia subjetivamente a correspondência entre os itens individuais e o construto, ou seja, verifica se os itens realmente avaliam os construtos que se pretende avaliar. Ainda conforme Hair Jr. et al. (2010), o objetivo nesse processo é garantir que a seleção de itens da escala aborde não apenas questões empíricas, mas também inclua considerações práticas e teóricas. 
Acrescenta Devellis (2003) que a validação de conteúdo deve ser realizada por especialistas na área relacionada à pesquisa, que avaliam o grau de concordância dos itens em relação ao construto. Nessa etapa, podem ser identificados problemas como, por exemplo, a falta de itens que poderiam medir outros aspectos do construto, ou a presença de itens que não são apropriados para medi-lo. Em suma, verificar o instrumento de coleta de dados em termos de representatividade, especificidade e adequação para medir o respectivo construto (dimensão).

\section{$\underline{\text { Mapeamento de especialistas }}$}

Com a finalidade de compor a equipe de especialistas para a validação de conteúdo, realizou-se uma pesquisa com o foco em identificar autores de trabalhos nas áreas de fatores organizacionais e cultura de segurança no campo nuclear. Por se tratar de um tema muito específico, optou-se por procurar esses especialistas junto às três últimas edições da International Nuclear Atlantic Conference (INAC), realizadas em 2009, 2011 e 2013.

A INAC, promovida pela Associação Brasileira de Energia Nuclear (ABEN), é uma conferência multidisciplinar na área nuclear voltada para os interesses de pesquisa e desenvolvimento tecnológico em âmbitos nacional e internacional. O público-alvo inclui os pesquisadores, professores, técnicos e estudantes ligados a faculdades, universidades, centros de pesquisa e indústria, envolvidos em trabalhos relacionados à área nuclear.

Foram identificados 11 pesquisadores possuidores de vários trabalhos publicados em fatores organizacionais e cultura de segurança na área nuclear, pertencentes aos seguintes institutos:

- 2 pesquisadores da Comissão Nacional de Energia Nuclear (CNEN-Sede);

- 2 pesquisadores do Centro de Desenvolvimento da Tecnologia Nuclear (CDTN);

- 3 pesquisadores do Instituto de Engenharia Nuclear (IEN);

- 2 pesquisadores do Instituto de Pesquisas Energéticas e Nucleares (IPEN);

- 1 pesquisador da Universidade Federal do Rio de Janeiro (UFRJ); 
- 1 pesquisador da Universidade de São Paulo (USP).

$\underline{\text { Avaliação dos especialistas }}$

Após alguns contatos com esses pesquisadores, todos se predispuseram a participar como especialistas nessa avaliação. Foram, então, enviados o questionário preliminar e uma carta de apresentação do processo, a qual se encontra como Apêndice A deste trabalho.

Basicamente, foram solicitadas aos especialistas as seguintes ações:

- Verificar a consistência conceitual do item em relação à dimensão;

- Detectar a ausência de itens que poderiam medir outro aspecto da dimensão;

- Identificar redundâncias com relação aos itens;

- Identificar itens que não são apropriados para medir a dimensão;

- Detectar itens que precisariam ser melhores redigidos;

- Avaliar a relevância do item para a medição daquela dimensão.

Como resultado dessas ações os especialistas podiam indicar itens que poderiam ser excluídos, atribuir ao item um grau de relevância (1, 2, 3 ou 4) para medir a dimensão e verificar problemas de redação em geral.

No Quadro 3.3-1 é apresentada uma síntese das principais recomendações e sugestões propostas pelos 11 especialistas, bem como as ações tomadas em cada situação.

Quadro 3.3-1 - Resultado das análises dos especialistas

\begin{tabular}{|l|l|}
\hline \multicolumn{1}{|c|}{ Observações dos especialistas } & \multicolumn{1}{c|}{ Ação tomada } \\
\hline Questão com grau de relevância 1 ou 2 & Excluída do questionário \\
\hline Questão com inconsistência na redação & Redação alterada \\
\hline Problemas nos termos empregados & Redação melhorada e atualizada \\
\hline Questão redundante & Excluída do questionário \\
\hline $\begin{array}{l}\text { Questão inapropriada para medir o } \\
\text { construto }\end{array}$ & $\begin{array}{l}\text { Realocada para outro construto / } \\
\text { Excluída do questionário }\end{array}$ \\
\hline
\end{tabular}


Com a revisão dos especialistas, foram excluídas 26 questões, algumas com a indicação explícita do especialista e outras por terem recebido grau 1 ou 2 na relevância para medir a dimensão. Algumas questões remanescentes sofreram alterações em seu texto e praticamente todas as questões foram renumeradas. Houve uma redução da quantidade de dimensões, por agrupamento, de 12 iniciais para 10, e uma consequente reorganização geral.

\subsubsection{Validação de face (pré-teste)}

Conforme Trochim (2006), a validação de face, também chamada de análise semântica, deve ser realizada com o auxílio de alguns indivíduos representantes da população alvo. Trata-se de um pré-teste com o objetivo de realizar eventuais ajustes no instrumento, verificando se as questões geram problemas na aceitação ou no entendimento por parte dos respondentes.

Após serem realizados os ajustes no questionário preliminar, decorrentes da validação de conteúdo, o instrumento foi submetido a uma pequena amostra do público alvo para proceder-se ao processo de validação de face. Contou-se com a participação de sete colaboradores do IPEN.

Esses avaliadores analisaram o questionário com o foco em detectar problemas de:

- Entendimento do que estava sendo perguntado;

- Ambiguidade, falhas e incompreensões;

- Comunicação, clareza e objetividade.

Para tanto, foi disponibilizado ao avaliador um formulário com campos específicos para o registro das questões ou das opções de respostas que apresentassem dificuldades de entendimento, que não estivessem claras ou que apresentassem dupla interpretação. Como resultado dessas análises, algumas questões tiveram que ser reeditadas. 
Os resultados desses processos de validação permitiram definir a estrutura conceitual de cultura de segurança, constituída por 10 dimensões, 49 indicadores de mensuração e 49 questões, conforme apresentada no Quadro 3.3-2. 
Quadro 3.3-2- Estrutura conceitual da cultura de segurança

\begin{tabular}{|c|c|c|}
\hline Dimensões (Construtos) & Indicadores de mensuração & Questões \\
\hline D1. Prioridade dada à segurança & $\begin{array}{l}\text { Conhecimento da política de segurança } \\
\text { Prioridade da segurança na política } \\
\text { Conteúdo da política de segurança } \\
\text { Abordagem da segurança nas reuniões } \\
\text { Segurança versus produção } \\
\text { Desvios e atalhos no processo }\end{array}$ & Q1 a Q6 \\
\hline D2. Alocação de recursos & $\begin{array}{l}\text { Recursos para equipamentos de segurança } \\
\text { Recursos para treinamentos } \\
\text { Recursos para manutenção } \\
\text { Revisão dos recursos }\end{array}$ & Q7 a Q10 \\
\hline D3. Funções e responsabilidades & $\begin{array}{l}\text { Def. de funções e responsabilidades } \\
\text { Conhecimento das Responsabilidades }\end{array}$ & Q11 e Q12 \\
\hline D4. Comprometimento com a segurança & $\begin{array}{l}\text { Comprometimento da Alta Adm } \\
\text { Comprometimento da Gerência } \\
\text { Estado atual da segurança }\end{array}$ & Q13 a Q15 \\
\hline D5. Comunicação e relacionamento & $\begin{array}{l}\text { Comunicação entre Adm e funcionários } \\
\text { Comunicação entre turnos } \\
\text { Verificação da comunicação } \\
\text { Relação dos funcionários com superiores } \\
\text { Relação da instituição com reguladores }\end{array}$ & Q16 a Q20 \\
\hline $\begin{array}{l}\text { D6. Qualificação e dimensionamento de } \\
\text { pessoal }\end{array}$ & $\begin{array}{l}\text { Adequação dos treinamentos } \\
\text { Revisão dos programas de treinamentos } \\
\text { Equipe de trabalho } \\
\text { Qualificação de pessoal }\end{array}$ & Q21 a Q24 \\
\hline D7. Documentação e procedimentos & $\begin{array}{l}\text { Conteúdo da documentação } \\
\text { Disponibilidade da documentação } \\
\text { Entendimento da documentação } \\
\text { Problemas na documentação } \\
\text { Atualização da documentação } \\
\text { Exequibilidade do processo }\end{array}$ & Q25 a Q30 \\
\hline D8. Condições de trabalho & $\begin{array}{l}\text { Carga de trabalho } \\
\text { Temperatura do ambiente } \\
\text { Luminosidade do ambiente } \\
\text { Qualidade do Ar } \\
\text { Ruídos no ambiente } \\
\text { Pressão do tempo } \\
\text { Ergonomia no trabalho } \\
\text { Limpeza do ambiente } \\
\text { Estado dos Sistemas de segurança } \\
\text { Estresse no trabalho } \\
\text { Demanda de horas extras } \\
\text { Satisfação no trabalho }\end{array}$ & Q31 a Q42 \\
\hline D9. Aprendizagem organizacional & $\begin{array}{l}\text { Lições aprendidas } \\
\text { Análise de acidentes } \\
\text { Ações corretivas } \\
\text { Divulgação das causas dos acidentes }\end{array}$ & Q43 a Q46 \\
\hline D10. Avaliações internas e externas & $\begin{array}{l}\text { Avaliações externas (receptividade) } \\
\text { Avaliações internas (frequência) } \\
\text { Divulgação dos resultados das avaliações }\end{array}$ & Q47 a Q49 \\
\hline
\end{tabular}




\subsubsection{Elaboração do instrumento de pesquisa (Questionário)}

O questionário definitivo para a coleta de dados foi elaborado e organizado em três seções: a primeira, uma carta de apresentação do questionário, como página inicial; a segunda, sete questões demográficas com o propósito de traçar um perfil dos respondentes; a terceira, 49 questões para os indicadores de mensuração com a finalidade de avaliar a cultura de segurança.

A carta de apresentação do questionário tratou dos seguintes aspectos:

- Solicitação de participação na pesquisa;

- Apresentação dos objetivos da pesquisa;

- Garantia de anonimato na participação da pesquisa;

- Garantia da confidencialidade das respostas;

- Canal de comunicação (telefone e e-mail) com o pesquisador para qualquer dúvida, observação ou esclarecimento adicional.

Questões demográficas

Trata-se da seção do questionário responsável pela caracterização do perfil demográfico dos participantes da pesquisa, composta por sete questões com a finalidade de obter as seguintes características:

- Instituição de lotação do respondente;

- Tempo de atividade do respondente na instituição;

- Área de atuação do respondente;

- Cargo ou função ocupado pelo respondente;

- Tempo de experiência na área nuclear;

- Faixa etária do respondente;

- Nível de escolaridade do respondente. 
Questões para os indicadores de mensuração

Essas questões têm a finalidade de avaliar as condições da cultura de segurança e de obter os dados necessários para a avaliação das propriedades psicométricas do instrumento de pesquisa. Foram elaboradas de forma a identificar a percepção e a opinião dos respondentes acerca da cultura de segurança na instituição em que trabalham.

Com base na estrutura conceitual da cultura de segurança concebida previamente (Quadro 3.3-2), foram elaboradas as 49 questões para os indicadores de mensuração. As dez dimensões da estrutura conceitual são denominadas no questionário de "Fatores determinantes da cultura de segurança" (Apêndice B).

Cada questão apresenta seis opções de respostas, rotuladas de forma verbal. As cinco primeiras são para o respondente expressar a sua opinião ou percepção acerca da característica avaliada. A última opção "Não aplicável” foi prevista para que o respondente assinalasse no caso de o assunto tratado não ser pertinente a ele, em razão da natureza da sua função, das suas atividades ou do seu local de trabalho.

As cinco primeiras opções de respostas foram dispostas de forma gradativa. As duas primeiras para uma situação mais favorável ou mais importante e as duas últimas para uma situação desfavorável ou menos importante. A opção central reflete uma posição intermediária.

A codificação numérica das opções de respostas foi realizada de forma que pudesse refletir a magnitude da opinião ou percepção do respondente em cada questão. Para tanto, foram atribuídos os valores 5 e 4 para as duas primeiras opções; os valores 2 e 1 para as duas últimas; o valor 3 para a opção central; e o valor 0 para a opção "Não aplicável”.

$\mathrm{Na}$ elaboração das opções de respostas de cada questão explorou-se de forma ampla o aspecto subjetivo no intuito de captar efetivamente a percepção, a opinião e o entendimento do respondente acerca da característica avaliada, bem como medir a sua intensidade de convicção. Conforme mencionado no Capítulo 2 deste trabalho, avaliar uma 
cultura de segurança consiste, basicamente, em determinar as opiniões, atitudes e percepções dos funcionários com relação à segurança na instituição. Esses aspectos são puramente subjetivos e podem ser melhor pesquisados com o emprego de expressões linguísticas apropriadas.

A principal vantagem dos métodos de avaliação subjetiva é que eles proporcionam um meio de aquisição de dados, que muitas vezes não podem ser obtidos por qualquer outra forma (Stanton et al., 2005).

Apesar de o tema cultura de segurança ser, regra geral, amplamente difundido em instalações nucleares, foram introduzidas no início do questionário as duas principais definições de cultura de segurança encontradas na literatura, com o intuito de relembrar, aos respondentes, os seus principais aspectos.

O desenvolvimento do questionário foi viabilizado pelo software LimeSurvey (Copyright (C) 2005) que permite criar questionários para pesquisa e aplicá-lo online através de um link de acesso. Esses recursos são administrados pela área de Gestão do Conhecimento do IPEN.

Por fim, é importante salientar que o desenvolvimento deste instrumento de coleta de dados contemplou os princípios metodológicos aplicados à modelagem de instrumentos de pesquisa.

O questionário completo composto pela a carta de apresentação que o acompanha, pelas questões demográficas e pelas questões dos indicadores de mensuração com as opções de respostas subjetivas podem ser observadas no Apêndice B deste trabalho.

\subsection{População e amostra}

A população alvo selecionada para a aplicação do questionário foi composta pelos servidores e funcionários dos institutos de pesquisa da Comissão Nacional de Energia Nuclear (CNEN). Participaram da pesquisa as seguintes unidades da CNEN: 
- Comissão Nacional de Energia Nuclear (CNEN-Sede);

- Centro de Desenvolvimento da Tecnologia Nuclear (CDTN);

- Centro Regional de Ciências Nucleares do Centro-Oeste (CRCN-CO);

- Centro Regional de Ciências Nucleares do Nordeste (CRCN-NE);

- Instituto de Engenharia Nuclear (IEN );

- Instituto de Pesquisas Energéticas e Nucleares (IPEN);

- Instituto de Radioproteção e Dosimetria (IRD).

A CNEN é uma autarquia federal, vinculada ao Ministério da Ciência, Tecnologia e Inovação (MCTI), com sede na cidade do Rio de Janeiro, que tem como missão institucional estabelecer as normas e regulamentos em radioproteção e segurança nuclear, licenciar, fiscalizar e controlar a atividade nuclear no Brasil. Este órgão também desenvolve pesquisas voltadas à utilização das técnicas nucleares em benefício da sociedade. Para poder cumprir com essas atribuições, a CNEN conta com os seus institutos, distritos e centros regionais de pesquisa e desenvolvimento, cujos objetivos são descritos a seguir:

$\underline{\text { Centro de Desenvolvimento da Tecnologia Nuclear (CDTN) }}$

O CDTN é uma instituição de pesquisa da área nuclear localizada no estado de Minas Gerais. O órgão tem como missão institucional: "Gerar e difundir conhecimentos, disponibilizar produtos e serviços em beneficio da sociedade por meio de pesquisa e desenvolvimento na área nuclear e em áreas correlatas".

\section{Centro Regional de Ciências Nucleares do Centro-Oeste (CRCN-CO)}

O CRCN-CO é uma unidade da CNEN localizada no município de Abadia de Goiás (GO), que tem como objetivo primordial abrigar e monitorar os depósitos definitivos de rejeitos oriundos do acidente radiológico de Goiânia, ocorrido em setembro de 1987, mantendo ainda um acervo histórico das ações e soluções tecnológicas adotadas. 


\section{$\underline{\text { Centro Regional de Ciências Nucleares do Nordeste (CRCN-NE) }}$}

O CRCN-NE está localizado na cidade de Recife (PE) e tem como principal missão contribuir para o bem estar da sociedade, em especial das regiões Norte e Nordeste do Brasil, por meio de pesquisa, desenvolvimento e inovação; da formação de recursos humanos; e produtos e serviços nas áreas nuclear e correlatas.

O Centro também atua no desenvolvimento e implementação de técnicas de otimização das instalações, transporte de material radioativo e cálculo de blindagens, proteção durante o atendimento a emergências radiológicas, assim como participa ativamente na formação de recursos humanos e em assessoria de radioproteção.

\section{$\underline{\text { Instituto de Engenharia Nuclear (IEN) }}$}

Desde a sua fundação, em 1962, o IEN vem contribuindo para o domínio nacional de tecnologias na área nuclear e correlatas. Localizado na cidade do Rio de Janeiro, suas atividades de pesquisa, desenvolvimento e inovação geram produtos e serviços como patentes, publicações, licenciamento de tecnologias, fornecimento de radiofármacos, ensaios e análises de materiais, recolhimento de rejeitos radioativos, consultorias e formação de recursos humanos.

\section{$\underline{\text { Instituto de Pesquisas Energéticas e Nucleares (IPEN) }}$}

O IPEN está localizado na cidade de São Paulo. Tem uma destacada atuação em vários setores da atividade nuclear entre elas, aplicações das radiações e radioisótopos, reatores nucleares, materiais do ciclo do combustível, radioproteção e dosimetria. Os resultados vêm proporcionando avanços significativos no domínio de tecnologias, na produção de materiais e na prestação de serviços de valor econômico e estratégico para o país.

A multidisciplinaridade das atividades do setor nuclear tem permitido ao IPEN conduzir um amplo e variado programa de pesquisas e desenvolvimentos em outras áreas 
também. Dentre essas, destacam-se as áreas de biotecnologia, física nuclear, radioquímica, materiais avançados, cerâmicas especiais, biomateriais e monocristais para o uso em lasers.

O IPEN é ainda responsável, em associação com a USP, pela condução do programa de pós-graduação em Tecnologia Nuclear, nível de mestrado e doutorado.

\section{Instituto de Radioproteção e Dosimetria (IRD)}

O IRD é uma instituição de pesquisa, desenvolvimento e ensino na área de radioproteção, dosimetria e metrologia das radiações ionizantes. Ligado à Diretoria de Pesquisa e Desenvolvimento da CNEN, atua em colaboração com universidades, agências governamentais, indústrias, instalações médicas, centros de pesquisa e outros segmentos, de forma a contribuir com a segurança da população, dos trabalhadores do setor e do meio ambiente.

Por fim, a amostra foi constituída pelos colaboradores desses institutos, efetivos ou contratados, independentemente do cargo ou função ocupada.

\subsection{Aplicação do questionário}

Inicialmente foram realizados contatos com os dirigentes de cada unidade da CNEN com o propósito de angariar apoio para a pesquisa. Todos se predispuseram em disponibilizar o seu instituto para a aplicação do questionário, o qual foi enviado através de um link de acesso.

O período de coleta dos dados foi do dia 30 de Maio de 2014 a 15 de Julho de 2014, prazo em que o questionário ficou disponível online para os respondentes.

Após 19 dias do envio do questionário foi mandado um e-mail "lembrete" aos dirigentes dos institutos. Durante o período de aplicação também houve alguns contatos de respondentes com o pesquisador no intuito de sanar dúvidas ou fazer observações sobre o questionário. 


\section{APRESENTAÇÃO E ANÁLISE DOS RESULTADOS DA PESQUISA}

\subsection{Estruturação da base de dados da pesquisa}

Esta etapa teve como objetivo consolidar e organizar os dados obtidos na pesquisa.

A operacionalização computacional dessa base de dados foi inicialmente realizada no aplicativo LimeSurvey, mesmo ambiente em que foi criado o questionário (ver Capítulo 3).

Finalizado o prazo destinado à pesquisa, apurou-se na base de dados um retorno total de 226 questionários respondidos. Considerando que o efetivo total da CNEN é de aproximadamente 2000 servidores, obteve-se uma taxa de resposta de questionários respondidos próxima dos $11 \%$.

Em uma análise preliminar, verificou-se que dos 226 questionários respondidos, 28 apresentavam uma quantidade significante de questões sem respostas (valores ausentes). Optou-se pela eliminação desses 28 questionários da pesquisa em observância à orientação dada por Hair Jr. et al. (2010), que quando a quantidade de valores ausentes em um questionário respondido ultrapassa $50 \%$ do total das variáveis (questões) o mesmo deve ser descartado.

Dentre os 198 questionários restantes, 17 ainda apresentavam alguns dados ausentes, mas em quantidade remediável, ou seja, dentro do limite permissível para serem tratadas como valores ausentes (Hair Jr. et al., 2010).

Essa base de dados inicial foi exportada do aplicativo LimeSurvey para o software Statistical Package for the Social Sciences (SPSS), versão 19.0, que é um programa para tratamento estatístico especializado em análises uni e multivariadas de dados (SPSS, 2010). 
A partir dessa base de dados primária no SPSS, foram realizados todos os cálculos e análises para a interpretação dos dados, bem como os estudos das propriedades psicométricas do instrumento de pesquisa. Com a finalidade de dar suporte a todas essas atividades foi consolidada no Apêndice $\mathrm{C}$ deste trabalho a distribuição de frequências das respostas obtidas pela pesquisa.

\subsection{Preparação e tratamento dos dados}

Algumas etapas preliminares devem ser realizadas com a base de dados inicial antes das análises multivariadas dos dados, que compreendem os cálculos de confiabilidade e de validação de construto do instrumento.

Portanto, as atividades previstas nesta seção consistem em verificar a integridade e a qualidade dos dados e prepará-los, de forma apropriada, para serem processados. Para tanto, foram analisados os seguintes aspectos na base de dados:

- Os valores ausentes;

- A orientação positiva ou negativa na formulação de questões;

- As questões classificadas como "Não aplicável";

- A duplicidade de casos (respostas).

Uma estrutura de base de dados típica gerada em aplicativos estatísticos, indicando alguns valores ausentes, está representada na Figura 4.2-1. 


\begin{tabular}{|c|c|c|c|c|c|c|c|}
\hline Casos & \multicolumn{7}{|c|}{ Variáveis } \\
\hline ID & V1 & $\mathrm{V} 2$ & V3 & V4 & V5 & $\ldots$ & Vn \\
\hline 1 & 5 & 4 & 4 & 3 & 4 & & \\
\hline 2 & 3 & 1 & 5 & 0 & 5 & & \\
\hline 3 & 5 & 0 & 3 & ausente & 4 & & \\
\hline 4 & 4 & ausente & 4 & 3 & 3 & & \\
\hline 5 & 4 & ausente & 3 & 0 & 0 & & \\
\hline 6 & 3 & 4 & 5 & 4 & ausente & ausente & \\
\hline \multirow{5}{*}{$\dot{\vec{n}}$} & 4 & 5 & 4 & 1 & 5 & & \\
\hline & 3 & 4 & 4 & 0 & 3 & & \\
\hline & 5 & 3 & 1 & 2 & 5 & & \\
\hline & 4 & 5 & 5 & ausente & 4 & & \\
\hline & 4 & 3 & 2 & 1 & 4 & & \\
\hline
\end{tabular}

Figura 4.2-1 - Estrutura de uma base de dados típica

As colunas da base dados $\left(\mathrm{V}_{1} \ldots \mathrm{V}_{\mathrm{n}}\right)$ são as variáveis, os itens do questionário, que neste trabalho, correspondem às questões $D_{1} a D_{7}$ (variáveis demográficas) e às questões $\mathrm{Q}_{1}$ a $\mathrm{Q}_{49}$ para os indicadores de mensuração.

As linhas da base de dados $\left(\mathrm{ID}_{1} \ldots \mathrm{ID}_{\mathrm{n}}\right)$ são os casos observados, ou os questionários respondidos, que neste trabalho, correspondem às respostas de cada respondente, identificadas de 1 a 198.

\subsubsection{Análise e tratamento dos valores ausentes}

Valores ausentes são informações não disponíveis de um ou mais respondentes para uma ou mais questões da pesquisa. A sua ocorrência pode deteriorar a qualidade dos dados a ponto de distorcer ou mesmo impossibilitar uma análise coerente se não lhes forem dado um tratamento apropriado (Sekaran, 2003; Hair Jr. et al., 2010).

Os valores ausentes podem ter impactos significativos sobre qualquer análise, particularmente aquelas de natureza multivariada. O principal impacto é a redução do tamanho da amostra disponível para análise. Por outro lado, Hair Jr. et al. (2010) alertam para o fato de que a eliminação das variáveis ou dos casos nessas condições também traria problemas, pois poderia haver perda de informações para a realização das análises. 


\section{Métodos de atribuição de valores ausentes}

A atribuição é o processo de estimação do valor que substituirá o valor ausente, baseado em valores válidos de outras variáveis e/ou casos na amostra. A premissa é empregar relações conhecidas na amostra para auxiliar na estimação dos valores ausentes. Um valor obtido de todas as outras observações da amostra é o mais representativo para a substituição (Hair Jr. et al., 2005).

De acordo com Sekaran (2003), existem várias técnicas de atribuição de valores ausentes, mas as mais utilizadas são:

- Designar o ponto médio da escala como resposta àquele item em particular;

- Designar ao item o valor médio das respostas de todos aqueles que responderam

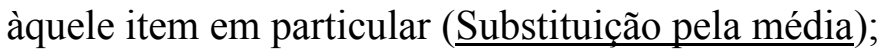

- Dar ao item a média das respostas desse respondente em particular dadas às outras questões;

- Dar à resposta em falta um número aleatório dentro do intervalo dessa escala;

Ainda segundo o autor, o método "Substituição pela média" é o mais utilizado e consiste na troca dos valores ausentes em uma variável pelo valor médio daquela variável, com base em todas as respostas válidas. De forma análoga, Netemeyer et al. (2003) também recomendam esse método, ressaltando que a média é o valor mais representativo para a atribuição de valores ausentes.

Na Tabela 4.2-1 são apresentados os critérios para uma tomada de ação com relação a valores ausentes, recomendados por (Hair Jr. et al., 2010). 
Tabela 4.2-1 - Critérios para o tratamento de valores ausentes

\begin{tabular}{ll}
\hline \multicolumn{1}{c}{ Proporção p de valores ausentes } & \multicolumn{1}{c}{ Ação recomendada } \\
\hline Variável com $\mathrm{p} \geq 50 \%$ do total de casos & Eliminar a variável da pesquisa \\
Questionário com $\mathrm{p} \geq 50 \%$ do total de variáveis & Eliminar o questionário da pesquisa \\
$10 \% \leq \mathrm{p}<50 \%$ do total de casos ou de variáveis & Adotar um método de atribuição \\
$\mathrm{p}<10 \%$ do total de casos ou de variáveis & $\begin{array}{l}\text { Ignorar os valores ausentes ou adotar um } \\
\text { método de atribuição }\end{array}$ \\
\hline
\end{tabular}

Fonte: Adaptado de Hair Jr. et al. (2010)

Faz-se necessário esclarecer que a opção de ignorar os valores ausentes tem o impacto direto na redução do tamanho da amostra para as análises multivariadas.

\section{$\underline{\text { Solução adotada }}$}

A análise dos valores ausentes na base de dados foi realizada tanto entre os casos (respondentes) como entre as variáveis (questões).

Com relação aos casos, conforme apresentado na Seção 4.1, havia 17 questionários (casos) na base de dados que apresentavam valores ausentes. Analisando esses casos na distribuição de frequências das respostas do Apêndice $C$, verificou-se que a situação mais extrema foi a de três respondentes que deixaram de responder vinte questões, correspondendo a $41 \%$ do total de questões, ficando, portanto, conforme a Tabela 4.2-1, dentro da faixa recomendada para tratamento.

No tocante às variáveis, observa-se ainda no Apêndice $\mathrm{C}$ que há vinte questões com valores ausentes distribuídos da seguinte forma: 1 questão com 3 valores ausentes; 1 questão com 8 valores ausentes; $\underline{6}$ questões com 11 valores ausentes; $\underline{4}$ questões com 12 valores ausentes; $\underline{5}$ questões com 13 valores ausentes e $\underline{3}$ questões com 17 valores ausentes. Nota-se que a situação mais extrema é a das questões com 17 valores ausentes, correspondendo a $9 \%$ do total de respostas, ficando, da mesma forma, conforme a Tabela 4.2-1, dentro da faixa recomendada para tratamento. 
Ainda nessa análise das variáveis, verifica-se que o total de células sem respostas na base de dados é de 241 células, que diante de um total na base de dados de 9702 (198 casos x 49 questões), tem-se 2,5\% de valores ausentes, ficando, da mesma forma, conforme a Tabela 4.2-1, dentro da faixa recomendada para tratamento.

O método adotado neste trabalho para o tratamento desses valores ausentes identificados foi o da substituição pela média.

Com esse tratamento aplicado aos valores ausentes, pôde-se contar com uma amostra de 198 casos válidos na base de dados para a realização das análises multivariadas dos dados.

\subsubsection{Orientação positiva e negativa dos itens}

$\mathrm{Na}$ literatura é prevista a intercalação de orientação positiva e negativa na formulação das questões, como uma forma de detectar seriedade e atenção do respondente (Sekaran, 2003; Hair Jr. et al., 2010). Neste trabalho, todas as questões foram elaboradas com orientação positiva, porém, de forma não intencional, a questão Q40 ficou com suas opções de resposta orientadas negativamente, ou seja, partindo de uma situação negativa, ou mais desfavorável, para uma situação positiva, ou mais favorável (ver Apêndice B). Portanto, a questão passou por um processo de inversão para que os seus valores ficassem alinhados com os valores das outras questões. A Tabela 4.2-2 mostra esses valores na forma original do questionário e na forma invertida (alterada).

Tabela 4.2-2 - Processo de inversão da questão Q40

\begin{tabular}{lll}
\hline \multicolumn{1}{c}{ Forma original } & \multicolumn{1}{c}{ Forma invertida } \\
\hline 5 Extremamente estressante & 5 Nem um pouco estressante \\
4 Muito estressante & 4 Pouco estressante \\
3 Razoavelmente estressante & 3 Razoavelmente estressante \\
2 Pouco estressante & 2 Muito estressante \\
1 Nem um pouco estressante & 1 Extremamente estressante \\
\hline
\end{tabular}


Com o propósito de verificar se foi mantida a frequência das respostas para cada opção da questão Q40, obteve-se a distribuição de frequência na forma invertida, conforme apresentada na Tabela 4.2-3.

Tabela 4.2-3 - Distribuição de frequência da questão Q40 na forma invertida

\begin{tabular}{|c|c|c|c|c|c|}
\hline \multicolumn{6}{|c|}{ Q40. Estresse no trabalho } \\
\hline & & Frequência & Porcentagem & $\begin{array}{l}\text { Porcentagem } \\
\text { válida }\end{array}$ & $\begin{array}{c}\text { Porcentagem } \\
\text { acumulada }\end{array}$ \\
\hline \multirow{6}{*}{ Válido } & $\begin{array}{lll}\begin{array}{l}\text { Nem um } \\
\text { estressante }\end{array} & \text { pouco }\end{array}$ & 21 & 10.6 & 11.3 & 11.3 \\
\hline & Pouco estressante & 62 & 31.3 & 33.3 & 44.6 \\
\hline & $\begin{array}{l}\text { Razoavelmente } \\
\text { estressante }\end{array}$ & 78 & 39.4 & 41.9 & 86.6 \\
\hline & Muito estressante & 19 & 9.6 & 10.2 & 96.8 \\
\hline & $\begin{array}{l}\text { Extremamente } \\
\text { estressante }\end{array}$ & 2 & 1.0 & 1.1 & 97.8 \\
\hline & $\begin{array}{l}\text { Não aplicável } \\
\text { Total }\end{array}$ & $\begin{array}{c}4 \\
186\end{array}$ & $\begin{array}{c}2.0 \\
93.9\end{array}$ & $\begin{array}{c}2.2 \\
100.0\end{array}$ & 100.0 \\
\hline \multirow{2}{*}{ Ausente } & Sistema & 12 & 6.1 & & \\
\hline & Total & 198 & 100.0 & & \\
\hline
\end{tabular}

Comparando essa Tabela com a distribuição de frequência na forma original, apresentada na Tabela 4.2-4, pode-se observar que as escolhas dos respondentes se mantiveram inalteradas na base de dados.

Tabela 4.2-4 - Distribuição de frequência da questão Q40 na forma original

\begin{tabular}{|c|c|c|c|c|c|}
\hline \multicolumn{6}{|c|}{ Q40. Estresse no trabalho } \\
\hline & & Frequência & Porcentagem & $\begin{array}{l}\text { Porcentagem } \\
\text { válida }\end{array}$ & $\begin{array}{c}\text { Porcentagem } \\
\text { acumulada }\end{array}$ \\
\hline \multirow{6}{*}{ Válido } & $\begin{array}{l}\text { Extremamente } \\
\text { estressante }\end{array}$ & 2 & 1,0 & 1,1 & 1,1 \\
\hline & Muito estressante & 19 & 9,6 & 10,2 & 11,3 \\
\hline & $\begin{array}{l}\text { Razoavelmente } \\
\text { estressante }\end{array}$ & 78 & 39,4 & 41,9 & 53,2 \\
\hline & Pouco estressante & 62 & 31,3 & 33,3 & 86,6 \\
\hline & $\begin{array}{l}\text { Nem um pouco } \\
\text { estressante }\end{array}$ & 21 & 10,6 & 11,3 & 97,8 \\
\hline & $\begin{array}{l}\text { Não aplicável } \\
\text { Total }\end{array}$ & $\begin{array}{c}4 \\
186\end{array}$ & $\begin{array}{c}2,0 \\
93,9\end{array}$ & $\begin{array}{c}2,2 \\
100,0\end{array}$ & 100,0 \\
\hline \multirow[t]{2}{*}{ Ausente } & Sistema & 12 & 6,1 & & \\
\hline & Total & 198 & 100,0 & & \\
\hline
\end{tabular}




\subsubsection{Tratamento para as respostas "Não aplicável"}

A presença de questões consideradas pelo respondente como não aplicáveis pode comprometer a interpretação dos resultados obtidos em razão da redução na quantidade de informações.

Observa-se no Apêndice $\mathrm{C}$ que algumas questões foram classificadas como "Não aplicável” pelos respondentes. Em princípio, essa opção foi escolhida em razão da natureza da instituição, da função, das atividades ou do local de trabalho dos respondentes. Foram identificadas oito variáveis que apresentavam quantidade significativa da opção "Não aplicável" (mais que 18\% das respostas), conforme apresentadas na Tabela 4.2-5.

Tabela 4.2-5 - Classificação significativa de "Não aplicável"

\begin{tabular}{lcc}
\multicolumn{1}{c}{ Questões } & Frequência & Porcentagem \\
\hline Q6. Desvios e atalhos no processo & 80 & $40.4 \%$ \\
\hline Q9. Recursos para manutenção & 37 & $18.7 \%$ \\
\hline Q17. Comunicação entre turnos & 123 & $62.1 \%$ \\
\hline Q18. Verificação da comunicação & 72 & $36.4 \%$ \\
\hline Q20. Relação com Reguladores & 41 & $20.7 \%$ \\
\hline Q41. Demanda de horas extras & 65 & $34,9 \%$ \\
\hline Q47. Avaliações externas (receptividade) & 35 & $19,3 \%$ \\
\hline Q49. Divulgação dos resultados das avaliações & 61 & $33,7 \%$ \\
\hline
\end{tabular}

A razão para a quantidade significativa dessa classificação é a diversidade de atribuições dos institutos avaliados. A CNEN abrange institutos atuantes nas áreas de pesquisa, proteção radiológica, produção de radioisótopos e radiofármacos, licenciamento de instalações e ensino, possuindo, dessa forma, um contingente de trabalho bastante diverso.

Comparando as questões Q6, Q9, Q17, Q18, Q20, Q41, Q47 e Q49 da Tabela 4.2-5 com os dados demográficos dos respondentes, verifica-se que elas não são pertinentes para alguns respondentes em razão da natureza da sua instituição, função, atividades ou do seu local de trabalho. 
Pelo fato dessas oito questões serem indicadores importantes e representativos para medir o construto ao qual pertencem, elas não foram excluídas do instrumento. Entretanto, elas não foram consideradas para efeito dos cálculos de confiabilidade e de validação de construto do instrumento.

\subsection{Análise das variáveis demográficas}

Esta seção trata da caracterização demográfica da amostra traçando um perfil dos respondentes.

As questões demográficas identificadas como D1 a D7 podem ser observadas no Apêndice $\mathrm{B}$ e os dados analisados são os contidos na distribuição de frequências do Apêndice $\mathrm{C}$ deste trabalho.

A fim de se obter uma melhor representação demográfica, a amostra foi classificada por institutos e pela $\underline{\text { CNEN como um todo. }}$

\section{D1. Instituição de lotação do respondente}

A composição da amostra global distribuída pelos institutos da CNEN é apresentada na Tabela 4.3-1.

Tabela 4.3-1 - Caracterização da amostra por institutos da CNEN

\begin{tabular}{llcc}
\hline \hline & Frequência & Porcentagem \\
\hline \multirow{6}{*}{ Válido } & CNEN/Sede & 16 & $8,1 \%$ \\
& CDTN & 10 & $5,1 \%$ \\
& CRCN/CO & 2 & $1,0 \%$ \\
& CRCN/NE & 2 & $1,0 \%$ \\
& IEN & 14 & $7,1 \%$ \\
& IPEN & 139 & $70,2 \%$ \\
& IRD & 15 & $7,6 \%$ \\
& Total & 198 & $100,0 \%$ \\
\hline \hline
\end{tabular}


Observa-se uma frequência expressiva de $70,2 \%$ dos respondentes pertencentes ao IPEN. Esse fato se deve ao instituto possuir um contingente proporcionalmente maior de servidores. Já no caso do CRCN/CO e do CRCN/NE tem-se uma relação inversa, pois são proporcionalmente menores.

Em razão da quantidade reduzida de dados obtida do $\mathrm{CRCN} / \mathrm{CO}$ e do CRCN/NE, a amostra não é considerada representativa da população. Portanto, esses institutos não serão objeto das análises previstas nesta seção.

\section{$\underline{\text { D2. Tempo de atividade do respondente na instituição }}$}

A distribuição dos respondentes pelo tempo de atividade em cada instituição e na CNEN em geral, pode ser vista na Tabela 4.3-2.

Tabela 4.3-2 - Caracterização da amostra pelo tempo de atividade na instituição

\begin{tabular}{|c|c|c|c|c|c|c|c|c|c|}
\hline \multirow{2}{*}{\multicolumn{2}{|c|}{ Característica }} & \multicolumn{7}{|c|}{ D1. Instituição } & \multirow{2}{*}{$\begin{array}{c}\text { Total } \\
\text { (CNEN) }\end{array}$} \\
\hline & & CNEN/Sede & CDTN & CRCN/CO & CRCN/NE & IEN & IPEN & IRD & \\
\hline \multirow{5}{*}{$\begin{array}{l}\text { D2. Tempo } \\
\text { na } \\
\text { instituição }\end{array}$} & $\begin{array}{l}\text { Menos que } 5 \\
\text { anos }\end{array}$ & $\begin{array}{c}2 \\
12,5 \% \\
\end{array}$ & $\begin{array}{c}0 \\
0,0 \% \\
\end{array}$ & $\begin{array}{c}0 \\
0,0 \% \\
\end{array}$ & $\begin{array}{c}0 \\
0,0 \%\end{array}$ & $\begin{array}{c}1 \\
7,1 \%\end{array}$ & $\begin{array}{c}16 \\
11,5 \% \\
\end{array}$ & $\begin{array}{c}1 \\
6,7 \%\end{array}$ & $\begin{array}{c}20 \\
10,1 \%\end{array}$ \\
\hline & $\begin{array}{l}\text { De } 6 \text { a } 10 \\
\text { anos }\end{array}$ & $\begin{array}{c}0 \\
0,0 \%\end{array}$ & $\begin{array}{c}0 \\
0,0 \%\end{array}$ & $\begin{array}{c}1 \\
50,0 \%\end{array}$ & $\begin{array}{c}0 \\
0,0 \%\end{array}$ & $\begin{array}{c}0 \\
0,0 \%\end{array}$ & $\begin{array}{c}1 \\
0,7 \%\end{array}$ & $\begin{array}{c}1 \\
6,7 \%\end{array}$ & $\begin{array}{c}3 \\
1,6 \%\end{array}$ \\
\hline & $\begin{array}{l}\text { De } 11 \text { a } 20 \\
\text { anos }\end{array}$ & $\begin{array}{c}3 \\
18,8 \% \\
\end{array}$ & $\begin{array}{c}4 \\
40,0 \% \\
\end{array}$ & $\begin{array}{c}0 \\
0,0 \% \\
\end{array}$ & $\begin{array}{c}2 \\
100,0 \% \\
\end{array}$ & $\begin{array}{c}6 \\
42,9 \% \\
\end{array}$ & $\begin{array}{c}20 \\
14,4 \% \\
\end{array}$ & $\begin{array}{c}5 \\
33,3 \% \\
\end{array}$ & $\begin{array}{c}40 \\
20,2 \% \\
\end{array}$ \\
\hline & $\begin{array}{l}\text { De } 21 \text { a } 30 \\
\text { anos }\end{array}$ & $\begin{array}{c}2 \\
12,5 \% \\
\end{array}$ & $\begin{array}{c}1 \\
10,0 \% \\
\end{array}$ & $\begin{array}{c}0 \\
0,0 \% \\
\end{array}$ & $\begin{array}{c}0 \\
0,0 \% \\
\end{array}$ & $\begin{array}{c}5 \\
35,7 \% \\
\end{array}$ & $\begin{array}{c}36 \\
25,9 \% \\
\end{array}$ & $\begin{array}{c}2 \\
13,3 \% \\
\end{array}$ & $\begin{array}{c}46 \\
23,2 \% \\
\end{array}$ \\
\hline & $\begin{array}{l}\text { Mais que } 30 \\
\text { anos }\end{array}$ & $\begin{array}{c}9 \\
56,3 \% \\
\end{array}$ & $\begin{array}{c}5 \\
50,0 \% \\
\end{array}$ & $\begin{array}{c}1 \\
50,0 \% \\
\end{array}$ & $\begin{array}{c}0 \\
0,0 \% \\
\end{array}$ & $\begin{array}{c}2 \\
14,3 \% \\
\end{array}$ & $\begin{array}{c}66 \\
47,5 \% \\
\end{array}$ & $\begin{array}{c}6 \\
40,0 \% \\
\end{array}$ & $\begin{array}{c}89 \\
44,9 \% \\
\end{array}$ \\
\hline \multicolumn{2}{|c|}{ Total por instituição } & $\begin{array}{c}16 \\
100,0 \%\end{array}$ & $\begin{array}{c}10 \\
100,0 \%\end{array}$ & $\begin{array}{c}2 \\
100,0 \%\end{array}$ & $\begin{array}{c}2 \\
100,0 \%\end{array}$ & $\begin{array}{c}14 \\
100,0 \%\end{array}$ & $\begin{array}{c}139 \\
100,0 \%\end{array}$ & $\begin{array}{c}15 \\
100,0 \%\end{array}$ & $\begin{array}{c}198 \\
100,0 \%\end{array}$ \\
\hline
\end{tabular}

Os valores na Tabela 4.3-2 indicam a classificação (frequência e porcentagem) das respostas dos respondentes em cada instituto e também considerando a CNEN como um todo.

Conforme se observa na tabela, a CNEN-Sede, o CDTN, o IPEN e o IRD, segundo a amostra analisada, são os órgãos que possuem o maior contingente de servidores com mais de 30 anos na instituição $56,3 \%, 50 \%, 47,5 \%$ e $40 \%$, respectivamente, o que 
revela grande concentração de experiência e conhecimento na área nuclear nesses institutos. Este fato também se reflete quando se observa a CNEN como o todo (44,9\%).

Em contrapartida, o IEN, segundo a amostra analisada, possui um contingente com menor tempo na instituição, de 11 a 20 anos.

\section{D3. Área de atuação do respondente}

A CNEN por abranger institutos atuantes nas áreas de pesquisa, proteção radiológica, produção de radiofármacos, licenciamento de instalações e ensino possui um contingente de trabalho bastante diversificado, como pode ser verificado na Tabela 4.3-3.

Tabela 4.3-3 - Caracterização da amostra em relação à área de atuação

\begin{tabular}{|c|c|c|c|c|c|c|c|c|c|}
\hline \multirow{2}{*}{\multicolumn{2}{|c|}{ Característica }} & \multicolumn{7}{|c|}{ D1. Instituição } & \multirow{2}{*}{$\begin{array}{c}\text { Total } \\
\text { (CNEN) }\end{array}$} \\
\hline & & CNEN/Sede & CDTN & CRCN/CO & CRCN/NE & IEN & IPEN & IRD & \\
\hline \multirow{10}{*}{$\begin{array}{c}\text { D3. } \\
\text { Área de } \\
\text { atuação }\end{array}$} & Operação & $\begin{array}{c}1 \\
6,3 \% \\
\end{array}$ & $\begin{array}{c}0 \\
0,0 \% \\
\end{array}$ & $\begin{array}{c}0 \\
0,0 \% \\
\end{array}$ & $\begin{array}{c}0 \\
0,0 \% \\
\end{array}$ & $\begin{array}{c}1 \\
7,1 \% \\
\end{array}$ & $\begin{array}{c}9 \\
6,5 \% \\
\end{array}$ & $\begin{array}{c}0 \\
0,0 \% \\
\end{array}$ & $\begin{array}{c}11 \\
5,6 \% \\
\end{array}$ \\
\hline & Produção & $\begin{array}{c}0 \\
0,0 \% \\
\end{array}$ & $\begin{array}{c}0 \\
0,0 \% \\
\end{array}$ & $\begin{array}{c}0 \\
0,0 \% \\
\end{array}$ & $\begin{array}{c}0 \\
0,0 \% \\
\end{array}$ & $\begin{array}{c}0 \\
0,0 \% \\
\end{array}$ & $\begin{array}{c}10 \\
7,2 \% \\
\end{array}$ & $\begin{array}{c}0 \\
0,0 \%\end{array}$ & $\begin{array}{c}10 \\
5,1 \%\end{array}$ \\
\hline & Manut. & $\begin{array}{c}0 \\
0,0 \% \\
\end{array}$ & $\begin{array}{c}0 \\
0,0 \% \\
\end{array}$ & $\begin{array}{c}0 \\
0,0 \% \\
\end{array}$ & $\begin{array}{c}0 \\
0,0 \% \\
\end{array}$ & $\begin{array}{c}0 \\
0,0 \% \\
\end{array}$ & $\begin{array}{c}2 \\
1,4 \% \\
\end{array}$ & $\begin{array}{c}0 \\
0,0 \% \\
\end{array}$ & $\begin{array}{c}2 \\
1,0 \% \\
\end{array}$ \\
\hline & Radiopr. & $\begin{array}{c}2 \\
12,5 \% \\
\end{array}$ & $\begin{array}{c}0 \\
0,0 \% \\
\end{array}$ & $\begin{array}{c}1 \\
50,0 \% \\
\end{array}$ & $\begin{array}{c}0 \\
0,0 \% \\
\end{array}$ & $\begin{array}{c}0 \\
0,0 \% \\
\end{array}$ & $\begin{array}{c}10 \\
7,2 \% \\
\end{array}$ & $\begin{array}{c}7 \\
46,7 \% \\
\end{array}$ & $\begin{array}{c}20 \\
10,1 \% \\
\end{array}$ \\
\hline & Seg. Nuclear & $\begin{array}{c}5 \\
31,3 \% \\
\end{array}$ & $\begin{array}{c}1 \\
10,0 \% \\
\end{array}$ & $\begin{array}{c}0 \\
0,0 \% \\
\end{array}$ & $\begin{array}{c}0 \\
0,0 \% \\
\end{array}$ & $\begin{array}{c}2 \\
14,3 \% \\
\end{array}$ & $\begin{array}{c}4 \\
2,9 \% \\
\end{array}$ & $\begin{array}{c}0 \\
0,0 \% \\
\end{array}$ & $\begin{array}{c}12 \\
6,1 \% \\
\end{array}$ \\
\hline & Seg Física & $\begin{array}{c}0 \\
0,0 \% \\
\end{array}$ & $\begin{array}{c}0 \\
0,0 \% \\
\end{array}$ & $\begin{array}{c}0 \\
0,0 \% \\
\end{array}$ & $\begin{array}{c}0 \\
0,0 \% \\
\end{array}$ & $\begin{array}{c}0 \\
0,0 \% \\
\end{array}$ & $\begin{array}{c}1 \\
0,7 \% \\
\end{array}$ & $\begin{array}{c}0 \\
0,0 \% \\
\end{array}$ & $\begin{array}{c}1 \\
0,5 \% \\
\end{array}$ \\
\hline & $\begin{array}{l}\text { Pesquisa / } \\
\text { Desenv }\end{array}$ & $\begin{array}{c}5 \\
31,3 \% \\
\end{array}$ & $\begin{array}{c}7 \\
70,0 \% \\
\end{array}$ & $\begin{array}{c}1 \\
50,0 \% \\
\end{array}$ & $\begin{array}{c}2 \\
100,0 \% \\
\end{array}$ & $\begin{array}{c}5 \\
35,7 \% \\
\end{array}$ & $\begin{array}{c}88 \\
63,3 \% \\
\end{array}$ & $\begin{array}{c}4 \\
26,7 \% \\
\end{array}$ & $\begin{array}{c}112 \\
56,6 \% \\
\end{array}$ \\
\hline & $\begin{array}{l}\text { Garantia da } \\
\text { Qualid }\end{array}$ & $\begin{array}{c}2 \\
12,5 \% \\
\end{array}$ & $\begin{array}{c}0 \\
0,0 \% \\
\end{array}$ & $\begin{array}{c}0 \\
0,0 \% \\
\end{array}$ & $\begin{array}{c}0 \\
0,0 \% \\
\end{array}$ & $\begin{array}{c}0 \\
0,0 \% \\
\end{array}$ & $\begin{array}{c}3 \\
2,2 \% \\
\end{array}$ & $\begin{array}{c}0 \\
0,0 \% \\
\end{array}$ & $\begin{array}{c}5 \\
2,5 \% \\
\end{array}$ \\
\hline & Ensino & $\begin{array}{c}0 \\
0,0 \% \\
\end{array}$ & $\begin{array}{c}0 \\
0,0 \% \\
\end{array}$ & $\begin{array}{c}0 \\
0,0 \% \\
\end{array}$ & $\begin{array}{c}0 \\
0,0 \% \\
\end{array}$ & $\begin{array}{c}2 \\
14,3 \% \\
\end{array}$ & $\begin{array}{c}1 \\
0,7 \% \\
\end{array}$ & $\begin{array}{c}1 \\
6,7 \% \\
\end{array}$ & $\begin{array}{c}4 \\
2,0 \% \\
\end{array}$ \\
\hline & Outra. & $\begin{array}{c}1 \\
6,3 \% \\
\end{array}$ & $\begin{array}{c}2 \\
20,0 \% \\
\end{array}$ & $\begin{array}{c}0 \\
0,0 \% \\
\end{array}$ & $\begin{array}{c}0 \\
0,0 \% \\
\end{array}$ & $\begin{array}{c}4 \\
28,6 \% \\
\end{array}$ & $\begin{array}{c}11 \\
7,9 \% \\
\end{array}$ & $\begin{array}{c}3 \\
20,0 \% \\
\end{array}$ & $\begin{array}{c}21 \\
10,5 \% \\
\end{array}$ \\
\hline \multicolumn{2}{|c|}{ Total por instituição } & $\begin{array}{c}16 \\
100,0 \%\end{array}$ & $\begin{array}{c}10 \\
100,0 \%\end{array}$ & $\begin{array}{c}2 \\
100,0 \%\end{array}$ & $\begin{array}{c}2 \\
100,0 \%\end{array}$ & $\begin{array}{c}14 \\
100,0 \%\end{array}$ & $\begin{array}{c}139 \\
100,0 \%\end{array}$ & $\begin{array}{c}15 \\
100,0 \%\end{array}$ & $\begin{array}{c}198 \\
100 \%\end{array}$ \\
\hline
\end{tabular}

Segundo a amostra analisada, observa-se uma predominância nas áreas de Pesquisa \& Desenvolvimento, tanto nos institutos, como na CNEN em geral (56,6\%). A pequena parcela de respondentes que atua nas áreas de operação e produção é devida a institutos que possuem reator de pesquisa. 
A grande concentração em radioproteção no IRD (46,7\%) se deve à natureza das atribuições desse instituto: radioproteção e dosimetria.

Na CNEN-Sede também predominou atuação dos respondentes em segurança nuclear por conta das atividades de licenciamento do órgão.

\section{$\underline{\text { A opção "Outra área" }}$}

Apesar de ter sido proporcionada no questionário uma gama ampla de opções de áreas de atuação para a classificação do respondente, foi prevista a opção "Outra" com um campo "Comentários” para o respondente designar uma área de atuação não prevista na questão ou adicionar informações complementares. Houve 21 campos preenchidos e o principal aspecto observado diz respeito à atuação em mais de uma área. Dentre as áreas designadas que não estavam previstas, as principais foram: Administração em geral, Biblioteca, Administração (Alta Direção), Administração (Diretoria) e Licenciamento (Nuclear e Ambiental).

\section{D4. Cargo ou funcão ocupado pelo respondente}

A distribuição dos respondentes com relação ao cargo ou função ocupada em cada instituto e na CNEN em geral é mostrada na Tabela 4.3-4. 
Tabela 4.3-4 - Caracterização da amostra em relação ao Cargo / Função

\begin{tabular}{|c|c|c|c|c|c|c|c|c|c|}
\hline \multirow{2}{*}{\multicolumn{2}{|c|}{ Característica }} & \multicolumn{7}{|c|}{ D1. Instituição } & \multirow{2}{*}{$\begin{array}{c}\text { Total } \\
(\mathrm{CNEN})\end{array}$} \\
\hline & & CNEN/Sede & CDTN & CRCN/CO & CRCN/NE & IEN & IPEN & IRD & \\
\hline \multirow{7}{*}{$\begin{array}{c}\text { D4. Cargo } \\
\text { / Função }\end{array}$} & Superin/te & $\begin{array}{c}1 \\
6,3 \% \\
\end{array}$ & $\begin{array}{c}1 \\
10,0 \% \\
\end{array}$ & $\begin{array}{c}0 \\
0,0 \% \\
\end{array}$ & $\begin{array}{c}0 \\
0,0 \% \\
\end{array}$ & $\begin{array}{c}1 \\
7,1 \% \\
\end{array}$ & $\begin{array}{c}1 \\
0,7 \% \\
\end{array}$ & $\begin{array}{c}0 \\
0,0 \% \\
\end{array}$ & $\begin{array}{c}4 \\
2,0 \% \\
\end{array}$ \\
\hline & Gerente & $\begin{array}{c}0 \\
0,0 \%\end{array}$ & $\begin{array}{c}1 \\
10,0 \%\end{array}$ & $\begin{array}{c}0 \\
0,0 \%\end{array}$ & $\begin{array}{c}0 \\
0,0 \%\end{array}$ & $\begin{array}{c}0 \\
0,0 \%\end{array}$ & $\begin{array}{c}14 \\
10,1 \%\end{array}$ & $\begin{array}{c}0 \\
0,0 \%\end{array}$ & $\begin{array}{c}15 \\
7,6 \%\end{array}$ \\
\hline & $\begin{array}{l}\text { Enc. Divis/ } \\
\text { Seção }\end{array}$ & $\begin{array}{c}2 \\
12,5 \% \\
\end{array}$ & $\begin{array}{c}1 \\
10,0 \% \\
\end{array}$ & $\begin{array}{c}0 \\
0,0 \% \\
\end{array}$ & $\begin{array}{c}0 \\
0,0 \% \\
\end{array}$ & $\begin{array}{c}0 \\
0,0 \% \\
\end{array}$ & $\begin{array}{c}6 \\
4,3 \% \\
\end{array}$ & $\begin{array}{c}3 \\
20,0 \% \\
\end{array}$ & $\begin{array}{c}12 \\
6,1 \% \\
\end{array}$ \\
\hline & Pesquisador & $\begin{array}{c}6 \\
37,5 \% \\
\end{array}$ & $\begin{array}{c}3 \\
30,0 \% \\
\end{array}$ & $\begin{array}{c}2 \\
100,0 \% \\
\end{array}$ & $\begin{array}{c}2 \\
100,0 \% \\
\end{array}$ & $\begin{array}{c}8 \\
57,1 \% \\
\end{array}$ & $\begin{array}{c}73 \\
52,5 \% \\
\end{array}$ & $\begin{array}{c}9 \\
60,0 \% \\
\end{array}$ & $\begin{array}{c}103 \\
52,0 \% \\
\end{array}$ \\
\hline & Supervisor & $\begin{array}{c}0 \\
0,0 \% \\
\end{array}$ & $\begin{array}{c}1 \\
10,0 \% \\
\end{array}$ & $\begin{array}{c}0 \\
0,0 \% \\
\end{array}$ & $\begin{array}{c}0 \\
0,0 \% \\
\end{array}$ & $\begin{array}{c}1 \\
7,1 \% \\
\end{array}$ & $\begin{array}{c}7 \\
5,0 \% \\
\end{array}$ & $\begin{array}{c}1 \\
6,7 \% \\
\end{array}$ & $\begin{array}{c}10 \\
5,1 \% \\
\end{array}$ \\
\hline & $\begin{array}{l}\text { Téc. de } \\
\text { Manutenção }\end{array}$ & $\begin{array}{c}0 \\
0,0 \% \\
\end{array}$ & $\begin{array}{c}0 \\
0,0 \% \\
\end{array}$ & $\begin{array}{c}0 \\
0,0 \% \\
\end{array}$ & $\begin{array}{c}0 \\
0,0 \% \\
\end{array}$ & $\begin{array}{c}0 \\
0,0 \% \\
\end{array}$ & $\begin{array}{c}2 \\
1,4 \% \\
\end{array}$ & $\begin{array}{c}0 \\
0,0 \% \\
\end{array}$ & $\begin{array}{c}2 \\
1,0 \% \\
\end{array}$ \\
\hline & Outra & $\begin{array}{c}6 \\
37,5 \% \\
\end{array}$ & $\begin{array}{c}3 \\
30,0 \% \\
\end{array}$ & $\begin{array}{c}0 \\
0,0 \% \\
\end{array}$ & $\begin{array}{c}0 \\
0,0 \% \\
\end{array}$ & $\begin{array}{c}4 \\
28,6 \% \\
\end{array}$ & $\begin{array}{c}23 \\
16,5 \% \\
\end{array}$ & $\begin{array}{c}1 \\
6,7 \% \\
\end{array}$ & $\begin{array}{c}37 \\
18,7 \% \\
\end{array}$ \\
\hline \multicolumn{2}{|c|}{ Total por instituição } & $\begin{array}{c}16 \\
100,0 \%\end{array}$ & $\begin{array}{c}10 \\
100,0 \%\end{array}$ & $\begin{array}{c}2 \\
100,0 \%\end{array}$ & $\begin{array}{c}2 \\
100,0 \%\end{array}$ & $\begin{array}{c}14 \\
100,0 \%\end{array}$ & $\begin{array}{c}139 \\
100,0 \%\end{array}$ & $\begin{array}{c}15 \\
100,0 \%\end{array}$ & $\begin{array}{c}198 \\
100,0 \%\end{array}$ \\
\hline
\end{tabular}

Um aspecto importante a observar na tabela é que os questionários foram bem distribuídos entre os níveis funcionais nos institutos. Outro aspecto é que os dados da Tabela 4.3-4 demonstram uma relação direta com os resultados da questão anterior, ou seja, a predominância das respostas em pesquisa, tanto na área de atuação como na função de pesquisador exercida pelos respondentes. Esse fato se deve à natureza de pesquisa e desenvolvimento da CNEN.

\section{A opção "Outra função"}

Pela mesma razão que na questão D3, foi prevista a opção "Outra" com um campo "Comentários" para o respondente designar um cargo ou função não previstos na questão ou adicionar informações complementares. Houve 37 campos preenchidos e o principal aspecto observado diz respeito à acumulação de cargo ou função. Os principais casos de acumulação apresentados foram com os cargos no ensino, de assessor e de diretor.

Dentre os cargos e funções designadas que não estavam previstas, os principais foram: Analista em C\&T, Tecnologista e Coordenador. 


\section{D5. Tempo de experiência na área nuclear}

Essa talvez seja a principal característica demográfica desta pesquisa porque aliada com o tempo de atuação na instituição (questão D2), revela o nível do conhecimento e da experiência que cada respondente detém.

Na Tabela 4.3.5 é apresentada a distribuição dos respondentes em função do seu tempo de experiência na área nuclear.

Tabela 4.3-5 - Caracterização da amostra em função da experiência nuclear

\begin{tabular}{|c|c|c|c|c|c|c|c|c|c|}
\hline \multirow{2}{*}{\multicolumn{2}{|c|}{ Característica }} & \multicolumn{7}{|c|}{ D1. Instituição } & \multirow{2}{*}{$\begin{array}{c}\text { Total } \\
\text { (CNEN) }\end{array}$} \\
\hline & & CNEN/Sede & CDTN & $\mathrm{CRCN} / \mathrm{CO}$ & CRCN/NE & IEN & IPEN & IRD & \\
\hline \multirow{5}{*}{$\begin{array}{c}\text { D5. } \\
\text { Experiênc } \\
\text { nuclear }\end{array}$} & $\begin{array}{l}\text { Menos que } 5 \\
\text { anos }\end{array}$ & $\begin{array}{c}3 \\
18,8 \% \\
\end{array}$ & $\begin{array}{c}0 \\
0,0 \% \\
\end{array}$ & $\begin{array}{c}0 \\
0,0 \% \\
\end{array}$ & $\begin{array}{c}0 \\
0,0 \% \\
\end{array}$ & $\begin{array}{c}1 \\
7,1 \% \\
\end{array}$ & $\begin{array}{c}15 \\
10,8 \% \\
\end{array}$ & $\begin{array}{c}1 \\
6,7 \% \\
\end{array}$ & $\begin{array}{c}20 \\
10,1 \% \\
\end{array}$ \\
\hline & De 6 a 10 anos & $\begin{array}{c}0 \\
0,0 \% \\
\end{array}$ & $\begin{array}{c}0 \\
0,0 \% \\
\end{array}$ & $\begin{array}{c}0 \\
0,0 \% \\
\end{array}$ & $\begin{array}{c}0 \\
0,0 \% \\
\end{array}$ & $\begin{array}{c}0 \\
0,0 \% \\
\end{array}$ & $\begin{array}{c}6 \\
4,3 \% \\
\end{array}$ & $\begin{array}{c}0 \\
0,0 \% \\
\end{array}$ & $\begin{array}{c}6 \\
3,0 \% \\
\end{array}$ \\
\hline & $\begin{array}{l}\text { De } 11 \text { a } 20 \\
\text { anos }\end{array}$ & $\begin{array}{c}1 \\
6,3 \% \\
\end{array}$ & $\begin{array}{c}4 \\
40,0 \% \\
\end{array}$ & $\begin{array}{c}1 \\
50,0 \% \\
\end{array}$ & $\begin{array}{c}0 \\
0,0 \% \\
\end{array}$ & $\begin{array}{c}6 \\
42,9 \% \\
\end{array}$ & $\begin{array}{c}23 \\
16,5 \% \\
\end{array}$ & $\begin{array}{c}6 \\
40,0 \% \\
\end{array}$ & $\begin{array}{c}41 \\
20,7 \% \\
\end{array}$ \\
\hline & $\begin{array}{l}\text { De } 21 \text { a } 30 \\
\text { anos }\end{array}$ & $\begin{array}{c}2 \\
12,5 \% \\
\end{array}$ & $\begin{array}{c}0 \\
0,0 \% \\
\end{array}$ & $\begin{array}{c}1 \\
50,0 \% \\
\end{array}$ & $\begin{array}{c}0 \\
0,0 \% \\
\end{array}$ & $\begin{array}{c}5 \\
35,7 \%\end{array}$ & $\begin{array}{c}33 \\
23,7 \% \\
\end{array}$ & $\begin{array}{c}2 \\
13,3 \% \\
\end{array}$ & $\begin{array}{c}43 \\
21,7 \% \\
\end{array}$ \\
\hline & $\begin{array}{l}\text { Mais que } 30 \\
\text { anos }\end{array}$ & $\begin{array}{c}10 \\
62,5 \%\end{array}$ & $\begin{array}{c}6 \\
60,0 \% \\
\end{array}$ & $\begin{array}{c}0 \\
0,0 \%\end{array}$ & $\begin{array}{c}2 \\
100,0 \%\end{array}$ & $\begin{array}{c}2 \\
14,3 \% \\
\end{array}$ & $\begin{array}{c}62 \\
44,6 \% \\
\end{array}$ & $\begin{array}{c}6 \\
40,0 \% \\
\end{array}$ & $\begin{array}{c}88 \\
44,4 \% \\
\end{array}$ \\
\hline \multicolumn{2}{|c|}{ Total por instituição } & $\begin{array}{c}16 \\
100,0 \%\end{array}$ & $\begin{array}{c}10 \\
100,0 \%\end{array}$ & $\begin{array}{c}2 \\
100,0 \%\end{array}$ & $\begin{array}{c}2 \\
100,0 \%\end{array}$ & $\begin{array}{c}14 \\
100,0 \%\end{array}$ & $\begin{array}{c}139 \\
100,0 \%\end{array}$ & $\begin{array}{c}15 \\
100,0 \%\end{array}$ & $\begin{array}{c}198 \\
100,0 \%\end{array}$ \\
\hline
\end{tabular}

Observa-se em cada instituto uma estreita relação com os valores apresentados na Tabela 4.3-2 (tempo na instituição), sugerindo que a maior parte dos respondentes iniciou as suas atividades profissionais nos institutos da CNEN.

Na CNEN-Sede, no CDTN e no IPEN predomina o pessoal com mais de 30 anos de atividade na área nuclear. No IEN, pessoal entre 11 e 20 anos de atividade e no IRD há uma divisão entre o pessoal na faixa de 11 a 20 e com mais de 30 anos de atividade na área nuclear.

Considerando a CNEN como o todo, observa-se que predomina o pessoal com mais de 30 anos de experiência $(44,4 \%)$ e que apenas $13,1 \%$ dos respondentes têm menos de 10 anos de experiência na área nuclear. Esses dados, segundo a amostra analisada, 
demonstram que os institutos da CNEN possuem um quadro de funcionários bastante experientes na atividade fim do órgão.

\section{D6. Faixa etária do respondente}

Na Tabela 4.3.6 é apresentada a distribuição dos respondentes em função da sua faixa etária.

Tabela 4.3-6 - Caracterização da amostra em relação à faixa etária

\begin{tabular}{|c|c|c|c|c|c|c|c|c|c|}
\hline \multirow{2}{*}{\multicolumn{2}{|c|}{ Característica }} & \multicolumn{7}{|c|}{ D1. Instituição } & \multirow{2}{*}{$\begin{array}{l}\text { Total } \\
\text { (CNEN) }\end{array}$} \\
\hline & & CNEN/Sede & CDTN & CRCN/CO & CRCN/NE & IEN & IPEN & IRD & \\
\hline \multirow{5}{*}{$\begin{array}{c}\text { D6. } \\
\text { Idade }\end{array}$} & $\begin{array}{l}18 \text { a } 25 \\
\text { anos }\end{array}$ & $\begin{array}{c}1 \\
6,3 \% \\
\end{array}$ & $\begin{array}{c}0 \\
0,0 \%\end{array}$ & $\begin{array}{c}0 \\
0,0 \% \\
\end{array}$ & $\begin{array}{c}0 \\
0,0 \% \\
\end{array}$ & $\begin{array}{c}1 \\
7,1 \% \\
\end{array}$ & $\begin{array}{c}0 \\
0,0 \% \\
\end{array}$ & $\begin{array}{c}0 \\
0,0 \% \\
\end{array}$ & $\begin{array}{c}2 \\
1,0 \% \\
\end{array}$ \\
\hline & $\begin{array}{l}26 \text { a } 35 \\
\text { anos } \\
\end{array}$ & $\begin{array}{c}1 \\
6,3 \% \\
\end{array}$ & $\begin{array}{c}0 \\
0,0 \% \\
\end{array}$ & $\begin{array}{c}0 \\
0,0 \% \\
\end{array}$ & $\begin{array}{c}0 \\
0,0 \% \\
\end{array}$ & $\begin{array}{c}1 \\
7,1 \% \\
\end{array}$ & $\begin{array}{c}9 \\
6,5 \% \\
\end{array}$ & $\begin{array}{c}0 \\
0,0 \% \\
\end{array}$ & $\begin{array}{c}11 \\
5,6 \% \\
\end{array}$ \\
\hline & $\begin{array}{l}36 \text { a } 45 \\
\text { anos } \\
\end{array}$ & $\begin{array}{c}1 \\
6,3 \% \\
\end{array}$ & $\begin{array}{c}2 \\
20,0 \% \\
\end{array}$ & $\begin{array}{c}0 \\
0,0 \% \\
\end{array}$ & $\begin{array}{c}0 \\
0,0 \% \\
\end{array}$ & $\begin{array}{c}1 \\
7,1 \% \\
\end{array}$ & $\begin{array}{c}13 \\
9,4 \% \\
\end{array}$ & $\begin{array}{c}1 \\
6,7 \% \\
\end{array}$ & $\begin{array}{c}18 \\
9,1 \% \\
\end{array}$ \\
\hline & $\begin{array}{l}46 \text { a } 55 \\
\text { anos }\end{array}$ & $\begin{array}{c}4 \\
25,0 \% \\
\end{array}$ & $\begin{array}{c}3 \\
30,0 \% \\
\end{array}$ & $\begin{array}{c}1 \\
50,0 \% \\
\end{array}$ & $\begin{array}{c}0 \\
0,0 \%\end{array}$ & $\begin{array}{c}6 \\
42,9 \% \\
\end{array}$ & $\begin{array}{c}55 \\
39,6 \% \\
\end{array}$ & $\begin{array}{c}7 \\
46,7 \% \\
\end{array}$ & $\begin{array}{c}76 \\
38,4 \% \\
\end{array}$ \\
\hline & $\begin{array}{l}56 \text { anos ou } \\
\text { mais }\end{array}$ & $\begin{array}{c}9 \\
56,3 \%\end{array}$ & $\begin{array}{c}5 \\
50,0 \%\end{array}$ & $\begin{array}{c}1 \\
50,0 \%\end{array}$ & $\begin{array}{c}2 \\
100,0 \%\end{array}$ & $\begin{array}{c}5 \\
35,7 \%\end{array}$ & $\begin{array}{c}62 \\
44,6 \%\end{array}$ & $\begin{array}{c}7 \\
46,7 \%\end{array}$ & $\begin{array}{c}91 \\
46,0 \%\end{array}$ \\
\hline \multicolumn{2}{|c|}{ Total por instituição } & $\begin{array}{c}16 \\
100,0 \%\end{array}$ & $\begin{array}{c}10 \\
100,0 \%\end{array}$ & $\begin{array}{c}2 \\
100,0 \%\end{array}$ & $\begin{array}{c}2 \\
100,0 \%\end{array}$ & $\begin{array}{c}14 \\
100,0 \%\end{array}$ & $\begin{array}{c}139 \\
100,0 \%\end{array}$ & $\begin{array}{c}15 \\
100,0 \%\end{array}$ & $\begin{array}{c}198 \\
100,0 \%\end{array}$ \\
\hline
\end{tabular}

É importante observar a congruência desses valores com aqueles apresentados nas Tabelas 4.3-2 (tempo na instituição) e 4.3.5 (tempo de experiência na área nuclear).

Uma característica que talvez requeira certa atenção por parte dos institutos, segundo a amostra analisada, é o fato de na CNEN, em geral, apenas 15,7\% dos respondentes terem menos de 45 anos de idade e que a maioria (46\%) tem 56 anos ou mais. Esses dados sugerem a implementação de políticas de reposição de pessoal em curto prazo pela CNEN.

\section{$\underline{\text { D7. Nível de escolaridade do respondente }}$}

A distribuição dos respondentes pelo nível de escolaridade pode ser vista na Tabela 4.3-7. 
Tabela 4.3-7 - Caracterização da amostra em relação à escolaridade

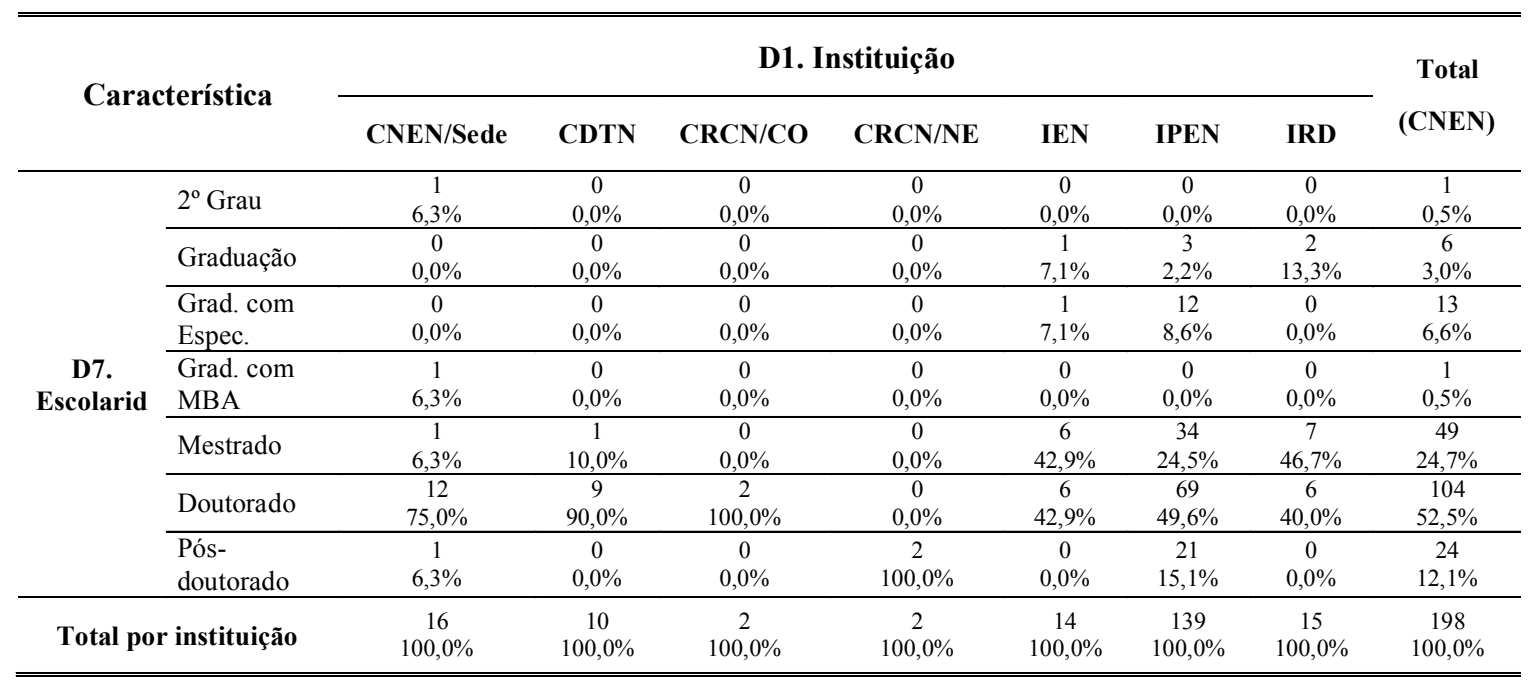

Observa-se que as maiores porcentagens para o grau de escolaridade dos respondentes estão entre mestrado e doutorado, sendo este último responsável por 52,5\% da amostra. Além disso, há uma porcentagem muito pequena de respondentes que estudaram apenas até a graduação $(3,5 \%)$.

Outra observação importante é que o total de respondentes com pós-doutorado é maior que o total de respondentes com apenas graduação.

É importante notar nas tabelas analisadas nesta seção que os valores da coluna "Total CNEN" coincidem com aqueles apresentados no Apêndice C, os quais foram baseados considerando a CNEN como um todo.

\subsection{Análise dos indicadores de mensuração da cultura de segurança}

Esta seção trata das análises dos indicadores de mensuração das dimensões propostas para avaliar a cultura de segurança. As 49 questões identificadas como Q1 a Q49 podem ser observadas no Apêndice B e os dados analisados são os contidos na distribuição de frequências do Apêndice $\mathrm{C}$ deste trabalho. 
As análises da distribuição das respostas se baseiam nos valores positivos, nos valores negativos e nos valores intermediários, atribuídos às questões. Valores positivos correspondem à porcentagem acumulada das duas opções de respostas de melhor conceito e de maior valor ( 5 e 4 ) atribuídas à questão. Valores negativos correspondem às opções de respostas de pior conceito e de menor valor (2 e 1). No caso dos valores intermediários, correspondem às opções de respostas de posição central (3). A porcentagem acumulada equivale à porcentagem da soma das frequências dessas opções em relação à frequência total.

\section{Dimensão D1. Prioridade dada à segurança}

No âmbito da CNEN, a prioridade dada à segurança nos institutos pode ser evidenciada pela classificação obtida pelos indicadores de mensuração, conforme apresentados na Tabela 4.4-1.

Tabela 4.4-1 - Indicadores da dimensão D 1. Prioridade dada à segurança

\begin{tabular}{lcl}
\hline \hline \multicolumn{1}{c}{ Indicadores } & $\begin{array}{c}\text { Frequência } \\
\text { total }\end{array}$ & Classificação \\
\hline Q1. Conhecimento da política de & 198 & Positiva $63,1 \%$ \\
segurança & 198 & Positiva $61,6 \%$ \\
Q2. Prioridade da segurança na política & 198 & Positiva $51,0 \%$ \\
Q3. Conteúdo da política de segurança & 198 & Positiva $49,0 \%$ \\
Q4. Abordagem da segurança nas reuniões & 198 & Positiva $65,2 \%$ \\
Q5. Segurança versus produção & 198 & Positiva $44,4 \%$ \\
Q6. Desvios e atalhos no processo & & \\
\hline \hline
\end{tabular}

Com relação à política de segurança observa-se que:

- $63,1 \%$ dos respondentes consideram que o seu conhecimento individual da política de segurança da sua instituição é muito bom ou bom;

- $\mathrm{Na}$ percepção de $61,6 \%$ dos respondentes as questões de segurança na política têm prioridade máxima ou alta;

- $51,0 \%$ dos respondentes classificam o seu conteúdo como muito bom ou bom. 
Esses resultados sugerem que a política de segurança é tratada com seriedade pelos institutos da CNEN.

Nas reuniões para tratar de assuntos relacionados à segurança, 49,0\% dos respondentes percebem que a preocupação da organização com a segurança é significativa.

Os indicadores Q5 e Q6 estão relacionados às unidades que possuem reatores de pesquisas (IPEN, CDTN e IEN). No caso de Q5, 65,2\% dos respondentes julgam que na sua unidade sempre pode haver interrupção do processo ou da operação por questões de segurança e com relação a Q6, 44,4\% dos respondentes afirmam que, mesmo que a unidade esteja com atraso no processo ou na operação não são admitidos "desvios" ou "atalhos" nos procedimentos.

Portanto, os valores obtidos pelos indicadores são indícios de que a segurança nos institutos da CNEN tem prioridade em detrimento de outras atividades, sugerindo, dessa forma, tratar-se de uma área fortalecida em sua cultura de segurança.

\section{Dimensão D2. Alocação de Recursos}

A alocação de recursos para os setores que têm influência na segurança, considerando a CNEN como um todo, pode ser avaliada com base nos resultados obtidos pelos indicadores de mensuração dessa dimensão, conforme apresentados na Tabela 4.4-2.

Tabela 4.4-2 - Indicadores da dimensão D2. Alocação de Recursos

\begin{tabular}{lcll}
\hline \hline \multicolumn{1}{c}{ Indicadores } & $\begin{array}{c}\text { Frequência } \\
\text { total }\end{array}$ & \multicolumn{2}{c}{ Classificação } \\
\hline Q7. Recursos para equipamentos de & 198 & Intermed & $32,8 \%$ \\
segurança & 198 & Negativa & $36,9 \%$ \\
Q8. Recursos para treinamentos & 198 & Negativa & $34,4 \%$ \\
Q9. Recursos para manutenção & 198 & Intermed & $39,9 \%$ \\
Q10. Revisão dos recursos & & &
\end{tabular}

Na alocação de recursos para a aquisição de equipamentos de segurança houve um equilíbrio entre as classificações positiva e negativa resultando em uma classificação intermediária de 32,8\%. Esse valor mostra que a maior parte dos respondentes considera o 
grau de adequação dos recursos alocados para a aquisição de equipamentos de segurança moderado.

No caso dos recursos para treinamentos e para manutenção predominou uma classificação negativa, pois 36,9\% e 34,4\% dos respondentes, respectivamente, consideram que o grau de adequação da alocação desses recursos é baixo ou muito baixo.

Quanto às revisões periódicas da adequação desses recursos 39,9\% dos respondentes afirmam que elas ocorrem com relativa frequência.

Cabe ressaltar, segundo a amostra analisada, que os valores obtidos pelos indicadores Q7, Q8 e Q9 são indícios de que há problemas nos institutos da CNEN com relação aos recursos para equipamentos de segurança, treinamentos e manutenção, o que pode vir a comprometer a segurança nessas instituições.

\section{Dimensão D3. Funcẽes e responsabilidades}

Na Tabela 4.4-3 são apresentadas as classificações e a frequência total obtidas por cada indicador de mensuração dessa dimensão.

Tabela 4.4-3 - Indicadores da dimensão D3. Funções e responsabilidades

\begin{tabular}{|c|c|c|}
\hline Indicadores & $\begin{array}{c}\text { Frequência } \\
\text { total }\end{array}$ & Classificação \\
\hline Q11. Def. de funções e responsabilidades & 198 & Positiva $48,5 \%$ \\
\hline Q12. Conhecimento das Responsab & 198 & Positiva $43,9 \%$ \\
\hline
\end{tabular}

Observa-se na Tabela 4.4-3 que quase a metade dos respondentes $(48,5 \%)$ considera que, em seu instituto, as funções e responsabilidades são muito bem, ou pelo menos, bem definidas. Verifica-se ainda que 43,9\% dos respondentes têm um elevado conhecimento acerca das suas próprias atribuições e responsabilidades pela segurança na instalação. 
De acordo com a amostra analisada, os valores obtidos são indícios de que as funções e responsabilidades são áreas fortalecidas da cultura de segurança nas instituições. $\mathrm{Ou}$ seja, as atribuições e responsabilidades pela segurança na instalação estão bem definidas e os colaboradores têm um bom conhecimento das suas próprias atribuições e responsabilidades pela segurança na instalação.

\section{Dimensão D4. Comprometimento com a segurança}

Na Tabela 4.4-4 são apresentados os valores da classificação e da frequência total obtidos pelos indicadores de mensuração dessa dimensão.

Tabela 4.4-4 - Indicadores da dimensão D4. Comprometimento com a segurança

\begin{tabular}{|c|c|c|}
\hline Indicadores & $\begin{array}{c}\text { Frequência } \\
\text { total }\end{array}$ & Classificação \\
\hline Q13. Comprometimento da Alta Adm & 198 & Positiva $39,9 \%$ \\
\hline Q14. Comprometimento da Gerência & 198 & Intermed $43,4 \%$ \\
\hline Q15. Estado atual da segurança & 198 & Positiva $50,5 \%$ \\
\hline
\end{tabular}

Na Tabela é possível visualizar que 39,9\% dos respondentes têm a opinião que a Alta administração da sua instituição está extremamente comprometida ou pelo menos muito comprometida com a segurança. O mesmo não ocorre com relação ao comprometimento da gerência, pois $43,4 \%$ dos respondentes consideram que a gerência está apenas moderadamente comprometida.

Um aspecto importante a se observar é que mais da metade dos respondentes têm a percepção de que o estado da segurança em sua instituição é muito bom ou, pelo menos bom.

Esses dados são indícios de que o comprometimento com a segurança nos institutos da CNEN é uma característica forte em sua cultura de segurança. 


\section{Dimensão D5. Comunicação e relacionamento}

Na Tabela 4.4-5 são apresentadas as classificações das respostas atribuídas aos indicadores de mensuração dessa dimensão, bem como os valores da frequência total.

Tabela 4.4-5 - Indicadores da dimensão D5. Comunicação e relacionamento

\begin{tabular}{lccc}
\hline \hline \multicolumn{1}{c}{ Indicadores } & $\begin{array}{c}\text { Frequência } \\
\text { total }\end{array}$ & \multicolumn{2}{c}{ Classificação } \\
\hline $\begin{array}{l}\text { Q16. Comunicação entre Adm e } \\
\text { funcionários }\end{array}$ & 198 & Intermed & $43,9 \%$ \\
$\begin{array}{l}\text { Q17. Comunicação entre turnos } \\
\text { Q18. Verificação da comunicação }\end{array}$ & 198 & Positiva & $18,2 \%$ \\
$\begin{array}{l}\text { Q19. Relação dos funcionários com } \\
\text { superiores }\end{array}$ & 198 & Negativa & $24,2 \%$ \\
$\begin{array}{l}\text { Q20. Relação da instituição com } \\
\text { reguladores }\end{array}$ & 198 & Positiva & $79,8 \%$ \\
\hline \hline
\end{tabular}

A classificação intermediária para o indicador Q16 significa que 43,9\% dos respondentes afirmam que os canais de comunicação entre a Administração e os funcionários são relativamente transparentes.

Com relação à comunicação entre turnos predominou uma classificação positiva, pois a maior parte dos respondentes percebe que há bastante preocupação com a segurança nas informações transmitidas durante as trocas de turno.

A maioria dos respondentes atribuiu uma classificação negativa para a Q18. Isso significa que $24,2 \%$ dos respondentes observam que raramente a Administração confirma se comunicação foi efetivamente transmitida e compreendida pelos funcionários.

Os indicadores que tratam de relacionamento obtiveram classificação positiva, ou seja, $79,8 \%$ dos respondentes afirmaram que a relação de trabalho com os superiores hierárquicos sempre se baseia na confiança mútua e 36,9\% dos respondentes observam que a instalação é bastante receptiva com relação aos órgãos reguladores e fiscalizadores. 


\section{Dimensão D6. Qualificação e dimensionamento de pessoal}

Os resultados obtidos na avaliação dos indicadores de mensuração dessa dimensão são apresentados na Tabela 4.4-6.

Tabela 4.4-6 - Indicadores da dimensão D6. Qualificação e dimensionamento de pessoal

\begin{tabular}{lccc}
\hline \hline \multicolumn{1}{c}{ Indicadores } & $\begin{array}{c}\text { Frequência } \\
\text { total }\end{array}$ & \multicolumn{2}{c}{ Classificação } \\
\hline Q21. Adequação dos treinamentos & 198 & Positiva & $40,9 \%$ \\
Q22. Revisão dos progr de treinamentos & 198 & Positiva & $37,4 \%$ \\
Q23. Equipe de trabalho & 198 & Intermed & $39,4 \%$ \\
Q24. Qualificação de pessoal & 198 & Positiva & $75,8 \%$ \\
\hline \hline
\end{tabular}

A classificação positiva atribuída aos indicadores Q21 e Q22 sugere que a área de treinamentos nos institutos da CNEN é tratada com empenho, porque 40,9\% dos respondentes consideram que os treinamentos que recebem são adequados às atividades que executam. $37,4 \%$ dos respondentes consideram que os programas de treinamento são normalmente revisados para se adequarem às novas necessidades das equipes de trabalho.

Observa-se que $75,8 \%$ dos respondentes se consideram treinados e qualificados para as atividades que desempenham e que 39,4 \% julgam a sua equipe de trabalho, com relação ao dimensionamento e às competências individuais, adequada.

\section{Dimensão D7. Documentação e procedimentos}

A dimensão documentação e procedimentos foi avaliada por meio de seus indicadores de mensuração, cujos resultados são mostrados na Tabela 4.4-7.

Tabela 4.4-7 - Indicadores da dimensão D7. Documentação e procedimentos

\begin{tabular}{lccc}
\hline \hline \multicolumn{1}{c}{ Indicadores } & $\begin{array}{c}\text { Frequência } \\
\text { total }\end{array}$ & \multicolumn{2}{c}{ Classificação } \\
\hline Q25. Conteúdo da documentação & 198 & Positiva & $57,0 \%$ \\
Q26. Disponibilidade da documentação & 198 & Positiva & $68,7 \%$ \\
Q27. Entendimento da documentação & 198 & Positiva & $71,2 \%$ \\
Q28. Problemas na documentação & 198 & Positiva & $61,6 \%$ \\
Q29. Atualização da documentação & 198 & Positiva & $52,0 \%$ \\
Q30. Exequibilidade do processo & 195 & Positiva & $42,6 \%$ \\
\hline \hline
\end{tabular}


Como pode ser observado na Tabela 4.4-7, predominou a classificação positiva para todos os indicadores, merecendo destaque as Q26 e Q27, pois 71,2\% dos respondentes julgam que o seu nível de entendimento acerca da documentação utilizada na realização das suas atividades é elevado. Já 68,7\% dos respondentes afirmam que a documentação necessária para realizarem as suas atividades está sempre disponível em seu local de trabalho. Os valores atribuídos aos outros indicadores também indicam que os respondentes têm opinião e percepção positivas com relação à qualidade da documentação e procedimentos.

O processo das diversas atividades foi considerado pela maioria dos respondentes $(42,6 \%)$ como de fácil entendimento e execução.

Os resultados obtidos da amostra por esses indicadores são indícios de que a característica documentação e procedimentos é uma área fortalecida da cultura de segurança nos institutos da CNEN.

\section{Dimensão D8. Condiç̃es de trabalho}

Na Tabela 4.4-8 são apresentadas as classificações e a frequência total obtidas por cada indicador de mensuração dessa dimensão.

Tabela 4.4-8 - Indicadores da dimensão D8. Condições de trabalho

\begin{tabular}{|c|c|c|c|}
\hline Indicadores & $\begin{array}{c}\text { Frequência } \\
\text { total }\end{array}$ & \multicolumn{2}{|c|}{ Classificação } \\
\hline Q31. Carga de trabalho & 190 & Positiva & $50,5 \%$ \\
\hline Q32. Temperatura do ambiente & 187 & Positiva & $76,5 \%$ \\
\hline Q33. Luminosidade do ambiente & 187 & Positiva & $82,4 \%$ \\
\hline Q34. Qualidade do Ar & 187 & Positiva & $73,3 \%$ \\
\hline Q35. Ruídos no ambiente & 187 & Positiva & $60,4 \%$ \\
\hline Q36. Pressão do tempo & 187 & Intermed & $63,6 \%$ \\
\hline Q37. Ergonomia no trabalho & 187 & Positiva & $57,2 \%$ \\
\hline Q38. Limpeza do ambiente & 186 & Positiva & $75,3 \%$ \\
\hline Q39. Estado dos Sistemas de segurança & 186 & Positiva & $43,0 \%$ \\
\hline Q40. Estresse no trabalho & 186 & Positiva & $44.6 \%$ \\
\hline Q41. Demanda de horas extras & 186 & Positiva & $30,6 \%$ \\
\hline Q42. Satisfação no trabalho & 185 & Positiva & $40,0 \%$ \\
\hline
\end{tabular}

Inicialmente, é importante ressaltar que, em geral, atributos como carga de trabalho, pressão do tempo para realizar as atividades, estresse no trabalho, demanda de 
horas extras e satisfação no trabalho são muito relacionados um com o outro na gestão da segurança de uma organização. Qualquer sobrecarga de trabalho pode comprometer a segurança e pode estar relacionada com a política de horas extras na organização. Um ritmo de trabalho muito rápido ou muito lento pode resultar em fadiga. Trabalho com prazos não realistas podem resultar em estresse psicológico para o funcionário. Programação de trabalho exigindo que os funcionários trabalhem longas horas, em particular à noite, pode também resultar em fadiga, que por fim pode resultar em erros e acidentes. $\mathrm{O}$ comportamento dos funcionários pode ser influenciado pela sua motivação e satisfação no trabalho.

Nota-se nos resultados obtidos por esses indicadores que existe uma relação de equilíbrio dessas características nos institutos da CNEN.

Para o indicador pressão do tempo predominou a classificação intermediária, pois mais da metade dos respondentes consideram que o tempo dado para a realização das tarefas é equivalente ao tempo necessário para completá-las.

Com relação aos indicadores Q32, Q33, Q34, Q35, Q37 e Q38, que tratam das condições ambientais no trabalho, a maioria dos respondentes classificou esses aspectos como muito bom, ou pelo menos bom em suas instituições.

O indicador demanda de horas extras é difícil de ser avaliado porque depende de políticas governamentais pelo fato de a CNEN ser um órgão público federal. Poucos institutos podem conceder horas extras. De qualquer forma, nos institutos em que são praticadas, $30,6 \%$ dos respondentes afirmaram que raramente são solicitados para trabalhar após o seu período normal de atividades.

As diferenças nos valores da coluna "Frequência total" se devem ao fato de que nessas análises não estão sendo considerados os valores ausentes. 


\section{Dimensão D9. Aprendizagem organizacional}

Os valores obtidos pelos indicadores de avaliação dessa dimensão (classificação e frequência total) são apresentados na Tabela 4.4-9.

Tabela 4.4-9 - Indicadores da dimensão D9. Aprendizagem organizacional

\begin{tabular}{lccc}
\hline \hline \multicolumn{1}{c}{ Indicadores } & $\begin{array}{c}\text { Frequência } \\
\text { total }\end{array}$ & \multicolumn{2}{c}{ Classificação } \\
\hline Q43. Lições aprendidas & 185 & Positiva & $41,6 \%$ \\
Q44. Análise de acidentes & 185 & Positiva & $54,6 \%$ \\
Q45. Ações corretivas & 185 & Intermed & $44,9 \%$ \\
Q46. Divulgação das causas dos acidentes & 185 & Negativa & $31,4 \%$ \\
\hline \hline
\end{tabular}

A classificação positiva atribuída ao indicador Q43, significa que 41,6\% dos respondentes julgam que as experiências de outras instalações nucleares são consideradas como melhoria para a segurança em sua instalação.

Mais da metade dos respondentes (54,6\%) observam que quando ocorre um acidente em sua instalação é dada extrema importância para a investigação das suas causas. Por outro lado, $31,4 \%$ dos respondentes têm a percepção de que a divulgação das causas não é transparente quando se trata de questões segurança.

Com relação ao indicador Q45, grande parte dos respondentes (44,9\%) tem a opinião de que as ações corretivas não são muito eficazes.

\section{Dimensão D10. Avaliaç̃oes internas e externas}

Os resultados da classificação e da frequência total obtidos na avaliação dessa dimensão são encontrados na Tabela 4.4-10. 
Tabela 4.4-10 - Indicadores da dimensão D10. Avaliações internas e externas

\begin{tabular}{lccc}
\hline \hline \multicolumn{1}{c}{ Indicadores } & $\begin{array}{c}\text { Frequência } \\
\text { total }\end{array}$ & \multicolumn{2}{c}{ Classificação } \\
\hline Q47. Avaliações externas (receptividade) & 181 & Positiva & $37,0 \%$ \\
Q48. Avaliações internas (frequência) & 181 & Intermed & $33,7 \%$ \\
Q49. Divulgação dos resultados das & 181 & Negativa & $25,4 \%$ \\
avaliações & & & \\
\hline \hline
\end{tabular}

Como pode ser observado na Tabela 4.4-10, predominou uma classificação positiva para a Q47, em que 37 \% dos respondentes têm a percepção de que a instalação é bastante receptiva quando se trata de avaliações de segurança realizadas por pessoal externo.

Uma característica muito importante para a cultura de segurança são as avaliações internas relacionadas à segurança na instalação. Entretanto, boa parte dos respondentes $(37,7 \%)$ afirma que somente às vezes elas ocorrem.

De acordo com a classificação atribuída ao indicador Q49, os resultados das avaliações internas e externas são mal divulgados, na opinião de $25,4 \%$ dos respondentes. Esta classificação, aliada ao fato de que também há problemas na divulgação das causas dos acidentes, conforme verificado na análise da dimensão aprendizagem organizacional, indica fragilidades na cultura de segurança das instituições quando se trata de divulgar resultados. 


\section{AVALIAÇÃO DAS PROPRIEDADES PSICOMÉTRICAS DO MODELO}

Este capítulo tem o objetivo de apresentar os estudos das propriedades psicométricas - análise da confiabilidade e validação de construto - realizados para o modelo proposto neste trabalho.

A base de dados utilizada para estas avaliações recebeu um tratamento apropriado no Capítulo 4 e está configurada de forma que:

- Não estão sendo consideradas as questões Q6, Q9, Q17, Q18, Q20, Q41, Q47 e Q49 por terem recebido uma quantidade significativa de classificação "Não aplicável";

- Não estão sendo consideradas as opções de resposta "Não aplicável" atribuídas às demais questões;

- Valores ausentes receberam atribuição pela média, tornando-se dados válidos;

- Dispõe-se de um total de 198 casos válidos para as análises.

\subsection{Análise da adequação do tamanho da amostra}

No entendimento de Hair Jr. et al. (2010), uma das premissas mais importantes para uma análise multivariada de dados é com relação à adequação do tamanho da amostra. Esses autores ainda ressaltam que é essencial que a amostra seja de tamanho e qualidade suficientes para produzir resultados confiáveis em termos de precisão e coerência. Dificilmente se realiza uma análise fatorial com uma amostra menor que 50 observações, e de preferência o tamanho da amostra deve ser maior ou igual a 100. Os autores ainda esclarecem que, em geral, adota-se a quantidade de cinco vezes mais observações do que o número de variáveis a serem analisadas. Na opinião de Malhotra (2006) o tamanho da amostra ideal seria de quatro a cinco vezes a quantidade de itens da escala. De qualquer forma, esses autores recomendam sempre obter a maior proporção de casos por variável possível, empregando o conjunto de variáveis mais parcimonioso. 
Portanto, considerando o tratamento aplicado aos dados e a não consideração das variáveis Q6, Q9, Q17, Q18, Q20, Q41, Q47 e Q49, verifica-se que o tamanho da amostra para as estatísticas multivariadas previstas neste capítulo é adequado, uma vez que serão analisadas 41 variáveis com uma amostra de 198 casos válidos.

\subsection{Análise da confiabilidade do instrumento de pesquisa}

A medida de confiabilidade mais comumente usada é a consistência interna, a qual avalia a consistência entre as variáveis (indicadores) em uma escala múltipla. A ideia da consistência interna é que os indicadores individuais da escala devem medir o mesmo construto, e assim serem altamente intercorrelacionados. Se múltiplas medidas são realizadas, as medidas confiáveis também serão muito consistentes em seus valores.

Duas medidas diagnósticas de consistência interna devem ser consideradas: a que avalia os itens individualmente e a que avalia a escala como um todo. Na primeira, verifica-se a correlação item-total, ou seja, a correlação do item com o escore da escala múltipla; na segunda, a medida diagnóstica é o coeficiente de confiabilidade que avalia a escala total, sendo o alfa de Cronbach a medida mais amplamente usada.

Devellis (2003) ressalta em seu trabalho que o coeficiente alfa foi desenvolvido por Lee J. Cronbach e o seu cálculo é dado por:

$$
\alpha=\frac{n \bar{\rho}}{[1+\bar{\rho}(n-1)]}
$$

Onde:

$n=$ número de itens;

$\bar{\rho}=$ média dos coeficientes de correlação linear entre os itens.

O processo consiste no cálculo de todas as correlações $(\rho)$ entre o escore de cada item e o escore total do instrumento, resultando em um valor entre $\underline{0}$ e $\underline{1}$.

Conforme afirma Sekaran (2003), o alfa de Cronbach é um coeficiente de confiabilidade que indica quão bem os itens em um conjunto são positivamente 
correlacionados entre si. É calculado em termos da média de intercorrelações entre os itens que medem o conceito, o que traduz a homogeneidade do conjunto dos itens. Quanto mais próximo de 1 for o alfa de Cronbach, maior a consistência interna.

O limite inferior para o alfa de Cronbach geralmente aceito é de 0,70, apesar de poder diminuir para 0,60 em pesquisa exploratória (Hair Jr. et al., 2010; Hinkin, 2011). Compartilhando da mesma opinião desses autores, pesquisadores como Devellis (2003), Netemeyer et al. (2003) e Malhotra (2006) também consideram um alfa de 0,70 como o valor mínimo aceitável, embora coeficientes mais baixos possam ser aceitáveis, dependendo dos objetivos da pesquisa.

Com a finalidade de facilitar as análises de confiabilidade pelos pesquisadores, Hair Jr. et al. (2005) propuseram um critério para interpretação do valor do alfa de Cronbach, conforme apresentado na Tabela 5.2-1.

Tabela 5.2-1 - Regras práticas de interpretação do alfa de Cronbach

\begin{tabular}{cc}
\hline \hline Variação do coeficiente alfa $(\alpha)$ & Intensidade da associação \\
\hline$\alpha<0,60$ & Baixa \\
$0,60 \leq \alpha<0,70$ & Moderada \\
$0,70 \leq \alpha<0,80$ & Boa \\
$0,80 \leq \alpha<0,90$ & Muito boa \\
$0.90 \leq \alpha<0,95$ & Excelente \\
\hline \hline
\end{tabular}

Fonte: (Hair Jr. et al., 2005)

Para a avaliação da confiabilidade do instrumento de pesquisa desenvolvido neste trabalho, foram realizados os seguintes cálculos de confiabilidade:

- Cálculo do coeficiente alfa de Cronbach para o instrumento como um todo;

- Cálculo do coeficiente alfa de Cronbach para cada dimensão individualmente;

- Cálculo da correlação item-total.

O cálculo do coeficiente alfa de Cronbach para o instrumento como um todo (41 itens) resultou em 0,95. De acordo com Hair Jr. et al. (2005), esse valor de 0,95 para o 
alfa é considerado excelente (Tabela 5.2-1). Este resultado indica que há uma forte correlação entre os itens da escala total, demonstrando, assim, que o instrumento, como um todo, apresenta evidências de uma boa confiabilidade.

Os valores obtidos do coeficiente alfa de Cronbach para cada dimensão, individualmente, são apresentados na Tabela 5.2-2.

Tabela 5.2-2 - Coeficiente Alpha de Cronbach para cada dimensão

\begin{tabular}{lcc}
\hline \hline \multicolumn{1}{c}{ Dimensões (Construtos) } & No de itens & $\begin{array}{c}\text { Alfa de } \\
\text { Cronbach }\end{array}$ \\
\hline D1. Prioridade dada à segurança & 5 & 0,722 \\
D2. Alocação de recursos & 3 & 0,828 \\
D3. Funções e responsabilidades & 2 & 0,719 \\
D4. Comprometimento com a segurança & 3 & 0,875 \\
D5. Comunicação e relacionamento & 2 & 0,437 \\
D6. Qualificação e dimensionamento de pessoal & 4 & 0,717 \\
D7. Documentação e procedimentos & 6 & 0,793 \\
D8. Condições de trabalho & 11 & 0,773 \\
D9. Aprendizagem organizacional & 5 & 0,860 \\
\hline \hline
\end{tabular}

Vale observar que com a não consideração dos itens Q6, Q9, Q17, Q18, Q20, Q41, Q47 e o Q49, o item Q48, que seria o único na dimensão D10, foi remanejado para a dimensão D9, eliminando-se, assim, a dimensão D10. Este procedimento foi necessário em virtude de o alfa de Cronbach ser calculado com base na média dos coeficientes de correlação linear entre os itens, o que não seria possível para apenas um. Cabe ressaltar que esta ação tem efeito somente para as análises da confiabilidade do instrumento.

Analisando a Tabela 5.2-2, verifica-se que a dimensão D5 obteve um valor de coeficiente alfa considerado baixo $(0,437)$, indicando que há uma fraca correlação entre os itens dessa dimensão. Esses itens foram submetidos a análises mais detalhadas no cálculo da correlação item-total apresentadas a seguir.

Com relação às dimensões restantes, os valores de alfa situando-se na faixa de 0,717 a 0,875 indicam uma confiabilidade de consistência interna classificada entre boa e muito boa, conforme a Tabela 5.2-1. A dimensão D4 foi a que apresentou melhor 
consistência interna (valor alfa de 0,875 ), indicando uma forte correlação entre os seus itens.

A correlação item-total indica o grau com que cada item se correlaciona com o escore total do instrumento. Esses valores foram calculados e os resultados são apresentados na Tabela 5.2-3. 
Tabela 5.2-3 - Correlação item-total

\begin{tabular}{|c|c|c|c|}
\hline Dimensão & Itens / Indicadores & $\begin{array}{l}\text { Correlação } \\
\text { item-total }\end{array}$ & $\begin{array}{c}\text { Alfa da dimensão } \\
\text { se o item for } \\
\text { excluído }\end{array}$ \\
\hline \multirow{5}{*}{$\begin{array}{l}\text { D1. Prioridade dada à } \\
\text { segurança }\end{array}$} & Q1. Conhecimento da política de segurança & 0,414 & 0,700 \\
\hline & Q2. Prioridade da segurança na política & 0,712 & 0,580 \\
\hline & Q3. Conteúdo da política de segurança & 0,698 & 0,585 \\
\hline & Q4. Abordagem da segurança nas reuniões & 0,476 & 0,677 \\
\hline & Q5. Segurança versus produção & 0,197 & 0,795 \\
\hline \multirow{3}{*}{$\begin{array}{l}\text { D2. Alocação de } \\
\text { recursos }\end{array}$} & $\begin{array}{l}\text { Q7. Recursos para equipamentos de } \\
\text { segurança }\end{array}$ & 0,692 & 0,756 \\
\hline & Q8. Recursos para treinamentos & 0,775 & 0,668 \\
\hline & Q10. Revisão dos recursos & 0,599 & 0,842 \\
\hline \multirow{2}{*}{$\begin{array}{l}\text { D3. Funções e } \\
\text { responsabilidades }\end{array}$} & Q11. Definição de Responsabilidades & 0,561 & ---- \\
\hline & Q12. Conhecimento das Responsabilidades & 0,561 & --- \\
\hline \multirow{3}{*}{$\begin{array}{l}\text { D4. Comprometimento } \\
\text { com a segurança }\end{array}$} & Q13. Comprometimento da Alta Adm & 0,759 & 0,824 \\
\hline & Q14. Comprometimento da Gerência & 0,791 & 0,805 \\
\hline & Q15. Estado atual da segurança & 0,743 & 0,842 \\
\hline \multirow{2}{*}{$\begin{array}{l}\text { D5. Comunicação e } \\
\text { relacionamento }\end{array}$} & $\begin{array}{l}\text { Q16. Comunicação entre Adm e } \\
\text { funcionários }\end{array}$ & 0,284 & ---- \\
\hline & Q19. Relação com superiores & 0,284 & ---- \\
\hline \multirow{4}{*}{$\begin{array}{l}\text { D6. Qualificação e } \\
\text { dimensionamento de } \\
\text { pessoal }\end{array}$} & Q21. Adequação dos treinamentos & 0,516 & 0,649 \\
\hline & Q22. Revisão dos treinamentos & 0,599 & 0,594 \\
\hline & Q23. Equipe de trabalho & 0,516 & 0,651 \\
\hline & Q24. Qualificação & 0,401 & 0,712 \\
\hline \multirow{6}{*}{$\begin{array}{l}\text { D7. Documentação e } \\
\text { procedimentos }\end{array}$} & Q25. Conteúdo da documentação & 0,666 & 0,731 \\
\hline & Q26. Disponibilidade da documentação & 0,595 & 0,749 \\
\hline & Q27. Entendimento da documentação & 0,550 & 0,761 \\
\hline & Q28. Problemas na documentação & 0,657 & 0,735 \\
\hline & Q29. Atualização da documentação & 0,542 & 0,763 \\
\hline & Q30. Exequibilidade do processo & 0,274 & 0,816 \\
\hline \multirow{11}{*}{$\begin{array}{l}\text { D8. Condições de } \\
\text { trabalho }\end{array}$} & Q31. Carga de trabalho & 0,286 & 0,773 \\
\hline & Q32. Temperatura do ambiente & 0,482 & 0,749 \\
\hline & Q33. Luminosidade do ambiente & 0,505 & 0,748 \\
\hline & Q34. Qualidade do Ar & 0,490 & 0,748 \\
\hline & Q35. Ruídos no ambiente & 0,547 & 0,739 \\
\hline & Q36. Pressão do tempo & 0,337 & 0,765 \\
\hline & Q37. Ergonomia no trabalho & 0,508 & 0,745 \\
\hline & Q38. Limpeza do ambiente & 0,579 & 0,742 \\
\hline & Q39. Estado dos Sistemas de segurança & 0,517 & 0,744 \\
\hline & Q40. Estresse no trabalho & 0,200 & 0,779 \\
\hline & Q42. Satisfação no trabalho & 0,258 & 0,776 \\
\hline \multirow{5}{*}{$\begin{array}{l}\text { D9. Aprendizagem } \\
\text { organizacional }\end{array}$} & Q43. Lições aprendidas & 0,663 & 0,835 \\
\hline & Q44. Análise de acidentes & 0,756 & 0,810 \\
\hline & Q45. Ações corretivas & 0,685 & 0,834 \\
\hline & Q46. Divulgação das causas dos acidentes & 0,656 & 0,837 \\
\hline & Q48. Avaliações internas (frequência) & 0,654 & 0,838 \\
\hline
\end{tabular}

De acordo com Devellis (2003), um valor $<0,3$ para a correlação item-total indica que o item está medindo alguma coisa diferente da escala como um todo e o torna candidato à eliminação. 
Os valores da coluna "Alfa da dimensão se o item for excluído" têm a finalidade de verificar se com a eliminação de qualquer dos itens com correlação $<0,3$ haveria aumento ou diminuição do valor do alfa calculado para a respectiva dimensão. Observa-se que não foram gerados esses valores para as dimensões D3 e D5 pelo fato de que, como o alfa é calculado com base na média dos coeficientes de correlação entre os itens da dimensão, com a exclusão de um dos dois itens, não seria possível calcular o alfa da mesma.

O item Q5 da dimensão D1 obteve um valor de correlação item-total baixo $(0,197)$, sendo, portanto, indicado para eliminação. Mas observa-se que com a sua exclusão, o aumento no valor do alfa da dimensão seria insignificante (de 0,722 para 0,795), razão pela qual, optou-se pela não eliminação do item. Com relação aos outros itens da dimensão D1, os valores das correlações item-total confirmam que há uma boa consistência entre os itens.

Nas dimensões D2, D3 e D4 todos os itens apresentam uma forte correlação item-total, indicando uma boa consistência interna dentro de cada dimensão.

Com relação à dimensão D5, verificou-se que o problema da baixa correlação persistiu. Os itens Q16 e Q19 obtiveram correlações fracas, confirmando o baixo valor do alfa da dimensão $(0,437)$. Embora seja um caso de uma possível eliminação, optou-se por considerar a recomendação dada por Hair Jr. et al. (2010) que, em casos como esses, a dimensão pode ser mantida para uso posterior, mas com a advertência de ter uma confiabilidade menor e a necessidade de um futuro desenvolvimento de itens adicionais para medir a dimensão.

Os itens Q30, Q31, Q40 e Q42 das dimensões D7 e D8 obtiveram correlações um pouco abaixo do recomendado, sendo, portanto, candidatos à eliminação. Entretanto, observa-se na Tabela 5.2-2 que essas dimensões obtiveram um bom valor de alfa 0,793 e 0,773, respectivamente, e a eliminação desses itens proporcionaria um aumento muito pequeno ou nenhum no valor do alfa das dimensões. Optou-se, então, pela não eliminação desses itens. 
As dimensões D6 e D9 obtiveram valores das correlações acima do recomendado, demonstrando assim uma boa consistência entre os itens.

Portanto, os resultados obtidos nas análises realizadas nesta seção indicam que o instrumento, no geral, apresenta boas evidências de confiabilidade, ou seja, espera-se que se for aplicado novamente, nas mesmas instituições, os resultados sejam semelhantes, desde que não tenha havido grandes mudanças nas condições atuais.

\subsection{Validação de construto do instrumento de pesquisa}

Na definição de Hair Jr. et al. (2010), validade de construto é o grau com que um conjunto de itens medidos (indicadores), realmente, reflete o construto teórico a que estão associados. A evidência de validade de construto oferece a segurança de que as medidas tiradas de uma amostra representam o verdadeiro escore que existe na população.

Conforme observam Sekaran (2003) e Conway e Huffcutt (2003), a validade de construto pode ser obtida mediante a submissão dos dados a uma análise fatorial. Os resultados desta análise confirmarão ou não se as dimensões teorizadas (construtos) aparecem e se elas são de fato, derivadas dos itens da pesquisa.

A análise fatorial é uma técnica estatística multivariada de dados que fornece as ferramentas para analisar a estrutura das inter-relações (correlações) em um grande número de variáveis, como por exemplo, itens de um questionário. Ela define conjuntos de variáveis que são fortemente inter-relacionadas, conhecidos como componentes ou fatores que são considerados como representantes de dimensões dentro dos dados (Hair Jr. et al., 2010).

Ainda de acordo com os autores, a análise fatorial também é utilizada para examinar os padrões ou as relações latentes de um grande número de variáveis e determinar se a informação pode ser condensada ou resumida a um conjunto menor de fatores ou componentes. Ao resumir os dados, a análise fatorial obtém dimensões latentes 
que, quando interpretadas e compreendidas, descrevem os dados em um número muito menor de conceitos do que as variáveis individuais originais.

Em um processo de validação de construto Conway e Huffcutt (2003) apontam que a finalidade das técnicas de análise fatorial é encontrar um modo de resumir a informação contida em diversas variáveis originais em um conjunto menor de novas dimensões compostas (componentes), com uma perda mínima de informação. Dessa forma, a análise fatorial fornece a base para a criação de um novo conjunto de variáveis que incorporam o caráter e a natureza das variáveis originais.

Na criação de escalas múltiplas uma suposição inerente e exigência essencial é que os itens sejam unidimensionais, significando que eles estão fortemente associados um com o outro e que representam um só conceito, ou seja, se ajustando a uma única dimensão (componente). A análise fatorial tem um papel essencial na realização de uma avaliação empírica da dimensionalidade de um conjunto de itens, pela determinação do número de fatores (componentes) e das cargas fatoriais de cada variável nos mesmos. A unidimensionalidade significa que cada escala múltipla consiste de itens com cargas altas em um único componente. Se uma escala múltipla é proposta como tendo múltiplas dimensões, cada dimensão deve ser refletida por um componente separado (Hair Jr. et al., 2010).

No caso deste trabalho, a validação de construto foi realizada por meio de uma análise fatorial cuja função foi verificar se os itens da escala se agrupavam conforme o previsto na estrutura conceitual da cultura de segurança proposta para o modelo, confirmando ou não os construtos (dimensões) do plano teórico. Como método de extração de componentes foi adotado a Análise de Componentes Principais (ACP), como critério da quantidade de fatores a extrair, o da raiz latente (autovalor $>1$ ) e, como método de rotação fatorial, o ortogonal pelo critério Varimax.

A Análise de Componentes Principais (ACP) é usada quando o objetivo é resumir a maior parte da informação original a um número mínimo de fatores para fins de previsão. De acordo com Conway e Huffcutt (2003), é a técnica recomendada quando a 
preocupação maior é determinar o número mínimo de fatores que respondem pela máxima variância nos dados. Os fatores são chamados de componentes principais.

O processo de extração de fatores consiste na melhor combinação linear de variáveis originais que explicam a maior parte da variância nos dados como um todo. Dessa forma, o primeiro fator pode ser visto como o melhor resumo de relações lineares exibidas nos dados. O segundo fator é definido como a segunda melhor combinação linear e assim sucessivamente.

Pelo critério da raiz latente com autovalor $>1$, apenas os fatores que têm raízes latentes ou autovalores maiores que 1 são considerados significantes; todos os outros fatores são considerados insignificantes e são descartados.

De acordo com Conway e Huffcutt (2003) a rotação fatorial tem o propósito de melhorar a interpretação de uma matriz de fatores inicial (não rotacionada) reduzindo algumas das ambiguidades que frequentemente estão presentes na matriz de fatores inicial. A meta final de qualquer solução de rotação é obter alguns fatores teoricamente significativos e, se possível, a estrutura fatorial mais simples. Ainda de acordo com os autores, o método de rotação mais comumente utilizado é o procedimento Varimax. Tratase de um método ortogonal de rotação que minimiza o número de variáveis, com altas cargas sobre um fator, reforçando, assim, a interpretabilidade dos fatores. A rotação ortogonal tem como resultado fatores não-correlacionados.

Há um pressuposto estatístico que precede à análise fatorial que é o de garantir que as variáveis estejam suficientemente correlacionadas umas com as outras para produzir fatores representativos. Esse grau de relacionamento pode ser avaliado por medidas empíricas de diagnóstico da fatorabilidade da matriz de correlação. Caso as correlações sejam pequenas, ou todas iguais, a aplicação da análise fatorial deve ser questionada.

Uma das medidas da adequação da amostra para análise fatorial é o teste de esfericidade de Bartlett que é uma estatística de presença de correlações entre as variáveis. Ele fornece uma medida estatística de que a matriz de correlação tem correlações 
significantes (sign. $<0,05)$ entre pelo menos algumas das variáveis. Uma segunda medida da adequação da amostra muito utilizada é o Kaiser-Meyer-Olkin (KMO). Trata-se de uma estatística que indica a proporção da variância nas variáveis que poderiam ser causadas por fatores subjacentes. O teste KMO deve apresentar índices superiores a 0,50 para indicar que análise fatorial é apropriada (Netemeyer et al., 2003).

Dessa forma, precedendo à análise fatorial, foram realizados os dois testes de adequação da amostra. O KMO apresentou um valor de 0,838 e o teste de Bartlett um valor de sign. $=0,000$, conforme apresentados na Tabela 5.3-1.

Tabela 5.3-1 - Análise da adequação da amostra

\begin{tabular}{ll}
\hline \hline \multicolumn{2}{c}{ Teste de KMO e Bartlett } \\
\hline Medida Kaiser-Meyer-Olkin (KMO) & 0,838 \\
\hline Teste de esfericidade de Bartlett (Sign.) & 0,000 \\
\hline \hline
\end{tabular}

Esses valores apontam para uma forte correlação entre as varáveis, indicando, portanto que a análise fatorial é considerada uma técnica adequada a ser aplicada na validação de construto do instrumento.

Como uma primeira etapa foi realizada uma análise fatorial pelo método Análise de Componentes Principais (ACP), autovalor $>1$ e ajustada para 10 componentes. Foi gerada uma matriz de fatores não rotacionada, conforme apresentada na Tabela 5.3-2. 
Tabela 5.3-2 - Matriz fatorial não rotacionada

\begin{tabular}{|c|c|c|c|c|c|c|c|c|c|c|}
\hline \multirow{2}{*}{ Itens } & \multicolumn{10}{|c|}{ Componentes } \\
\hline & 1 & 2 & 3 & 4 & 5 & 6 & 7 & 8 & 9 & 10 \\
\hline Q1 & 0,607 & $-0,099$ & $-0,387$ & 0,005 & 0,009 & 0,189 & 0,061 & $-0,080$ & $-0,410$ & $-0,024$ \\
\hline Q2 & 0,683 & $-0,187$ & $-0,276$ & 0,172 & 0,029 & 0,004 & 0,298 & $-0,016$ & 0,006 & $-0,141$ \\
\hline Q3 & 0,712 & $-0,124$ & $-0,250$ & $-0,088$ & 0,181 & $-0,052$ & 0,333 & $-0,208$ & $-0,133$ & $-0,017$ \\
\hline Q4 & 0,706 & $-0,170$ & $-0,073$ & $-0,087$ & 0,097 & $-0,217$ & 0,193 & 0,116 & 0,263 & $-0,146$ \\
\hline Q5 & 0,225 & $-0,238$ & 0,265 & 0,425 & $-0,064$ & 0,154 & 0,404 & $-0,212$ & 0,090 & 0,454 \\
\hline Q7 & 0,685 & $-0,251$ & $-0,135$ & $-0,081$ & 0,197 & $-0,317$ & $-0,233$ & $-0,084$ & 0,184 & $-0,121$ \\
\hline Q8 & 0,732 & $-0,269$ & $-0,114$ & $-0,142$ & 0,047 & $-0,263$ & $-0,270$ & $-0,134$ & 0,082 & 0,080 \\
\hline Q10 & 0,614 & $-0,310$ & 0,032 & $-0,005$ & 0,086 & 0,002 & $-0,265$ & $-0,188$ & 0,143 & 0,258 \\
\hline Q11 & 0,659 & $-0,164$ & $-0,335$ & $-0,189$ & 0,205 & 0,128 & $-0,007$ & 0,117 & $-0,085$ & $-0,083$ \\
\hline Q12 & 0,547 & 0,040 & $-0,405$ & $-0,005$ & 0,210 & 0,270 & $-0,125$ & 0,222 & $-0,227$ & 0,174 \\
\hline Q13 & 0,776 & $-0,219$ & $-0,115$ & $-0,031$ & 0,175 & $-0,049$ & 0,094 & 0,029 & 0,176 & 0,001 \\
\hline Q14 & 0,764 & $-0,101$ & $-0,196$ & $-0,150$ & 0,044 & $-0,017$ & 0,144 & $-0,032$ & 0,248 & 0,024 \\
\hline Q15 & 0,846 & $-0,034$ & $-0,066$ & $-0,208$ & 0,081 & 0,009 & $-0,068$ & $-0,111$ & 0,069 & 0,126 \\
\hline Q16 & 0,725 & $-0,092$ & 0,005 & $-0,081$ & 0,312 & $-0,051$ & 0,081 & 0,074 & $-0,047$ & 0,193 \\
\hline Q19 & 0,467 & 0,059 & 0,143 & $-0,108$ & $-0,079$ & $-0,430$ & 0,125 & 0,555 & 0,073 & $-0,017$ \\
\hline Q21 & 0,650 & $-0,070$ & 0,105 & $-0,067$ & $-0,163$ & 0,210 & 0,066 & 0,172 & 0,011 & $-0,107$ \\
\hline Q22 & 0,594 & $-0,150$ & 0,204 & $-0,067$ & $-0,254$ & 0,326 & $-0,299$ & 0,189 & 0,221 & $-0,122$ \\
\hline Q23 & 0,478 & 0,367 & $-0,069$ & $-0,289$ & $-0,356$ & 0,114 & $-0,178$ & $-0,187$ & 0,124 & 0,100 \\
\hline Q24 & 0,434 & 0,248 & $-0,062$ & $-0,134$ & $-0,212$ & 0,246 & $-0,352$ & 0,249 & $-0,116$ & 0,078 \\
\hline Q25 & 0,728 & 0,086 & 0,044 & $-0,136$ & $-0,299$ & $-0,265$ & $-0,025$ & 0,040 & $-0,072$ & 0,261 \\
\hline Q26 & 0,629 & 0,229 & $-0,074$ & 0,090 & $-0,395$ & 0,005 & 0,236 & 0,068 & $-0,210$ & $-0,118$ \\
\hline Q27 & 0,555 & 0,383 & $-0,210$ & 0,070 & $-0,425$ & $-0,099$ & 0,245 & 0,095 & 0,041 & 0,038 \\
\hline Q28 & 0,648 & 0,156 & 0,029 & 0,012 & $-0,423$ & $-0,288$ & 0,059 & $-0,152$ & 0,088 & 0,032 \\
\hline Q29 & 0,632 & $-0,007$ & 0,287 & 0,049 & $-0,322$ & 0,032 & $-0,048$ & $-0,180$ & 0,004 & 0,062 \\
\hline Q30 & 0,401 & 0,224 & 0,095 & $-0,403$ & 0,087 & 0,190 & 0,125 & 0,205 & 0,073 & 0,180 \\
\hline Q31 & 0,267 & 0,602 & 0,110 & $-0,302$ & 0,136 & 0,113 & 0,317 & $-0,220$ & 0,197 & $-0,087$ \\
\hline Q32 & 0,468 & 0,191 & $-0,171$ & 0,506 & 0,085 & 0,192 & $-0,117$ & 0,232 & 0,334 & 0,080 \\
\hline Q33 & 0,452 & 0,404 & $-0,304$ & 0,403 & 0,134 & 0,107 & $-0,192$ & $-0,034$ & 0,179 & 0,106 \\
\hline Q34 & 0,498 & 0,127 & 0,346 & 0,506 & 0,122 & 0,031 & $-0,111$ & $-0,075$ & 0,105 & $-0,032$ \\
\hline Q35 & 0,480 & 0,334 & 0,026 & 0,498 & 0,215 & $-0,077$ & 0,049 & 0,004 & 0,013 & $-0,220$ \\
\hline Q36 & 0,181 & 0,561 & 0,334 & $-0,269$ & 0,354 & 0,032 & 0,011 & $-0,070$ & 0,083 & $-0,203$ \\
\hline Q37 & 0,475 & 0,388 & $-0,099$ & 0,179 & 0,114 & $-0,379$ & $-0,141$ & 0,086 & $-0,289$ & $-0,039$ \\
\hline Q38 & 0,586 & 0,343 & 0,031 & 0,169 & 0,105 & $-0,097$ & $-0,083$ & $-0,154$ & $-0,300$ & 0,189 \\
\hline Q39 & 0,650 & 0,210 & 0,133 & $-0,014$ & 0,148 & $-0,152$ & $-0,252$ & $-0,259$ & $-0,074$ & $-0,212$ \\
\hline Q40 & 0,210 & 0,277 & 0,331 & $-0,281$ & 0,427 & 0,172 & 0,100 & 0,076 & $-0,025$ & 0,265 \\
\hline Q42 & 0,312 & $-0,183$ & 0,533 & 0,128 & 0,150 & $-0,270$ & 0,041 & 0,322 & $-0,153$ & 0,158 \\
\hline Q43 & 0,662 & $-0,170$ & 0,408 & $-0,067$ & 0,045 & 0,087 & $-0,035$ & $-0,090$ & $-0,325$ & $-0,100$ \\
\hline Q44 & 0,759 & $-0,146$ & 0,218 & 0,139 & $-0,056$ & 0,145 & $-0,040$ & 0,044 & $-0,110$ & $-0,013$ \\
\hline Q45 & 0,736 & $-0,248$ & 0,256 & $-0,094$ & $-0,139$ & $-0,017$ & $-0,081$ & $-0,137$ & $-0,058$ & $-0,158$ \\
\hline Q46 & 0,731 & $-0,123$ & 0,089 & $-0,025$ & $-0,094$ & 0,298 & 0,115 & $-0,051$ & $-0,024$ & $-0,127$ \\
\hline Q48 & 0,673 & $-0,192$ & 0,208 & 0,173 & 0,042 & 0,292 & 0,082 & 0,104 & $-0,012$ & $-0,287$ \\
\hline
\end{tabular}

Na Tabela 5.3-2 são mostradas as cargas fatoriais de cada variável sobre cada fator. Carga fatorial é a correlação de cada variável com o componente (fator) e indica o grau de correspondência entre eles, com as cargas maiores tornando a variável representativa do fator. Quanto maior o seu valor absoluto, maior é a relação da variável com o fator (Malhotra, 2006).

Observa-se ainda na tabela que as cargas fatoriais contribuem muito pouco para definir os componentes na estrutura fatorial. Algumas variáveis apresentam cargas significantes em vários fatores; em outras, as cargas são baixas e alguns fatores são correlacionados com muitas variáveis. 
Diante das indefinições na matriz fatorial da Tabela 5.3-2, optou-se por realizar uma rotação fatorial na tentativa de melhorar a compreensão da relação entre as variáveis e de obter um padrão fatorial mais simples e teoricamente mais significativo. Dessa forma, foi realizada uma rotação fatorial pelo método ortogonal e critério Varimax, ajustada para 10 componentes. Seguindo a orientação de Hair Jr. et al. (2010), foi estabelecido o valor de corte para a significância de carga em 0,40. De acordo com os autores, para um tamanho de amostra de 200 casos, cargas fatoriais de 0,40 ou mais de significância de carga são consideradas representativas de um fator para fins de interpretação.

Na Tabela 5.3-3 é apresentada a matriz fatorial rotacionada, destacando as cargas fatoriais com valor acima de 0,40 .

Tabela 5.3-3 - Matriz fatorial rotacionada (10 fatores)

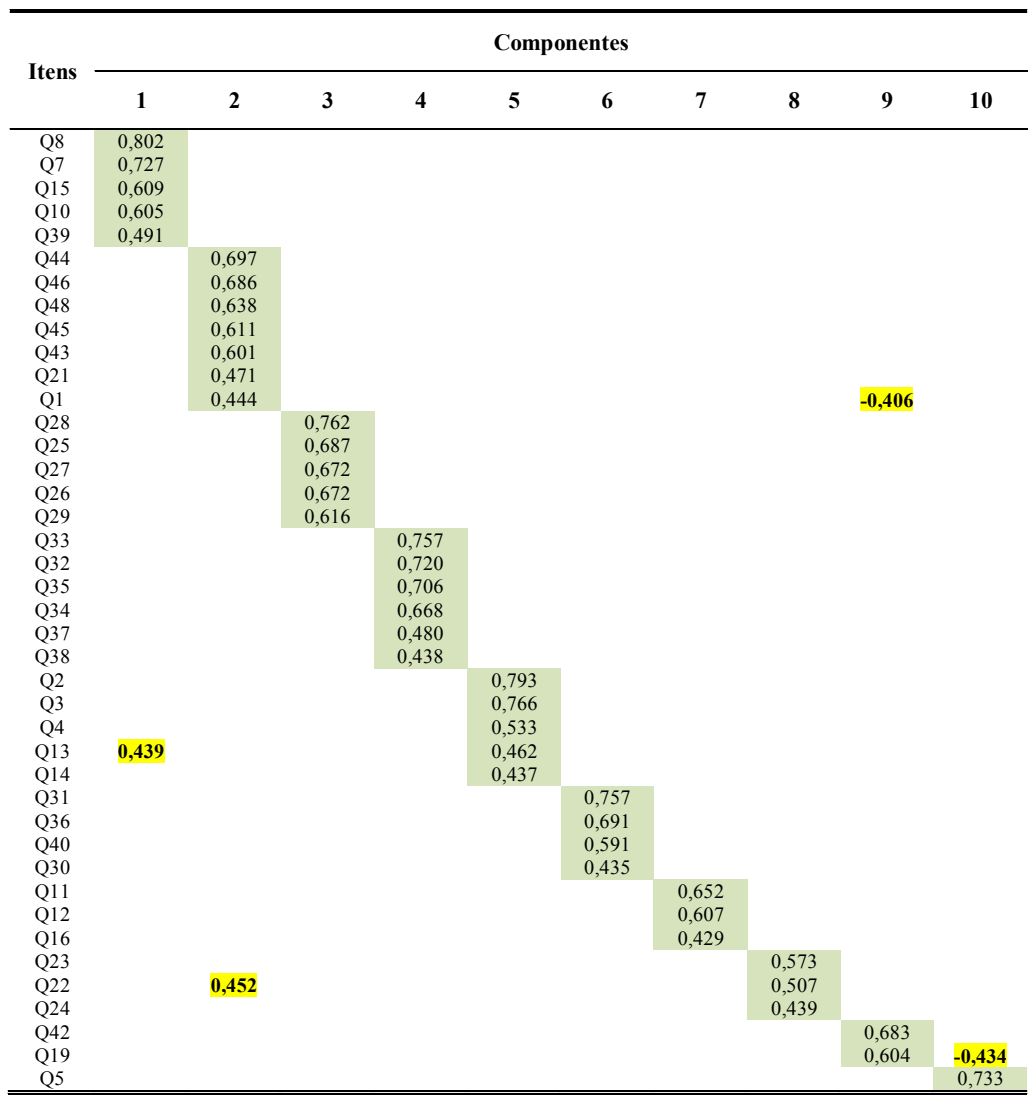


Inicialmente, observa-se na Tabela 5.3-3 que a solução fatorial manteve os 10 fatores extraídos previamente e que houve uma melhora considerável na distribuição das cargas fatoriais por componentes, proporcionando uma estrutura fatorial mais definida.

Entretanto, existem quatro casos de cargas cruzadas nas questões Q1, Q13, Q19 e Q22 (em realce na Tabela). Carga cruzada ocorre quando uma ou mais variáveis tem cargas significantes em mais de um fator. Como os fatores devem ser distintos e representar conceitos separados, eles não podem compartilhar variáveis. A esse respeito, Hair Jr. et al. (2010) recomendam que quando uma variável persiste em ter cargas cruzadas, ela se torna candidata à eliminação.

Dessa forma, na tentativa de encontrar uma melhor estrutura fatorial foram aplicadas novas rotações fatoriais, mas desta vez, sem ajustar a quantidade de componentes. A rotação convergiu com 29 iterações, gerando uma matriz fatorial com nove fatores, conforme apresentada na Tabela 5.3-4. 
Tabela 5.3-4 - Matriz fatorial rotacionada (9 fatores)

\begin{tabular}{|c|c|c|c|c|c|c|c|c|c|c|}
\hline \multirow{2}{*}{ Itens } & \multicolumn{9}{|c|}{ Componentes } & \multirow{2}{*}{ Comum. } \\
\hline & 1 & 2 & 3 & 4 & 5 & 6 & 7 & 8 & 9 & \\
\hline Q8 & 0,820 & & & & & & & & & 0,743 \\
\hline Q7 & 0,740 & & & & & & & & & 0,717 \\
\hline Q15 & 0,672 & & & & & & & & & 0,800 \\
\hline Q10 & 0,613 & & & & & & & & & 0,738 \\
\hline Q11 & 0,559 & & & & & & & & & 0,808 \\
\hline Q13 & 0,536 & & & & & & & & & 0,806 \\
\hline Q39 & 0,465 & & & & & & & & & 0,816 \\
\hline Q44 & & 0,700 & & & & & & & & 0,674 \\
\hline Q46 & & 0,692 & & & & & & & & 0,695 \\
\hline Q48 & & 0,648 & & & & & & & & 0,729 \\
\hline Q45 & & 0,595 & & & & & & & & 0,739 \\
\hline $\mathrm{Q} 43$ & & 0,584 & & & & & & & & 0,742 \\
\hline Q21 & & 0,462 & & & & & & & & 0,808 \\
\hline Q1 & & 0,451 & & & & & & & & 0,691 \\
\hline Q28 & & & 0,769 & & & & & & & 0,773 \\
\hline Q27 & & & 0,672 & & & & & & & 0,559 \\
\hline Q25 & & & 0,671 & & & & & & & 0,781 \\
\hline Q26 & & & 0,649 & & & & & & & 0,683 \\
\hline Q29 & & & 0,610 & & & & & & & 0,583 \\
\hline Q24 & & & 0,439 & & & & & & & 0,794 \\
\hline Q2 & & & & 0,764 & & & & & & 0,737 \\
\hline $\mathrm{Q} 3$ & & & & 0,741 & & & & & & 0,766 \\
\hline Q14 & & & & 0,497 & & & & & & 0,742 \\
\hline $\mathrm{Q} 4$ & & & & 0,496 & & & & & & 0,628 \\
\hline Q16 & & & & 0,488 & & & & & & 0,521 \\
\hline Q33 & & & & & 0,765 & & & & & 0,764 \\
\hline Q32 & & & & & 0,729 & & & & & 0,771 \\
\hline Q35 & & & & & 0,702 & & & & & 0,733 \\
\hline Q34 & & & & & 0,662 & & & & & 0,685 \\
\hline Q37 & & & & & 0,485 & & & & & 0,694 \\
\hline Q38 & & & & & 0,439 & & & & & 0,711 \\
\hline Q31 & & & & & & 0,744 & & & & 0,687 \\
\hline Q36 & & & & & & 0,697 & & & & 0,668 \\
\hline Q40 & & & & & & 0,611 & & & & 0,710 \\
\hline Q30 & & & & & & 0,445 & & & & 0,608 \\
\hline Q22 & & & & & & & 0,579 & & & 0,681 \\
\hline Q23 & & & & & & & 0,435 & & & 0,774 \\
\hline Q42 & & & & & & & & 0,662 & & 0,704 \\
\hline Q19 & & & & & & & & 0,659 & & 0,751 \\
\hline Q5 & & & & & & & & & $-0,740$ & 0,688 \\
\hline Q12 & & & & & & & & & 0,409 & 0,751 \\
\hline
\end{tabular}

Inicialmente verifica-se que foi gerada uma matriz fatorial mais simplificada e sem a ocorrência de cargas cruzadas.

O primeiro aspecto que se observa é que a unidimensionalidade dos itens foi assegurada mediante o agrupamento das cargas fatoriais significantes de cada variável em apenas um componente.

Comparando a matriz fatorial da Tabela 5.3-4 com a estrutura conceitual que deu origem ao instrumento de pesquisa (Quadro 3.3-2), observam-se em cada um dos sete primeiros componentes da matriz agrupamentos de itens oriundos de uma mesma dimensão da estrutura conceitual. No componente 1 predominou o agrupamento de itens da dimensão alocação de recursos; no componente 2 predominou o agrupamento dos itens relacionados às dimensões aprendizagem organizacional e avaliações internas e externas; no componente 3 agruparam-se os itens da dimensão documentação e 
procedimentos; no componente 4, os itens da dimensão condições de trabalho; no componente 5 , os itens da dimensão prioridade dada à segurança; no componente 6 , os itens da dimensão condições de trabalho e no componente 7 , os itens relacionados à qualificação e dimensionamento de pessoal. Há também nesses sete componentes alguns itens oriundos de dimensões distintas. Nos componentes 8 e 9 agruparam-se itens de quatro dimensões distintas.

O agrupamento na matriz de alguns itens oriundos de dimensões distintas é consequência de um desequilíbrio na estrutura conceitual do instrumento ocasionado pela não consideração dos itens Q6, Q9, Q17, Q18, Q20, Q41, Q47 e Q49 na análise fatorial. Essa medida, conforme discutido no Capítulo 4, foi necessária em virtude dessas variáveis terem recebido uma quantidade significativa de classificação "Não aplicável" na pesquisa. Decorre também dessa não consideração das oito variáveis que a melhor solução fatorial gerou uma matriz com base em nove componentes em vez de dez, como as dimensões da estrutura conceitual.

$\mathrm{Na}$ Tabela 5.3-4 também estão sendo apresentados os valores das comunalidades das variáveis. A comunalidade é um índice que avalia o quanto de variância em uma variável é explicada pela solução fatorial. De acordo com Hair Jr. et al. (2010), considerações práticas sugerem um valor mínimo de 0,5 para as comunalidades. Observase que todas as comunalidades são altas indicando, portanto, que todas as variáveis são adequadamente explicadas pela solução fatorial.

Essa matriz com nove componentes explica $61,3 \%$ da variância total e a variância explicada por cada componente é mostrada na Tabela 5.3-5. 
Tabela 5.3-5 - Variância total explicada

\begin{tabular}{ccc}
\hline \hline \multirow{2}{*}{ Componente } & \multicolumn{2}{c}{ Variância total explicada } \\
\cline { 2 - 3 } & \% de variância & \% cumulativa \\
\hline 1 & 11,450 & 11,450 \\
2 & 9,316 & 20,766 \\
3 & 8,581 & 29,347 \\
4 & 7,894 & 37,241 \\
5 & 7,740 & 44,981 \\
6 & 5,469 & 50,450 \\
7 & 3,917 & 54,367 \\
8 & 3,641 & 58,008 \\
9 & 3,303 & 61,310 \\
\hline \hline
\end{tabular}

Portanto, os resultados obtidos na análise fatorial revelam que existem boas evidências de validade de construto no instrumento de pesquisa. Foi observada a unidimensionalidade dos itens e, com o agrupamento de itens oriundos de uma mesma dimensão original, foi confirmada, no geral, as dimensões previstas na estrutura conceitual da cultura de segurança proposta para o modelo. 


\section{CONCLUSÕES}

\subsection{Considerações gerais}

O trabalho teve como objetivo geral desenvolver um modelo capaz de avaliar com medidas válidas e confiáveis a cultura de segurança em instalações nucleares. Para alcançar esse objetivo maior, foram propostos dois objetivos específicos. O primeiro foi a elaboração de um instrumento de coleta de dados e aplicação nos institutos de pesquisas da Comissão Nacional de Energia Nuclear (CNEN). A aplicação deste instrumento teve o propósito de identificar áreas de solidez ou de fragilidades na cultura de segurança dessas organizações e de obter os dados necessários para a avaliação das propriedades psicométricas do instrumento. O segundo objetivo específico foi avaliar as propriedades psicométricas do modelo, por meio da análise da confiabilidade e das validações de conteúdo, de face e de construto do instrumento de pesquisa.

Para cumprir com o primeiro objetivo específico, foi elaborado um instrumento preliminar de coleta de dados e submetido à validação de conteúdo e de face. Os resultados desses estudos foram bastante conclusivos, provocando uma reestruturação geral no instrumento preliminar de coleta de dados e possibilitando a elaboração do instrumento de pesquisa definitivo.

O questionário foi aplicado nos institutos de pesquisa da CNEN, obtendo-se um total de 226 questionários respondidos, caracterizando uma considerável receptividade à pesquisa.

Com relação à caracterização dos participantes da pesquisa, os resultados obtidos pelas variáveis demográficas permitiram concluir que na amostra, constituída pelos institutos da CNEN, a maior parte dos respondentes pertence ao IPEN, tem mais de 30 anos de atividade em sua respectiva instituição, atua na área de pesquisa e desenvolvimento, exerce a função de pesquisador, tem mais de 30 anos de experiência na área nuclear, tem mais de 56 anos de idade e possui doutorado. 
Os resultados também revelaram que nos institutos da CNEN há um bom nível de qualificação e experiência profissional, haja vista a maior parte dos servidores possuírem mais que 30 anos de experiência na área nuclear e de atividade na instituição. Entretanto, a grande maioria desses servidores ultrapassa os 56 anos de idade, o que pode resultar em muitas aposentadorias em curto prazo. Esse resultado sugere que os institutos da CNEN deveriam revisar a sua política de renovação de quadros.

É importante observar também a congruência dos resultados obtidos para a área de atuação, função exercida e escolaridade. A maior parte dos respondentes atua em pesquisa e desenvolvimento e exerce a função de pesquisador, o que vem ao encontro das atribuições institucionais da CNEN. Outro fato importante é que ficou evidente a preocupação nos institutos com relação à capacitação de pessoal, pois a maior parte dos quadros possui doutorado.

Quanto aos indicadores de mensuração da cultura de segurança, o presente estudo permitiu conhecer a percepção e a opinião dos respondentes acerca das condições da cultura de segurança nos institutos da CNEN. Para efeito de um diagnóstico conclusivo, três aspectos principais de intervenção devem ser analisados: a prioridade dada à segurança pela administração, o comprometimento da administração com a segurança e a aprendizagem organizacional praticada pela organização.

No que diz respeito à prioridade dada à segurança, os resultados analisados indicam que nos institutos da CNEN a política de segurança é estabelecida e difundida e que não há conflitos entre a segurança e a produção. Os dados indicam também que as funções e responsabilidades estão claramente definidas e compreendidas e que existe uma confiança mútua no relacionamento entre a administração e os funcionários e uma atitude de respeito entre a organização e os reguladores. Essas características observadas são evidências de que a segurança tem prioridade em detrimento de outros interesses nos institutos da CNEN.

Com relação ao comprometimento da administração com a segurança, há aspectos positivos e negativos a serem considerados. Por um lado, os resultados indicam que existe uma preocupação constante com a qualificação e treinamento do pessoal bem 
como em dotar as equipes de trabalho em quantidade suficiente de pessoas para a realização das tarefas. Percebeu-se também que existe uma consciência da importância da emissão e atualização de documentos e procedimentos utilizados pelos diversos setores dos institutos avaliados. Foi também observado o cuidado com as condições de trabalho, merecendo destaque, por exemplo, as condições ambientais, a carga de trabalho e o nível de estresse dos servidores. Vale ressaltar que um baixo nível de estresse e um alto nível de satisfação no trabalho, por parte dos integrantes de uma organização, indicam por si só um clima favorável para uma cultura de segurança sólida.

Por outro lado, o aspecto negativo a ser considerado com relação ao comprometimento com a segurança nos institutos, de uma forma geral, é a indicação da falta de recursos para áreas importantes como manutenção, treinamentos e equipamentos de segurança. É imprescindível que os institutos revejam esta condição para não comprometer seriamente a segurança, em especial no caso do CDTN, IEN e IPEN que possuem reator de pesquisa.

No tocante à aprendizagem organizacional praticada nos institutos, os resultados indicam que há uma atitude de melhoria contínua buscando experiências de outras instituições e realizando análise de acidentes. No entanto, há a necessidade de se aprimorar os programas de avaliações internas e de ações corretivas, como também ficou evidente que não existe uma política de divulgação das causas dos acidentes investigados. Essas deficiências vão de encontro aos princípios de uma cultura de aprendizagem organizacional.

Ainda que qualquer conclusão definitiva acerca do estado da cultura de segurança possa ser precipitada, os resultados sugerem a existência de áreas estáveis e fortalecidas na cultura de segurança das instituições. Em contrapartida, também revelam algumas fragilidades e vulnerabilidades na cultura de segurança, ou seja, áreas em que precisam ser direcionados esforços de melhoria, como por exemplo, a questão dos recursos e a divulgação de resultados das avaliações realizadas nos institutos.

Com relação ao segundo objetivo específico proposto, os estudos de avaliação das propriedades psicométricas levaram a várias conclusões, conforme descritas a seguir. 
O cálculo do coeficiente alfa de Cronbach para o instrumento como um todo e por dimensão, individualmente, aliado com a análise da correlação dos itens em relação à escala total proporcionaram resultados conclusivos para se afirmar que o instrumento de medida possui boas evidências de confiabilidade. Entretanto, os resultados também revelaram que a dimensão D5 apresenta um valor de alfa abaixo do recomendado, mas que se optou por mantê-la no instrumento adotando-se as recomendações previstas na literatura.

Quanto à validação de construto, o agrupamento observado na matriz fatorial de itens oriundos de uma mesma dimensão da estrutura conceitual e a disposição dos itens com cargas fatoriais significantes em um único componente, confirmando a unidimensionalidade dos itens, são fatos conclusivos de que o instrumento de pesquisa apresenta boas evidências de validade de construto.

Portanto, os resultados obtidos nos estudos das propriedades psicométricas são conclusivos, na medida em que permitem afirmar que o instrumento de pesquisa é capaz de obter medidas válidas e confiáveis na avaliação da cultura de segurança em instalações nucleares.

No entanto, na hipótese de uma nova aplicação do instrumento na mesma população, recomenda-se que sejam desenvolvidos itens adicionais para medir a dimensão D5 e selecionada uma instituição específica da CNEN como população alvo.

É importante destacar que o reagrupamento diverso de alguns itens na análise fatorial, observado na Seção 5.3, não compromete os resultados da pesquisa apresentados no Capítulo 4. Os valores obtidos pelos indicadores de mensuração retratam a efetiva percepção e opinião dos respondentes acerca da cultura de segurança em sua instituição. Além disso, o instrumento de avaliação obteve resultados consistentes por ocasião da validação de conteúdo, de face e da análise da confiabilidade.

Assim, disponibiliza-se um instrumento adequado para diagnosticar a cultura de segurança de instalações nucleares e uma importante ferramenta de gestão da segurança nessas organizações. Dessa forma, o modelo pode contribuir para a definição de estratégias 
de intervenção apropriadas, proporcionando significativos subsídios para políticas e ações de melhoria na segurança da organização.

Depreende-se da consistência dos resultados obtidos e das conclusões apresentadas nos parágrafos anteriores, que os objetivos propostos para este trabalho foram plenamente atingidos. $\mathrm{O}$ modelo desenvolvido preenche uma lacuna existente na literatura e contribui de forma original para o meio acadêmico e técnico-científico, disponibilizando um instrumento de pesquisa com qualidades psicométricas para avaliação da cultura de segurança em instalações nucleares.

\subsection{Limitações e sugestões para futuros desenvolvimentos}

Nesta seção são apresentadas as principais limitações inerentes ao desenvolvimento do modelo, bem como recomendações para futuros desenvolvimentos.

Dentre as principais limitações reconhecidas neste estudo estão aquelas relacionadas ao instrumento de pesquisa e à sua aplicação.

Em razão de a CNEN possuir uma área de atuação bastante diversificada, como por exemplo, pesquisa, proteção radiológica, produção de radioisótopos e radiofármacos, licenciamento de instalações e ensino, houve uma quantidade significativa da opção "Não aplicável", a qual teve influência na avaliação das propriedades psicométricas do instrumento de pesquisa. O questionário foi dirigido à CNEN como um todo, ou seja, não foi verificada a aplicabilidade dos indicadores para cada instituição individualmente. Sugere-se, portanto, que na hipótese de uma nova aplicação do instrumento seja selecionado um instituto específico e procedida uma validação de conteúdo direcionada para essa nova população. Os especialistas selecionados para as análises poderiam ser da instituição à qual fosse aplicado o instrumento de pesquisa, que verificariam a aplicabilidade ou não de cada item ao novo cenário, reduzindo, dessa forma, as respostas com classificação "Não aplicável".

É fato que foi observado uma taxa de resposta de questionários respondidos reduzida em alguns institutos. Uma forma de lidar com essa dificuldade seria a realização 
de palestras de conscientização, ou mesmo treinamentos, sobre os principais conceitos de cultura de segurança e a importância da sua avaliação, antecedendo a pesquisa.

Em uma revisão no questionário, realizada após a sua aplicação, foram detectados alguns problemas de duplicidade de conceitos na formulação das questões. No caso de uma reaplicação do instrumento, sugere-se que seja realizada uma nova análise no questionário com a finalidade de corrigir esses problemas.

Analisando as respostas das variáveis demográficas, constatou-se que na questão que trata da área de atuação do respondente deveriam ter sido previstas opções de respostas para Biblioteca, Administração (Alta Direção), Administração (Diretoria) e Licenciamento (Nuclear e Ambiental). Na questão que trata do cargo ou função ocupada pelo respondente deveriam ter sido previstas opções de resposta para Analista em C\&T, Tecnologista e Coordenador. Deveria também ter sido incluída uma questão relacionada ao sexo do respondente.

Apesar de o questionário utilizado como instrumento de pesquisa ser uma ferramenta amplamente disseminada para avaliação de cultura de segurança, seus resultados não devem ser interpretados isoladamente. Para um diagnóstico mais detalhado da cultura de segurança nos institutos avaliados, os aspectos mais profundos das atitudes, opiniões ou percepções dos funcionários podem ser captados por meio de recursos complementares, como por exemplo, um questionário escrito com elemento narrativo ou por entrevista pessoal. A vantagem desse tipo de questionário é que ele mantém as vantagens do questionário quantitativo e proporciona também um meio de explicar assuntos mais complexos. A principal vantagem da entrevista é que ela fornece meios relativamente eficientes de coleta de informações relativas à atitude, opinião ou percepção individual, mas tem a grande desvantagem de não fornecer informações estatisticamente confiáveis.

Por fim, é muito importante ressaltar que, apesar de ter sido validado utilizando os institutos da CNEN como base para a pesquisa, o modelo pode ser aplicado a outros cenários. Por meio de uma validação de conteúdo apropriada, o instrumento pode, por exemplo, ser aplicado nas usinas de Angra. Da mesma forma, através de um processo de 
tradução e adaptação transcultural o instrumento pode ser aplicado em instalações nucleares de outros países, assim como fizeram alguns autores de trabalhos na área de saúde, mencionados nesta tese. 


\section{REFERÊNCIAS BIBLIOGRÁFICAS}

AIChE (2005) AMERICAN INSTITUTE OF CHEMICAL ENGINEERS, Piper Alpha Case History. AIChE, Center for Chemical Process Safety, New York.

AIChE (2007) AMERICAN INSTITUTE OF CHEMICAL ENGINEERS, Human factors methods for improving performance in the process industries. AIChE, John Wiley \& Sons, Inc., Hoboken, New Jersey.

ALEXANDER, E. L. Safety Culture in the Nuclear Power Industry: Attributes for Regulatory Assessment. Massachusetts Institute of Technology, USA, 2004.

BATALHA, E. M. S. S. A cultura de segurança do paciente na percepção de profissionais de enfermagem de um hospital de ensino. 2012. Dissertação (Mestrado) Universidade de São Paulo, São Paulo.

CARVALHO, R. E. F. L. Adaptação transcultural do Safety Attitudes Questionnaire para o Brasil - questionário de atitudes de segurança. 2011. Tese (Doutorado) Universidade de São Paulo, São Paulo.

CASTRO, B. L.; GRACIA, F. J.; PEIRÓ, J. M. Testing the validity of the International Atomic Energy Agency (IAEA) safety culture model. Accident Analysis and Prevention, 60, p. 231-244, 2013.

CHA, E.; KIM, K. H.; ERLEN, J. A. Translation of scales in cross-cultural research: issues and techniques. Journal of Advanced Nursing, v.58, 2007.

CHARLTON S, G; O'BRIEN T, G. Handbook of human factors testing and evaluation, Second Edition, Lawrence Erlbaum Associates, Inc., Publishers, 2002.

CONWAY, J. M.; HUFFCUTT, A. I. A Review and Evaluation of Exploratory Factor Analysis, Organizational Research Methods, v. 6, n. 2, p. 147-168, 2003.

COOPER, M. D. Towards a Model of Safety Culture. Safety Science, 36, p. 111-136, 2000 .

COSTA, I. M. D. Adaptação e validação para português do questionário Nursing Home Survey on Patient Safety Culture (NHSPSC). 2013. Dissertação (Mestrado) Universidade de Coimbra, Portugal.

COX, S. J.; CHEYNE, A. J. T. Assessing safety culture in offshore environments. Safety Science, n.34, p. 215-257, 2000.

DEVELLIS, R. F. Scale Development: theory and applications. 2. ed. Thousand Oaks: Sage Publications, 2003.

DIAZ-CABRERA, D.; HERNANDEZ-FERNAUD, E.; ISLA-DIAZ, R. An evaluation of a new instrument to measure organizational safety culture values and practices. Accident Analysis \& Prevention, 39(6), p. 1202-1211, 2007. 
FILHO, A. P. G. Cultura e gestão de segurança no trabalho em organizações industriais: uma proposta de modelo. 2011. Tese (Doutorado) - Universidade Federal da Bahia, Bahia.

GONÇALVES, C. M. D. P. Validação do instrumento ICOS - Inventário de Clima Organizacional de Segurança - na área industrial de uma usina de álcool e açúcar. 2007. Dissertação (Mestrado) - Universidade de São Paulo, São Paulo.

GULDENMUND, F. W. The nature of safety culture: a review of theory and research. Safety Science, n.34, p. 193-214, 2000.

GULDENMUND, F. W. Understanding and Exploring Safety Culture. Uitgeverij: BOXPress, 2010.

HAIR JR., J. F.; BABIN, B.; MONEY, A. H.; SAMOUEL, P. Fundamentos de Métodos de Pesquisa em Administração. Porto Alegre: Bookman, 2005.

HAIR JR., J. F.; BLACK, W. C.; BABIN, B. J.; ANDERSON, R. E. Multivariate Data Analysis. 7. ed. New Jersey: Prentice Hall, 2010.

HINKIN, T. R. A Brief Tutorial on the Development of Measures for Use in Survey Questionnaires. Organizational Research Methods, SAGE Publications, V.1, p. 104-121, 2011.

HOLlnagel, E. Understanding Accidents - From Root Causes to Performance Variability, In: Proceedings of the 2002 IEEE 7th Conference on Human Factors and Power Plants, Scottsdal, Arizona, p. 1-6, 2002.

HSG48 (2007) HEALTH AND SAFETY EXECUTIVE, Reducing error and influencing behavior. United Kingdom.

HSG65 (2008) HEALTH AND SAFETY EXECUTIVE, Successful health and safety management. HSE Books, (Second edition), United Kingdom.

IAEA (1998) INTERNATIONAL ATOMIC ENERGY AGENCY, Developing Safety Culture in Nuclear Activities. IAEA, Vienna.

IAEA (1999) INTERNATIONAL ATOMIC ENERGY AGENCY, Report on the Preliminary Fact Finding Mission Following the Accident at the Nuclear Fuel Processing Facility in Tokaimura. IAEA, Vienna.

IAEA (2006) INTERNATIONAL ATOMIC ENERGY AGENCY, Fundamental Safety Principles. IAEA, Vienna.

IAEA (2009) INTERNATIONAL ATOMIC ENERGY AGENCY, Safety Assessment for Facilities and Activities. IAEA, Vienna.

IAEA (2010) INTERNATIONAL ATOMIC ENERGY AGENCY, Periodic Safety Review of Nuclear Power Plants: Experience of Member States. IAEA, Vienna.

IAEA (2012) INTERNATIONAL ATOMIC ENERGY AGENCY, Safety Culture in PreOperational Phases of Nuclear Power Plant Projects. IAEA, Vienna. 
ICFTU (1985) INTERNATIONAL CONFEDERATION OF FREE TRADE UNIONS, The Trade Union Report on Bhopal. ICFTU-ICEF, Geneva, Switzerland.

INPO (2011) Institute of Nuclear Power Operations. Special Report on the Nuclear Accident at the Fukushima Daiichi Nuclear Power Station, INPO 011-005.

INSAG-4 (1991) INTERNATIONAL ATOMIC ENERGY AGENCY, Safety Culture. IAEA, Vienna.

INSAG-7 (1992) INTERNATIONAL ATOMIC ENERGY AGENCY, The Chernobyl Accident: Updating of INSAG-1. IAEA, Vienna.

INSAG-15 (2002) INTERNATIONAL ATOMIC ENERGY AGENCY, Key practical issues in strengthening safety culture. IAEA, Vienna.

LEE, T. Assessment of safety culture at a nuclear reprocessing plant. Environmental Psychology and Policy Research Unit, University of St Andrews, UK, 12:3, p. 217-237, 1998.

LEE, T.; HARRISON, K. Assessing safety culture in nuclear power stations. Safety Science, 34, p. 61-97, 2000.

MALHOTRA, N. K. Pesquisa de Marketing. Uma orientação aplicada. 4. ed. Porto Alegre: Bookman, 2006.

MARTINS, M. P. S. Estudo de fatores humanos, e observação dos seus aspectos básicos, focados em operadores do reator de pesquisa IEA-R1, objetivando a prevenção de acidentes ocasionados por falhas humanas. 2008. Dissertação (Mestrado) - Instituto de Pesquisas Energéticas e Nucleares, São Paulo.

MASSOCO, E. C. P. Percepção da equipe de enfermagem de um hospital de ensino acerca da segurança do paciente. 2012. Dissertação (Mestrado) - Universidade de São Paulo, São Paulo.

MKRTCHYAN, L.; TURCANU, C. Safety Culture Assessment Tools in Nuclear and Non-Nuclear Domains. Nuclear Science and Technology Studies, SCK・CEN-BLG-1085, 2012.

MORROW, S. Independent Evaluation of INPO's Nuclear Safety Culture Survey and Construct Validation Study. Office of Nuclear Regulatory Research, Division of Risk Analysis, 2012.

NAS (2014) NATIONAL ACADEMIES OF SCIENCES, Lessons Learned from the Fukushima Nuclear Accident for Improving Safety and Security of U.S. Nuclear Plants. National Research Council, USA.

NEA (1999) NUCLEAR ENERGY AGENCY, Committee on the Safety of Nuclear Installations. Identification and assessment of organisational factors related to the safety of NPPs. State-of-the-Art Report,. Paris, France. 
NETEMEYER, R.G.; BEARDEN, W.O.; SHARMA, S. Scaling Procedures: issues and applications. Thousand Oaks: Sage Publications, 2003.

NETO, A. S. V.; BARROSO, A. C. O.; GONÇALVES, A. Knowledge basis in safety culture for researchers and practitioners. Proceedings of the International Nuclear Atlantic Conference - INAC, Rio de Janeiro, Brasil, 2009.

NETO, A. S. V.; MARRA, A. N.; OLIVEIRA, P.S.P., SAXENA, R.N.; CARVALHO, R. N.; FRAJNDLICH, R.; PAIVA, R. P. Experience of IPEN - CNEN/SP in the execution of the first phase of the safety culture enhancement programme at IEA-R1 research reactor. Proceedings of the International Nuclear Atlantic Conference - INAC, São Paulo, Brasil, 2007.

NUREG-0585 (1979) U. S. NUCLEAR REGULATORY COMMISSION. TMI-2Lessons Learned Task Force Final Report. Washington, DC.

NUREG-1756 (2002) U. S. NUCLEAR REGULATORY COMMISSION. Safety Culture: A Survey of the State-of-the-Art. Washington, DC.

NUREG-2165 (2014) U. S. NUCLEAR REGULATORY COMMISSION. Safety Culture Common Language. Washington, DC.

OBADIA, I. J. Sistema de gestão adaptativo para organizações com tecnologia perigosa: a cultura de segurança como pressuposto de excelência nuclear. 2004. Tese (Doutorado) - Universidade Federal do Rio de Janeiro (COPPE), Rio de Janeiro.

OLIVEIRA, P.S.P., SAXENA, R.N. Safety culture assessment programme: statistical analysis of a survey conducted at IEA-R1 Brazilian Research Reactor. Proceedings of an International Conference on Research Reactor Utilization, Safety, Decommissioning, Fuel and Waste Management, Santiago, Chile, 2003.

PASQUALI, L. Psicometria. Revista Escola de Enfermagem da Universidade de São Paulo - USP, 2009.

PEREIRA, C. H. V. A influência de redes sociais na cultura de segurança. 2011. Dissertação (Mestrado) - Instituto de Pesquisas Energéticas e Nucleares, São Paulo.

PONTE JUNIOR, G.P. Gerenciamento de riscos baseado em fatores humanos e cultura de segurança, 1. Ed., Elsevier, Rio de Janeiro, 2014.

PONTES, L. C. S. Cultura de segurança e suas implicações na prevenção de acidentes do trabalho. 2008. Dissertação (Mestrado) - Faculdade Novos Horizontes, Minas Gerais.

REASON, J.T. Human Error, Cambridge University Press, New York, 1990.

REASON, J.T. Managing the Risk of Organizational Accidents, 1rd Edition, Ashgate, Alder Shot; New York, 1997.

REASON, J. T. Achieving a safe culture: Theory and Practice. Work \& Stress: An International Journal of Work, Health \& Organizations, 1998. 
REIS, C. T.; LAGUARDIA, J.; MARTINS M. Adaptação transcultural da versão brasileira do Hospital Survey on Patient Safety Culture: etapa inicial. Cad. Saúde Pública, Rio de Janeiro, 28(11), p. 2199-2210, 2012.

SCART (2008) INTERNATIONAL ATOMIC ENERGY AGENCY, Safety Culture Assessment Review Team (SCART). IAEA, Vienna.

SEKARAN, U. Research methods for business: a skill-building approach. 4.ed. New York: John Wiley, 2003.

SORENSON, J.N. Safety culture: a survey of the state-of-the-art. Reliability Engineering and System Safety, 76, 2002.

SPSS (2010) IBM Corp. Released 2010. IBM SPSS Statistics for Windows, Version 19.0. Armonk, NY: IBM Corp.

STANTON, N.; HEDGE, A.; BROOKHUIS, K.; SALAS, E.; HENDRICK, H. Handbook of Human Factors and Ergonomics Methods. CRC Press, New York, Washington, D.C., 2005.

TECDOC-943 (1995) INTERNATIONAL ATOMIC ENERGY AGENCY. Organizational factors influencing human performance in nuclear power plants. Report of a Technical Committee meeting held in Ittingen, Switzerland. IAEA. Vienna.

TECDOC-1125 (1999) INTERNATIONAL ATOMIC ENERGY AGENCY, Selfassessment of operational safety for nuclear power plants. IAEA, Vienna.

TECDOC-1321 (2002) INTERNATIONAL ATOMIC ENERGY AGENCY, Selfassessment of safety culture in nuclear installations. IAEA, Vienna.

TECDOC-1329 (2002) INTERNATIONAL ATOMIC ENERGY AGENCY, Safety culture in nuclear installations. IAEA, Vienna.

TROCHIM, W. M. The Research Methods Knowledge Base. 2nd Edition, Atomic Dog Publishing, 2006. Disponível em: $<$ http://www.socialresearchmethods.net/kb/> Acesso em 22 setembro 2013.

USNRC (1980) U.S. NUCLEAR REGULATORY COMMISSION, Three Mile Island - $\boldsymbol{A}$ Report to the Commissioners and to the Public, USNRC Volume I - Part 2, Washington.

WEIDMER, B. Issues and Guidelines for translation in cross-cultural research, Danvers, Massachusetts. 1994.

WILLEY, R. J. The Accident in Bhopal: Observations 20 Years Later. American Institute of Chemical Engineers - AIChE, 40th Annual Loss Prevention Symposium, Florida, 2006.

WILliAMS, A. S. Validating a Safety Culture Survey. Maryland Fire and Rescue Institute, College Park, Maryland, 2008.

WILPERT, B.; ITOIGAWA, N. Safety culture in nuclear power operations. 1. ed. London: Taylor \& Francis, 2001. 
ZOHAR, D. Safety climate in industrial organizations: Theoretical and applied implications. Journal of Applied Psychology, 65, 1980.

ZOHAR, D. Thirty years of safety climate research: Reflections and future directions. Accident Analysis and Prevention, 42, 2010. 


\title{
APÊNDICE A - Validação de conteúdo do instrumento de pesquisa
}

\author{
Sr Especialista
}

Trata-se de um projeto de pesquisa dentro da tradição do método quantitativo que tem a finalidade de avaliar a cultura de segurança de instalações nucleares.

Este processo de validação visa verificar os itens da escala em termos de representatividade, especificidade e adequação para medir o respectivo construto (Variável Latente).

A estrutura conceitual desse modelo (ver Quadros 1a e 1b) é fruto de uma ampla revisão da literatura pertinente e foi desenvolvida com base nos princípios psicométricos estabelecidos para pesquisas de campo. Está fundamentada em 4 Dimensões, 12 Construtos (Fatores) e 75 itens da escala.

As questões para avaliar os itens da escala (75) foram elaboradas com base na definição conceitual do respectivo construto (ver Quadros 2.1 a 2.4).

Com relação ao emprego de termos linguísticos nas opções de respostas, há duas principais razões:

1) Previsão no Plano de Trabalho para o Doutorado como um dos aspectos da originalidade da Tese;

2) As informações a serem obtidas sobre a cultura de segurança referem-se, basicamente, a atitudes, opiniões ou percepções dos funcionários na instalação, que podem ser melhores exploradas através desses termos;

3) Esse método não trará nenhum problema por ocasião das análises estatísticas, porque a atribuição numérica às opções segue o mesmo critério das realizadas nas escalas Likert de concordância.

Dessa forma, deverão ser verificados aspectos, como por exemplo:

- Consistência conceitual do item em relação ao construto;

- Relevância do item para a medição daquele construto;

- Falta de itens que poderiam medir outro aspecto da pesquisa;

- Redundâncias;

- $\quad$ Presença de itens que não são apropriados para medir o construto; e

- Itens que precisam ser melhores redigidos.

Antes de serem enviados aos respondentes, serão inseridos nos questionários os campos para marcação das respostas. O questionário também contará com questões demográficas relativas aos respondentes e com instruções sobre a opção "Não aplicável".

Portanto, para a sua avaliação (Quadros 2.1 a 2.4), pediria que fossem assinalados os campos correspondentes a cada item (Questão), de acordo com o seu discernimento.

Basicamente, as opções para cada questão são as seguintes:

A verificação inicial consiste em apontar se a questão deve permanecer ou não.

Caso você considere que a questão não deva ficar, clique (com um "X") em Excluir.

Caso você considere que a questão deva ficar, então:

- Indique o Grau de relevância para avaliar cultura de segurança desta questão; e

- Se achar que o texto da questão ou das opções de resposta deva ser melhorado, clique em Alterar redação e sugira a modificação; e

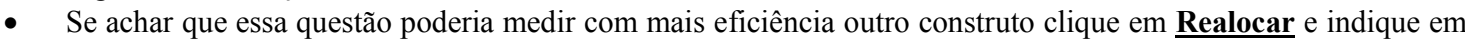
qual construto seria melhor empregada.

E por fim, caso você conclua que, em algum construto, deveria haver mais questões para medir outros aspectos, por favor, indique-as.

Por enquanto, muito obrigado e toda crítica, orientação e sugestão serão bem vindas.

Atenciosamente,

Claudio Souza do Nascimento 


\section{APÊNDICE B - Questionário de avaliação da cultura de segurança}

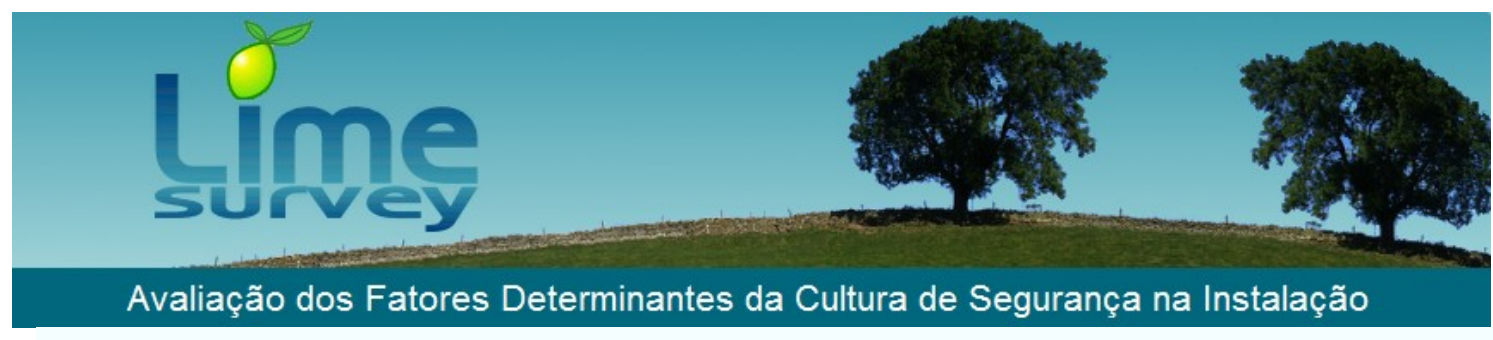

Instituto de Pesquisas Energéticas e Nucleares (IPEN)

Divisão de Ensino

Pós-Graduação

Prezado Avaliador:

Vimos solicitar sua colaboração nesse projeto de pesquisa acadêmica, com fins puramente científicos, que tem a finalidade de avaliar a Cultura de Segurança de instalações nucleares.

Caso esteja de acordo, sua participação consiste em responder esse questionário versando sobre a Cultura de Segurança da sua instalação.

Não é necessário se identificar, basta apenas informar alguns dados demográficos (Questões D1 a D7). A confidencialidade sobre a sua participação está assegurada porque suas respostas serão tratadas de modo sigiloso e os resultados serão divulgados de modo agregado.

Esse link que você está acessando é totalmente seguro, pois foi desenvolvido pelo Grupo de Gestão do Conhecimento do IPEN e os dados, aqui gerados, serão armazenados em uma base que só o pesquisador tem acesso.

A estimativa de tempo para o preenchimento das questões é de $12 \mathrm{~min}$

Agradecemos pela sua atenção e participação e colocamo-nos à sua disposição para qualquer esclarecimento ou informação nos seguintes endereços:

claudiosn@usp.br

Fone: (11) 3817-7462

Atenciosamente,

Aluno: CLAUDIO SOUZA DO NASCIMENTO (Pesquisador)

Orientador: Dr. DELVONEI ALVES DE ANDRADE (IPEN)

Coorientador: DR. ROBERTO NAVARRO DE MESQUITA (IPEN) 
$0 \%$ $100 \%$

\title{
IAEA e CNEN
}

${ }^{a}$ Cultura de Segurança é o conjunto de características e atitudes de organizações e de indivíduos que estabelece como prioridade maior que as questões de segurança da instalação receberão atenção proporcional à sua importância".

\section{Health and Safety Executive (HSE):}

"A cultura de segurança de uma organização é o produto de valores, atitudes, percepções, competências e padrões de comportamento, individuais e de grupo, que determinam o empenho, o estilo e a proficiência da gestão da saúde e da segurança de uma organização"

Portanto, são esses aspectos de Cultura de Segurança, sublinhados nas definições acima, que se pretende avaliar na sua instalação por meio deste questionário.

\section{Questões Demográficas}

\section{Nas Questões D1 a D7, clique na opção que melhor corresponde a sua situação atual.}

\author{
D1. Qual a sua instalação? \\ Escolha uma das seguintes respostas: \\ CNEN - Sede \\ - CDTN \\ $\mathrm{CRCN} / \mathrm{CO}$ \\ CRCN/NE \\ - IEN \\ O IPEN \\ ○ IRD
}

\section{D2. Há quanto tempo você trabalha na instituição?}

Escolha uma das seguintes respostas:

- Menos que 5 anos

- De 6 a 10 anos

- De 11 a 20 anos

- De 21 a 30 anos

- Mais que 30 anos 


\section{D3. Qual a sua área de atuação na instituição?}

Escolha uma das seguintes respostas:
Operação
Produção
- Manutenção
Radioproteção
Segurança Nuclear
- Segurança Industrial
- Segurança Física
- Pesquisa / Desenvolvimento
- Garantia da Qualidade
Tecnologia da Informação
Ensino
Outra. (Comentário)

Por favor, coloque aqui o seu comentário:

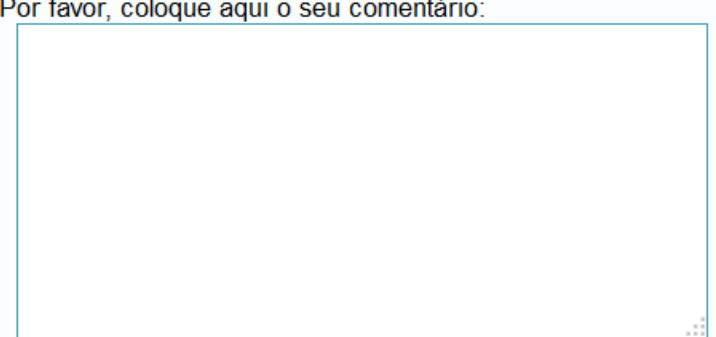

\section{D4. Qual o seu cargo / função atual?}

Escolha uma das seguintes respostas:
Superintendente
Gerente
Chefe de Departamento
Encarregado (Divisão / Seção)
- Pesquisador
- Supervisor
Operador
- Técnico de Radioproteção
- Técnico de Manutenção
Outra. (Comentário)

Por favor, coloque aqui o seu comentário:

\section{D5. Qual o seu tempo de experiência na área nuclear?}

Escolha uma das seguintes respostas:
- Menos que 5 anos
- De 6 a 10 anos
De 11 a 20 anos
C De 21 a 30 anos
- Mais que 30 anos 


\section{D6. Qual a sua idade?}

Escolha uma das seguintes respostas:

- 18 a 25 anos

- 26 a 35 anos

- 36 a 45 anos

- 46 a 55 anos

- 56 anos ou mais

D7. Qual o seu nivel de escolaridade?

Escolha uma das seguintes respostas:
$2^{\circ} \mathrm{Grau}$
Graduação
- Graduação com Especialização
- Graduação com MBA
- Mestrado
( ) Doutorado
- Pós-doutorado 
Clique na opção que melhor expresse a sua percepção do assunto em questão.

Clique em "Não aplicável" somente se o assunto em questão não for pertinente a você em razão da natureza da sua função, das suas atividades ou do seu local de trabalho.

Q1. Avalie o seu grau de conhecimento sobre a política de segurança estabelecida para a instalação.

OBS: Política de Segurança é uma declaração do comprometimento da organização com um excelente desempenho em todas as atividades importantes para a segurança, deixando claro que a segurança tem prioridade absoluta, prevalecendo, se necessário, sobre as demandas de produçäo ou cronogramas de projetos.

Escolha uma das seguintes respostas:

Muito bom

Bom

Razoável

Ruim

Muito ruim

Não aplicável

Q2. Em sua percepção, qual o nível de prioridade que a política de segurança atribui à segurança na instalação?

Escolha uma das seguintes respostas:

Prioridade máxima

Prioridade alta

Prioridade moderada

Prioridade baixa

Nenhuma prioridade

Não aplicável

Q3. De que forma você classificaria o conteúdo da política de segurança, com relação a sua consistência, clareza e a objetividade?

Escolha uma das seguintes respostas:

Muito bom

Bom

- Razoável

Ruim

Muito ruim

- Não aplicáve 
Q4. Nas reuniöes para tratar de assuntos relacionados à segurança, como você percebe a preocupação da chefia imediata / gerência em relação a essas questöes?

Escolha uma das seguintes respostas:

Preocupação absoluta

Bastante preocupação

Preocupação moderada

Pouca preocupação

Nenhuma preocupação

- Não aplicável

Q5. Em seu julgamento, em que situaçöes pode haver interrupção do processo / operação na instalaçäo por questöes de segurança?

Escolha uma das seguintes respostas:

Sempre

Geralmente

- Às Vezes

Raramente

Nunca

Não aplicável

Q6. Quando uma unidade da instalação está com atraso no processo / operação, você é autorizado a não cumprir uma ou mais etapas previstas nos procedimentos ou não obedecer à sua sequência?

Escolha uma das seguintes respostas:

Nunca

Raramente

Às vezes

Geralmente

- Sempre

- Não aplicável 
Clique na opção que melhor expresse a sua percepção do assunto em questão.

Clique em "Não aplicável" somente se o assunto em questão não for pertinente a você em razão da natureza da sua função, das suas atividades ou do seu local de trabalho.

\title{
Q7. Classifique o grau de adequação dos recursos alocados para a aquisição de equipamentos de segurança.
}

\author{
Escolha uma das seguintes respostas: \\ Muito alto \\ Alto \\ Moderado \\ Baixo \\ Muito baixo \\ Não aplicável
}

Q8. Classifique o grau de adequação dos recursos alocados para realização de treinamentos.

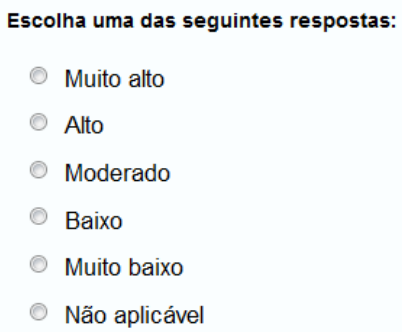

Q9. Classifique o grau de adequação dos recursos alocados para custear a manutenção da área operacional.

Escolha uma das seguintes respostas:

Muito alto

Alto

- Moderado

- Baixo

Muito baixo

- Não aplicável 
Q10. Com que frequência você acredita que ocorrem revisöes da adequação desses recursos alocados?

Escolha uma das seguintes respostas:
Sempre
Geralmente
Às Vezes
Raramente
Nunca
- Não aplicável

Sair e apagar o questionário

Retomar mais tarde 
Clique na opção que melhor expresse a sua percepção do assunto em questão.

Clique em "Não aplicável" somente se o assunto em questão não for pertinente a você em razão da natureza da sua função, das suas atividades ou do seu local de trabalho.

Q11. Em seu conceito, as atribuiçöes e responsabilidades pela segurança na instalação estão claramente definidas?

Escolha uma das seguintes respostas:

Muito bem definidas

Bem definidas

Razoavelmente definidas

Mal definidas

Muito mal definidas

Não aplicável

Q12. Classifique o seu conhecimento sobre as suas atribuiçöes e responsabilidades pela segurança na instalação.

Escolha uma das seguintes respostas:

Muito alto

Alto

Razoável

Baixo

Muito baixo

Não aplicável 
Clique na opção que melhor expresse a sua percepção do assunto em questão.

Clique em "Não aplicável" somente se o assunto em questão não for pertinente a você em razão da natureza da sua função, das suas atividades ou do seu local de trabalho.

Q13. De que forma você vê o comprometimento da Alta administração com a segurança, considerando suas ações ou omissőes?

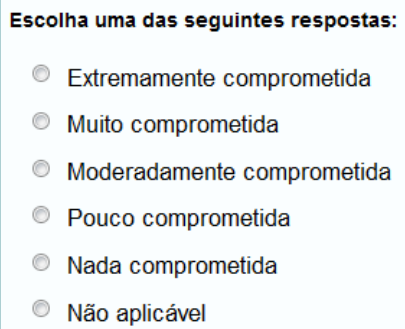

Pouco comprometida

(- Nada comprometida

Não aplicável

Q14. Como você julga o comprometimento dos diversos níveis gerenciais com a segurança na instalação, considerando suas ações ou omissões?

Escolha uma das seguintes respostas:

Extremamente comprometida

Muito comprometida

Moderadamente comprometida

Pouco comprometida

Nada comprometida

Não aplicável

Q15. Em sua percepção, qual é o estado atual da segurança na instalação?

Escolha uma das seguintes respostas:

Muito Bom

Bom

Regular

Ruim

- Muito ruim

- Não aplicável 
Clique na opção que melhor expresse a sua percepção do assunto em questão.

Clique em "Não aplicável" somente se o assunto em questão não for pertinente a você em razão da natureza da sua função, das suas atividades ou do seu local de trabalho.

Q16. Em sua percepção, os canais de comunicação, entre a Administração e os funcionários, são transparentes e eficazes quando se trata de questöes segurança?

Escolha uma das seguintes respostas:

Extremamente transparentes e eficazes

Muito transparentes e eficazes

Razoavelmente transparentes e eficazes

Pouco transparentes e eficazes

Muito pouco transparentes e eficazes

Não aplicável

Q17. De acordo com sua observação, há preocupação com a segurança nas informaçöes transmitidas durante as trocas de turno?

Escolna uma das seguintes respostas:

Preocupação absoluta

Bastante preocupação

Preocupação moderada

Pouca preocupação

Nenhuma preocupação

Não aplicável

Q18. A Administração sempre confirma se as mensagens / avisos / comunicados, relativos às questöes de segurança, foram efetivamente transmitidos e compreendidos pelos funcionários?

Escolha uma das seguintes respostas:

Sempre

Geralmente

Às Vezes

- Raramente

Nunca

( Não aplicável 
Q19. A relação de trabalho entre você e os seus superiores hierárquicos se baseia na confiança mútua?

Escolha uma das seguintes respostas:

Sempre

Geralmente

(1) Às Vezes

Raramente

Nunca

Não aplicável

Q20. De que forma você observa a receptividade do pessoal da instalaçäo para com os Órgãos Reguladores e Fiscalizadores (CNEN, SIPRON, IBAMA, CETESB)?

Escolha uma das seguintes respostas:

Extremamente receptiva

Muito receptiva

Razoavelmente receptiva

- Pouco receptiva

Muito pouco receptiva

Não aplicável

Sair e apagar o questionário 
Clique na opção que melhor expresse a sua percepção do assunto em questão.

Clique em "Não aplicável" somente se o assunto em questão não for pertinente a você em razão da natureza da sua função, das suas atividades ou do seu local de trabalho.

Q21. Atribua um grau de adequação para os treinamentos que você recebe, com relação à aplicabilidade nas atividades que você executa.

Escolha uma das seguintes respostas:
Máximo
Alto
Regular
Baixo
- Mínimo
ㅅão aplicável

Q22. Os programas de treinamento são revisados periodicamente para serem atualizados ou se adequarem às novas necessidades das equipes de trabalho?

Escolha uma das seguintes respostas:

- Sempre

- Geralmente

Às Vezes

Raramente

- Nunca

Não aplicáve

Q23. Que grau de adequação você atribuiria à sua equipe de trabalho com relação ao seu tamanho e às competências individuais, frente à demanda das atividades?

Escolha uma das seguintes respostas:

Máximo

Alto

Regular

Baixo

Mínimo

Não aplicável 
Q24. Você se considera treinado e qualificado para as atividades que desempenha?

Escolha uma das seguintes respostas:
Muito Bem
Bem
Razoavelmente
(.) Mal
Muito mal
Não aplicável

\begin{tabular}{|c|}
\hline Anterior Próximo \\
Sair e apagar o questionário \\
Retomar mais tarde
\end{tabular}


Clique na opção que melhor expresse a sua percepção do assunto em questão.

Clique em "Não aplicável" somente se o assunto em questão não for pertinente a você em razão da natureza da sua função, das suas atividades ou do seu local de trabalho.

Q25. Avalie a qualidade do conteúdo da documentaçäo utilizada em seu local de trabalho, considerando a sua consistência $e$ objetividade.

Escolha uma das seguintes respostas:

Muito Boa

Boa

- Razoável

- Ruim

- Muito ruim

Não aplicável

Q26. A documentação necessária para você realizar as suas atividades está sempre disponivel em seu local de trabalho?

Escolha uma das seguintes respostas:

Sempre

Geralmente

Às Vezes

Raramente

Nunca

Não aplicáve

Q27. Qual o nivel de entendimento que você tem da documentação utilizada na realização das atividades em seu local de trabalho?

Escolha uma das seguintes respostas:

Muito Alto

Alto

Razoável

(O) Baixo

() Muito baixo

- Não aplicável 
Q28. Avalie a qualidade da documentação utilizada em seu local de trabalho, considerando a existência de erros de conteúdo ou a falta de informação.

Escolha uma das seguintes respostas:
Muito Boa
Boa
Razoável
Ruim
Muito ruim
Não aplicável

Q29. Avalie a qualidade da documentação utilizada em seu local de trabalho, com relação a sua atualização.

Escolha uma das seguintes respostas:
Muito Boa
Boa
Razoável
Ruim
Muito ruim
Não aplicável

Q30. Avalie o processo de realização das suas tarefas com relação à facilidade de entendimento e de execução. Escolha uma das seguintes respostas:
Extremamente fácil
Muito fácil
Razoavelmente fácil
Difícil
Muito difícil
Não aplicável 
Clique na opção que melhor expresse a sua percepção do assunto em questão.

Clique em "Não aplicável" somente se o assunto em questão não for pertinente a você em razão da natureza da sua função, das suas atividades ou do seu local de trabalho.

Q31. Você considera a sua carga de trabalho equilibrada?

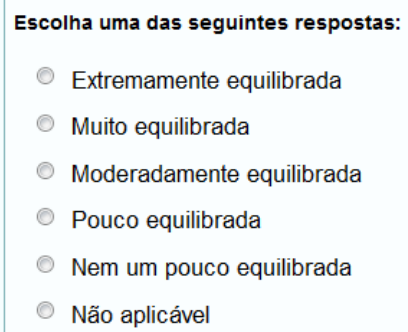

Q32. Classifique o seu local de trabalho com relação à temperatura do ambiente.

Escolha uma das seguintes respostas:

Muito bom

Bom

Razoável

Ruim

Muito ruim

Não aplicável

Q33. Classifique o seu local de trabalho com relação à luminosidade para realizar as atividades.

Escolha uma das seguintes respostas:

Muito bom

Bom

Razoável

Ruim

Muito ruim

Não aplicável

Q34. Avalie a qualidade do ar em seu ambiente de trabalho, considerando gases, vapores e poeiras.

Escolha uma das seguintes respostas:

Otima

Boa

Regular

Ruim

Muito ruim

- Nầ aplicável 
Q35. Classifique o seu local de trabalho com relaçào à aparição de ruidos ou outros fatores que causem distraçäo.
Muito bom
Bom
Razodvel
Ruim
Muito ruim
- Nẫo aplicável

Escolha uma das seguintes respostas:

Q36. De uma forma geral, como é o tempo dado para você realizar as tarefas em relação ao tempo necessário para completá-las?

Escolha uma das seguintes respostas:

Muito maior

Maior

Equivalente

(-) Menor

Muito menor

Não aplicável

Q37. Avalie a qualidade ergonômica do seu local de trabalho com relação ao arranjo físico de equipamentos e painéis de instrumentaçäo e controle.

Escolha uma das seguintes respostas:
Muito boa
Boa
Razoáve
Ruim
(- Muito ruim
Não aplicável

Q38. Avalie as condiçöes gerais de limpeza do seu local de trabalho.
Escolha uma das seguintes respostas:
Ótimas
Boas
- Razodveis
Ruins
Muito ruins
- Năo aplicável 
Q39. Que classificaçào vocé daria para o estado de conservaçào dos equipamentos / componentes dos sistemas de segurança da instalaçào?

\section{Escolha uma das seguintes respostas:}
Ótimo
Bom
- Razodivel
Ruim
Muito ruim
- Năo aplicável

Q40. Você considera o seu trabalho estressante?

Escolha uma das seguintes respostas:

Extremamente estressante

- Muito estressante

- Razoavelmente estressante

- Pouco estressante

- Nem um pouco estressante

Não aplicável

Q41. De acordo com a política de horas extras da sua instalação, com que frequência lhe é demandado trabalhar após o seu período normal de atividades?

Escolha uma das seguintes respostas:

Nunca

Raramente

De vez em quando

- Geralmente

Sempre

Não aplicáve 
Q42. Indique o seu nível de satisfação no trabalho, no que diz respeito ao reconhecimento pelo seu esforço e recompensas por bons trabalhos realizados.

Escolha uma das seguintes respostas:
Máximo
Alto
Moderado
Baixo
- Mínimo
Não aplicável

4 Anterior Próximo

Sair e apagar o questionário

Retomar mais tarde 
Clique na opção que melhor expresse a sua percepção do assunto em questão.

Clique em "Não aplicável" somente se o assunto em questão não for pertinente a você em razão da natureza da sua função, das suas atividades ou do seu local de trabalho.

Q43. Em sua percepção, que consideração é dada às experiências de outras instalações nucleares, na melhoria da segurança da sua instalação?

Escolha uma das seguintes respostas:

Consideração total

- Bastante consideração

Consideração moderada

Pouca consideração

- Nenhuma consideração

Não aplicável

Q44. Quando ocorre um acidente / incidente em sua instalação, que importância é dada para a investigação das suas causas? Escolna uma das seguintes respostas:

Extrema importância

Muita importância

Importância moderada

Pouca importância

Nenhuma importância

Não aplicável

Q45. Como você avalia o processo de implementação de açöes corretivas para os problemas detectados nas avaliações ou nas investigaçöes de acidentes / incidentes?

Escolha uma das seguintes respostas:

Extremamente eficazes

Muito eficazes

Razoavelmente eficazes

Pouco eficazes

Ineficazes

Não aplicável 
Q46. Em sua percepção, a divulgação das causas dos acidentes / incidentes na instalação é transparente quando se trata de questöes segurança?

\section{Escolha uma das seguintes respostas:}

- Extremamente transparente

- Muito transparente

- Razoavelmente transparente

- Pouco transparente

- Não transparente

Não aplicável

Sair e apagar o questionário 
Clique na opção que melhor expresse a sua percepção do assunto em questão.

Clique em "Não aplicável" somente se o assunto em questão não for pertinente a você em razão da natureza da sua função, das suas atividades ou do seu local de trabalho.

Q47. Em sua percepção, como é a receptividade do pessoal da instalação em relação às avaliações de segurança, realizadas por pessoal externo?

\section{Escolha uma das seguintes respostas:}

Extremamente receptiva

Muito receptiva

Razoavelmente receptiva

Pouco receptiva

Muito pouco receptiva

Não aplicável

\section{Q48. Com que frequência você observa que ocorrem avaliações internas relacionadas à segurança na instalação?}

Escolha uma das seguintes respostas:

Sempre ocorrem

Geralmente ocorrem

Às vezes ocorrem

Raramente ocorrem

Nunca ocorrem

Não aplicáve

Q49. Como é a divulgação dos resultados das avaliações internas e externas relacionadas à segurança, para os funcionários da instalação?

\section{Escolha uma das seguintes respostas:}

Muito bem divulgados

- Bem divulgados

- Razoavelmente divulgados

- Mal divulgados

- Muito mal divulgados

- Não aplicáve 


\section{APÊNDICE C - Distribuição de frequência das respostas}

Este apêndice foi inserido neste trabalho com a finalidade de dar suporte às análises e interpretação dos resultados e à avaliação das propriedades psicométricas do modelo.

É apresentada a distribuição de frequência das respostas obtidas pelas 7 variáveis demográficas e pelas 49 variáveis indicadores de mensuração. Esses resultados estão considerando a CNEN como um todo, ou seja, como uma amostra.

As diferenças de valores entre a coluna "Porcentagem" e a coluna "Porcentagem válida" se devem ao fato dessas últimas não considerarem os valores ausentes nesses cálculos, ou seja, "Porcentagem" é a porcentagem de respondentes na pesquisa e "Porcentagem válida" é a porcentagem de respostas. A porcentagem acumulada se refere à porcentagem válida. 
D1. Instalação

\begin{tabular}{|cl|c|c|c|}
\hline & Frequência & Porcentagem & $\begin{array}{c}\text { Porcentagem } \\
\text { válida }\end{array}$ \\
\hline \multirow{6}{*}{ Válido } & CNEN/Sede & 16 & 8,1 & 8,1 \\
CDTN & 10 & 5,1 & 5,1 \\
CRCN/CO & 2 & 1,0 & 1,0 \\
CRCN/NE & 2 & 1,0 & 1,0 \\
& IEN & 14 & 7,1 & 7,1 \\
& IPEN & 139 & 70,2 & 70,2 \\
IRD & 15 & 7,6 & 7,6 \\
Total & 198 & 100,0 & 100,0 \\
\hline
\end{tabular}

D2. Tempo na instituição

\begin{tabular}{|ll|c|c|c|c|}
\hline & Frequência & Porcentagem & $\begin{array}{c}\text { Porcentagem } \\
\text { válida }\end{array}$ & $\begin{array}{c}\text { Porcentagem } \\
\text { acumulada }\end{array}$ \\
\hline \multirow{4}{*}{ Válido } & Menos que 5 anos & 20 & 10,1 & 10,1 & 10,1 \\
& De 6 a 10 anos & 3 & 1,5 & 1,6 & 11,7 \\
& De 11 a 20 anos & 40 & 20,2 & 20,2 & 31,9 \\
& De 21 a 30 anos & 46 & 23,2 & 23,2 & 55,1 \\
& Mais que 30 anos & 89 & 44,9 & 44,9 & 100,0 \\
Total & 198 & 100,0 & 100,0 & \\
\hline
\end{tabular}

D3. Área de atuação

\begin{tabular}{|c|c|c|c|c|}
\hline & & Frequência & Porcentagem & $\begin{array}{l}\text { Porcentagem } \\
\text { válida }\end{array}$ \\
\hline Válido & $\begin{array}{l}\text { Operação } \\
\text { Produção } \\
\text { Manutenção } \\
\text { Radioproteção } \\
\text { Segurança Nuclear } \\
\text { Segurança Física } \\
\text { Pesquisa / Desenvolvimento } \\
\text { Garantia da Qualidade } \\
\text { Ensino } \\
\text { Outra. (Comentário) } \\
\text { Total }\end{array}$ & $\begin{array}{c}11 \\
10 \\
2 \\
20 \\
12 \\
1 \\
112 \\
5 \\
4 \\
21 \\
198\end{array}$ & $\begin{array}{c}5,6 \\
5,1 \\
1,0 \\
10,1 \\
6,1 \\
0,5 \\
56,6 \\
2,5 \\
2,0 \\
10,6 \\
100,0\end{array}$ & $\begin{array}{c}5,6 \\
5,1 \\
1,0 \\
10,1 \\
6,1 \\
0,5 \\
56,6 \\
2,5 \\
2,0 \\
10,5 \\
100,1\end{array}$ \\
\hline
\end{tabular}

D4. Cargo / Função

\begin{tabular}{|c|c|c|c|c|}
\hline & & Frequência & Porcentagem & $\begin{array}{l}\text { Porcentagem } \\
\text { válida }\end{array}$ \\
\hline Válido & $\begin{array}{l}\text { Superintendente } \\
\text { Gerente } \\
\text { Chefe de Departamento } \\
\text { Encarregado (Divisão / Seção) } \\
\text { Pesquisador } \\
\text { Supervisor } \\
\text { Operador } \\
\text { Técnico de Radioproteção } \\
\text { Técnico de Manutenção } \\
\text { Outra. (Comentário) } \\
\text { Total }\end{array}$ & $\begin{array}{c}4 \\
15 \\
6 \\
12 \\
103 \\
10 \\
7 \\
2 \\
2 \\
37 \\
198\end{array}$ & $\begin{array}{c}2,0 \\
7,6 \\
3,0 \\
6,1 \\
52,0 \\
5,1 \\
3,5 \\
1,0 \\
1,0 \\
18,7 \\
100,0\end{array}$ & $\begin{array}{c}2,0 \\
7,6 \\
3,0 \\
6,1 \\
52,0 \\
5,1 \\
3,5 \\
1,0 \\
1,0 \\
18,7 \\
100,0\end{array}$ \\
\hline
\end{tabular}


D5. Experiência nuclear

\begin{tabular}{|c|c|c|c|c|c|}
\hline & & Frequência & Porcentagem & $\begin{array}{c}\text { Porcentagem } \\
\text { válida }\end{array}$ & $\begin{array}{c}\text { Porcentagem } \\
\text { acumulada }\end{array}$ \\
\hline \multirow{6}{*}{ Válido } & Menos que 5 anos & 20 & 10,1 & 10,1 & 10,1 \\
\hline & De 6 a 10 anos & 6 & 3,0 & 3,0 & 13,1 \\
\hline & De 11 a 20 anos & 41 & 20,7 & 20,7 & 33,8 \\
\hline & De 21 a 30 anos & 43 & 21,7 & 21,7 & 55,6 \\
\hline & Mais que 30 anos & 88 & 44,4 & 44,4 & 100,0 \\
\hline & Total & 198 & 100,0 & 100,0 & \\
\hline
\end{tabular}

D6. Idade

\begin{tabular}{|c|c|c|c|c|c|}
\hline & & Frequência & Porcentagem & $\begin{array}{c}\text { Porcentagem } \\
\text { válida }\end{array}$ & $\begin{array}{c}\text { Porcentagem } \\
\text { acumulada }\end{array}$ \\
\hline \multirow{6}{*}{ Válido } & 18 a 25 anos & 2 & 1,0 & 1,0 & 1,0 \\
\hline & 26 a 35 anos & 11 & 5,6 & 5,6 & 6,6 \\
\hline & 36 a 45 anos & 18 & 9,1 & 9,1 & 15,7 \\
\hline & 46 a 55 anos & 76 & 38,4 & 38,4 & 54,0 \\
\hline & 56 anos ou mais & 91 & 46,0 & 46,0 & 100,0 \\
\hline & Total & 198 & 100,0 & 100,0 & \\
\hline
\end{tabular}

D7. Escolaridade

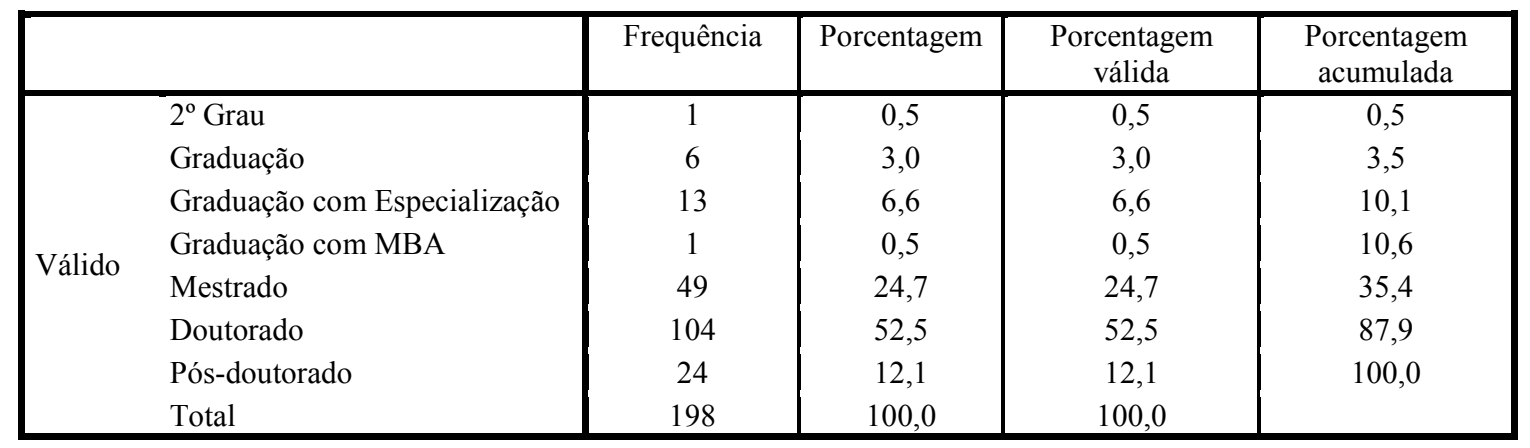

Q1. Conhecimento da política de segurança

\begin{tabular}{|c|c|c|c|c|c|}
\hline & & Frequência & Porcentagem & $\begin{array}{l}\text { Porcentagem } \\
\text { válida }\end{array}$ & $\begin{array}{c}\text { Porcentagem } \\
\text { acumulada }\end{array}$ \\
\hline \multirow{7}{*}{ Válido } & Muito bom & 40 & 20,2 & 20,2 & 20,2 \\
\hline & Bom & 85 & 42,9 & 42,9 & 63,1 \\
\hline & Razoável & 45 & 22,7 & 22,7 & 85,9 \\
\hline & Ruim & 14 & 7,1 & 7,1 & 92,9 \\
\hline & Muito ruim & 10 & 5,1 & 5,1 & 98,0 \\
\hline & Não aplicável & 4 & 2,0 & 2,0 & 100,0 \\
\hline & Total & 198 & 100,0 & 100,0 & \\
\hline
\end{tabular}


Q2. Prioridade da segurança na política

\begin{tabular}{|c|c|c|c|c|c|}
\hline & & Frequência & Porcentagem & $\begin{array}{l}\text { Porcentagem } \\
\text { válida }\end{array}$ & $\begin{array}{c}\text { Porcentagem } \\
\text { acumulada }\end{array}$ \\
\hline \multirow{7}{*}{ Válido } & Prioridade máxima & 49 & 24,7 & 24,7 & 24,7 \\
\hline & Prioridade alta & 73 & 36,9 & 36,9 & 61,6 \\
\hline & Prioridade moderada & 44 & 22,2 & 22,2 & 83,8 \\
\hline & Prioridade baixa & 24 & 12,1 & 12,1 & 96,0 \\
\hline & Nenhuma prioridade & 3 & 1,5 & 1,5 & 97,5 \\
\hline & Não aplicável & 5 & 2,5 & 2,5 & 100,0 \\
\hline & Total & 198 & 100,0 & 100,0 & \\
\hline
\end{tabular}

\section{Q3. Conteúdo da política de segurança}

\begin{tabular}{|c|c|c|c|c|c|}
\hline & & Frequência & Porcentagem & $\begin{array}{l}\text { Porcentagem } \\
\text { válida }\end{array}$ & $\begin{array}{l}\text { Porcentagem } \\
\text { acumulada }\end{array}$ \\
\hline \multirow{7}{*}{ Válido } & Muito bom & 30 & 15,2 & 15,2 & 15,2 \\
\hline & Bom & 71 & 35,9 & 35,9 & 51,0 \\
\hline & Razoável & 57 & 28,8 & 28,8 & 79,8 \\
\hline & Ruim & 23 & 11,6 & 11,6 & 91,4 \\
\hline & Muito ruim & 9 & 4,5 & 4,5 & 96,0 \\
\hline & Não aplicável & 8 & 4,0 & 4,0 & 100,0 \\
\hline & Total & 198 & 100,0 & 100,0 & \\
\hline
\end{tabular}

Q4. Prioridade da segurança nas reuniões

\begin{tabular}{|c|c|c|c|c|c|}
\hline & & Frequência & Porcentagem & $\begin{array}{l}\text { Porcentagem } \\
\text { válida }\end{array}$ & $\begin{array}{c}\text { Porcentagem } \\
\text { acumulada }\end{array}$ \\
\hline \multirow{7}{*}{ Válido } & Preocupação absoluta & 30 & 15,2 & 15,2 & 15,2 \\
\hline & Bastante preocupação & 67 & 33,8 & 33,8 & 49,0 \\
\hline & Preocupação moderada & 62 & 31,3 & 31,3 & 80,3 \\
\hline & Pouca preocupação & 20 & 10,1 & 10,1 & 90,4 \\
\hline & Nenhuma preocupação & 7 & 3,5 & 3,5 & 93,9 \\
\hline & Não aplicável & 12 & 6,1 & 6,1 & 100,0 \\
\hline & Total & 198 & 100,0 & 100,0 & \\
\hline
\end{tabular}

\section{Q5. Segurança versus produção}

\begin{tabular}{|c|c|c|c|c|c|}
\hline & & Frequência & Porcentagem & $\begin{array}{l}\text { Porcentagem } \\
\text { válida }\end{array}$ & $\begin{array}{l}\text { Porcentagem } \\
\text { acumulada }\end{array}$ \\
\hline \multirow{7}{*}{ Válido } & Sempre & 104 & 52,5 & 52,5 & 52,5 \\
\hline & Geralmente & 25 & 12,6 & 12,6 & 65,2 \\
\hline & Às Vezes & 37 & 18,7 & 18,7 & 83,8 \\
\hline & Raramente & 16 & 8,1 & 8,1 & 91,9 \\
\hline & Nunca & 7 & 3,5 & 3,5 & 95,5 \\
\hline & Não aplicável & 9 & 4,5 & 4,5 & 100,0 \\
\hline & Total & 198 & 100,0 & 100,0 & \\
\hline
\end{tabular}


Q6. Desvios e atalhos no processo

\begin{tabular}{|c|c|c|c|c|c|}
\hline & & Frequência & Porcentagem & $\begin{array}{l}\text { Porcentagem } \\
\text { válida }\end{array}$ & $\begin{array}{c}\text { Porcentagem } \\
\text { acumulada }\end{array}$ \\
\hline \multirow{7}{*}{ Válido } & Nunca & 68 & 34,3 & 34,3 & 34,3 \\
\hline & Raramente & 20 & 10,1 & 10,1 & 44,4 \\
\hline & Às vezes & 21 & 10,6 & 10,6 & 55,1 \\
\hline & Geralmente & 4 & 2,0 & 2,0 & 57,1 \\
\hline & Sempre & 5 & 2,5 & 2,5 & 59,6 \\
\hline & Não aplicável & 80 & 40,4 & 40,4 & 100,0 \\
\hline & Total & 198 & 100,0 & 100,0 & \\
\hline
\end{tabular}

Q7. Recursos para equipamentos de segurança

\begin{tabular}{|l|c|c|c|c|}
\hline & Frequência & Porcentagem & $\begin{array}{c}\text { Porcentagem } \\
\text { válida }\end{array}$ & $\begin{array}{c}\text { Porcentagem } \\
\text { acumulada }\end{array}$ \\
\hline Muito alto & 12 & 6,1 & 6,1 & 6,1 \\
Alto & 46 & 23,2 & 23,2 & 29,3 \\
Moderado & 65 & 32,8 & 32,8 & 62,1 \\
Válido & Baixo & 20,2 & 20,2 & 82,3 \\
Muito baixo & 18 & 9,1 & 9,1 & 91,4 \\
Não aplicável & 17 & 8,6 & 8,6 & 100,0 \\
$\quad$ Total & 198 & 100,0 & 100,0 & \\
\hline
\end{tabular}

Q8. Recursos para treinamentos

\begin{tabular}{|c|c|c|c|c|c|}
\hline & & Frequência & Porcentagem & $\begin{array}{l}\text { Porcentagem } \\
\text { válida }\end{array}$ & $\begin{array}{c}\text { Porcentagem } \\
\text { acumulada }\end{array}$ \\
\hline \multirow{7}{*}{ Válido } & Muito alto & 8 & 4,0 & 4,0 & 4,0 \\
\hline & Alto & 39 & 19,7 & 19,7 & 23,7 \\
\hline & Moderado & 63 & 31,8 & 31,8 & 55,6 \\
\hline & Baixo & 55 & 27,8 & 27,8 & 83,3 \\
\hline & Muito baixo & 18 & 9,1 & 9,1 & 92,4 \\
\hline & Não aplicável & 15 & 7,6 & 7,6 & 100,0 \\
\hline & Total & 198 & 100,0 & 100,0 & \\
\hline
\end{tabular}

\section{Q9. Recursos para manutenção}

\begin{tabular}{|l|c|c|c|c|}
\hline & Frequência & Porcentagem & $\begin{array}{c}\text { Porcentagem } \\
\text { válida }\end{array}$ & $\begin{array}{c}\text { Porcentagem } \\
\text { acumulada }\end{array}$ \\
\hline Muito alto & 4 & 2,0 & 2,0 & 2,0 \\
Alto & 34 & 17,2 & 17,2 & 19,2 \\
Moderado & 55 & 27,8 & 27,8 & 47,0 \\
Válido & Baixo & 27,8 & 27,8 & 74,7 \\
Muito baixo & 13 & 6,6 & 6,6 & 81,3 \\
Não aplicável & 37 & 18,7 & 18,7 & 100,0 \\
$\quad$ Total & 198 & 100,0 & 100,0 & \\
\hline
\end{tabular}


Q10. Revisão dos recursos

\begin{tabular}{|c|c|c|c|c|c|}
\hline & & Frequência & Porcentagem & $\begin{array}{l}\text { Porcentagem } \\
\text { válida }\end{array}$ & $\begin{array}{l}\text { Porcentagem } \\
\text { acumulada }\end{array}$ \\
\hline \multirow{7}{*}{ Válido } & Sempre & 16 & 8,1 & 8,1 & 8,1 \\
\hline & Geralmente & 39 & 19,7 & 19,7 & 27,8 \\
\hline & Às Vezes & 79 & 39,9 & 39,9 & 67,7 \\
\hline & Raramente & 38 & 19,2 & 19,2 & 86,9 \\
\hline & Nunca & 9 & 4,5 & 4,5 & 91,4 \\
\hline & Não aplicável & 17 & 8,6 & 8,6 & 100,0 \\
\hline & Total & 198 & 100,0 & 100,0 & \\
\hline
\end{tabular}

Q11. Definição de Responsabilidades

\begin{tabular}{|c|c|c|c|c|c|}
\hline & & Frequência & Porcentagem & $\begin{array}{c}\text { Porcentagem } \\
\text { válida }\end{array}$ & $\begin{array}{c}\text { Porcentagem } \\
\text { acumulada }\end{array}$ \\
\hline \multirow{7}{*}{ Válido } & Muito bem definidas & 17 & 8,6 & 8,6 & 8,6 \\
\hline & Bem definidas & 79 & 39,9 & 39,9 & 48,5 \\
\hline & Razoavelmente definidas & 49 & 24,7 & 24,7 & 73,2 \\
\hline & Mal definidas & 33 & 16,7 & 16,7 & 89,9 \\
\hline & Muito mal definidas & 15 & 7,6 & 7,6 & 97,5 \\
\hline & Não aplicável & 5 & 2,5 & 2,5 & 100,0 \\
\hline & Total & 198 & 100,0 & 100,0 & \\
\hline
\end{tabular}

Q12. Conhecimento das Responsabilidades

\begin{tabular}{|l|c|c|c|c|}
\hline & Frequência & Porcentagem & $\begin{array}{c}\text { Porcentagem } \\
\text { válida }\end{array}$ & $\begin{array}{c}\text { Porcentagem } \\
\text { acumulada }\end{array}$ \\
\hline Muito Alto & 32 & 16,2 & 16,2 & 16,2 \\
Alto & 55 & 27,8 & 27,8 & 43,9 \\
Razoável & 67 & 33,8 & 33,8 & 77,8 \\
Válido & Baixo & 13,1 & 13,1 & 90,9 \\
Muito baixo & 12 & 6,1 & 6,1 & 97,0 \\
Não aplicável & 6 & 3,0 & 3,0 & 100,0 \\
$\quad$ Total & 198 & 100,0 & 100,0 & \\
\hline
\end{tabular}

\section{Q13. Comprometimento da Alta Adm}

\begin{tabular}{|l|c|c|c|c|}
\hline & Frequência & Porcentagem & $\begin{array}{c}\text { Porcentagem } \\
\text { válida }\end{array}$ & $\begin{array}{c}\text { Porcentagem } \\
\text { acumulada }\end{array}$ \\
\hline Extremamente comprometida & 18 & 9,1 & 9,1 & 9,1 \\
Muito comprometida & 61 & 30,8 & 30,8 & 39,9 \\
Moderadamente comprometida & 70 & 35,4 & 35,4 & 75,3 \\
Válido & 40 & 20,2 & 20,2 & 95,5 \\
Pouco comprometida & 4 & 2,0 & 2,0 & 97,5 \\
Nada comprometida & 5 & 2,5 & 2,5 & 100,0 \\
Não aplicável & 198 & 100,0 & 100,0 & \\
\multicolumn{1}{|r|}{ Total } & & & \\
\hline
\end{tabular}


Q14. Comprometimento da Gerência

\begin{tabular}{|c|c|c|c|c|c|}
\hline & & Frequência & Porcentagem & $\begin{array}{l}\text { Porcentagem } \\
\text { válida }\end{array}$ & $\begin{array}{c}\text { Porcentagem } \\
\text { acumulada }\end{array}$ \\
\hline \multirow{7}{*}{ Válido } & Extremamente comprometida & 8 & 4,0 & 4,0 & 4,0 \\
\hline & Muito comprometida & 58 & 29,3 & 29,3 & 33,3 \\
\hline & Moderadamente comprometida & 86 & 43,4 & 43,4 & 76,8 \\
\hline & Pouco comprometida & 37 & 18,7 & 18,7 & 95,5 \\
\hline & Nada comprometida & 2 & 1,0 & 1,0 & 96,5 \\
\hline & Não aplicável & 7 & 3,5 & 3,5 & 100,0 \\
\hline & Total & 198 & 100,0 & 100,0 & \\
\hline
\end{tabular}

Q15. Estado atual da segurança

\begin{tabular}{|c|c|c|c|c|c|}
\hline & & Frequência & Porcentagem & $\begin{array}{l}\text { Porcentagem } \\
\text { válida }\end{array}$ & $\begin{array}{l}\text { Porcentagem } \\
\text { acumulada }\end{array}$ \\
\hline \multirow{7}{*}{ Válido } & Muito bom & 24 & 12,1 & 12,1 & 12,1 \\
\hline & Bom & 76 & 38,4 & 38,4 & 50,5 \\
\hline & Regular & 60 & 30,3 & 30,3 & 80,8 \\
\hline & Ruim & 28 & 14,1 & 14,1 & 94,9 \\
\hline & Muito ruim & 7 & 3,5 & 3,5 & 98,5 \\
\hline & Não aplicável & 3 & 1,5 & 1,5 & 100,0 \\
\hline & Total & 198 & 100,0 & 100,0 & \\
\hline
\end{tabular}

Q16. Comunicação entre Adm e funcionários

\begin{tabular}{|ll|c|c|c|c|}
\hline & Frequência & $\begin{array}{c}\text { Porcentage } \\
\mathrm{m}\end{array}$ & $\begin{array}{c}\text { Porcentagem } \\
\text { válida }\end{array}$ & $\begin{array}{c}\text { Porcentagem } \\
\text { acumulada }\end{array}$ \\
\hline Extremamente transparentes e eficazes & 15 & 7,6 & 7,6 & 7,6 \\
Muito transparentes e eficazes & 34 & 17,2 & 17,2 & 24,7 \\
Razoavelmente transparentes e eficazes & 87 & 43,9 & 43,9 & 68,7 \\
Válido & 36 & 18,2 & 18,2 & 86,9 \\
Pouco transparentes e eficazes & 23 & 11,6 & 11,6 & 98,5 \\
Muito pouco transparentes e eficazes & 3 & 1,5 & 1,5 & 100,0 \\
Não aplicável & 198 & 100,0 & 100,0 & \\
& \multicolumn{2}{c}{ Total } & & &
\end{tabular}

\section{Q17. Comunicação entre turnos}

\begin{tabular}{|l|c|c|c|c|}
\hline & Frequência & Porcentagem & $\begin{array}{c}\text { Porcentagem } \\
\text { válida }\end{array}$ & $\begin{array}{c}\text { Porcentagem } \\
\text { acumulada }\end{array}$ \\
\hline Preocupação absoluta & 6 & 3,0 & 3,0 & 3,0 \\
Bastante preocupação & 30 & 15,2 & 15,2 & 18,2 \\
Preocupação moderada & 21 & 10,6 & 10,6 & 28,8 \\
Válido & 15 & 7,6 & 7,6 & 36,4 \\
Pouca preocupação & 3 & 1,5 & 1,5 & 37,9 \\
Nenhuma preocupação & 123 & 62,1 & 62,1 & 100,0 \\
Não aplicável & 198 & 100,0 & 100,0 & \\
\multicolumn{1}{|r|}{ Total } & & &
\end{tabular}


Q18. Checagem da comunicação

\begin{tabular}{|c|c|c|c|c|c|}
\hline & & Frequência & Porcentagem & $\begin{array}{l}\text { Porcentagem } \\
\text { válida }\end{array}$ & $\begin{array}{c}\text { Porcentagem } \\
\text { acumulada }\end{array}$ \\
\hline \multirow{7}{*}{ Válido } & Sempre & 12 & 6,1 & 6,1 & 6,1 \\
\hline & Geralmente & 34 & 17,2 & 17,2 & 23,2 \\
\hline & Às Vezes & 32 & 16,2 & 16,2 & 39,4 \\
\hline & Raramente & 24 & 12,1 & 12,1 & 51,5 \\
\hline & Nunca & 24 & 12,1 & 12,1 & 63,6 \\
\hline & Não aplicável & 72 & 36,4 & 36,4 & 100,0 \\
\hline & Total & 198 & 100,0 & 100,0 & \\
\hline
\end{tabular}

Q19. Relação com superiores

\begin{tabular}{|c|c|c|c|c|c|}
\hline & & Frequência & Porcentagem & $\begin{array}{l}\text { Porcentagem } \\
\text { válida }\end{array}$ & $\begin{array}{l}\text { Porcentagem } \\
\text { acumulada }\end{array}$ \\
\hline \multirow{7}{*}{ Válido } & Sempre & 83 & 41,9 & 41,9 & 41,9 \\
\hline & Geralmente & 75 & 37,9 & 37,9 & 79,8 \\
\hline & Às Vezes & 24 & 12,1 & 12,1 & 91,9 \\
\hline & Raramente & 8 & 4,0 & 4,0 & 96,0 \\
\hline & Nunca & 3 & 1,5 & 1,5 & 97,5 \\
\hline & Não aplicável & 5 & 2,5 & 2,5 & 100,0 \\
\hline & Total & 198 & 100,0 & 100,0 & \\
\hline
\end{tabular}

Q20. Relação com Reguladores

\begin{tabular}{|l|c|c|c|c|}
\hline & Frequência & Porcentagem & $\begin{array}{c}\text { Porcentagem } \\
\text { válida }\end{array}$ & $\begin{array}{c}\text { Porcentagem } \\
\text { acumulada }\end{array}$ \\
\hline Extremamente receptiva & 22 & 11,1 & 11,1 & 11,1 \\
Muito receptiva & 51 & 25,8 & 25,8 & 36,9 \\
Razoavelmente receptiva & 61 & 30,8 & 30,8 & 67,7 \\
Válido & 15 & 7,6 & 7,6 & 75,3 \\
Pouco receptiva & 8 & 4,0 & 4,0 & 79,3 \\
Muito pouco receptiva & 41 & 20,7 & 20,7 & 100,0 \\
Não aplicável & 198 & 100,0 & 100,0 & \\
\multicolumn{2}{|r}{ Total } & & &
\end{tabular}

Q21. Adequação dos treinamentos

\begin{tabular}{|c|c|c|c|c|c|}
\hline & & Frequência & Porcentagem & $\begin{array}{l}\text { Porcentagem } \\
\text { válida }\end{array}$ & $\begin{array}{c}\text { Porcentagem } \\
\text { acumulada }\end{array}$ \\
\hline \multirow{7}{*}{ Válido } & Máximo & 9 & 4,5 & 4,5 & 4,5 \\
\hline & Alto & 72 & 36,4 & 36,4 & 40,9 \\
\hline & Regular & 69 & 34,8 & 34,8 & 75,8 \\
\hline & Baixo & 22 & 11,1 & 11,1 & 86,9 \\
\hline & Mínimo & 13 & 6,6 & 6,6 & 93,4 \\
\hline & Não aplicável & 13 & 6,6 & 6,6 & 100,0 \\
\hline & Total & 198 & 100,0 & 100,0 & \\
\hline
\end{tabular}


Q22. Revisão dos treinamentos

\begin{tabular}{|c|c|c|c|c|c|}
\hline & & Frequência & Porcentagem & $\begin{array}{l}\text { Porcentagem } \\
\text { válida }\end{array}$ & $\begin{array}{c}\text { Porcentagem } \\
\text { acumulada }\end{array}$ \\
\hline \multirow{7}{*}{ Válido } & Sempre & 23 & 11,6 & 11,6 & 11,6 \\
\hline & Geralmente & 51 & 25,8 & 25,8 & 37,4 \\
\hline & Às Vezes & 57 & 28,8 & 28,8 & 66,2 \\
\hline & Raramente & 37 & 18,7 & 18,7 & 84,8 \\
\hline & Nunca & 9 & 4,5 & 4,5 & 89,4 \\
\hline & Não aplicável & 21 & 10,6 & 10,6 & 100,0 \\
\hline & Total & 198 & 100,0 & 100,0 & \\
\hline
\end{tabular}

Q23. Equipe de trabalho

\begin{tabular}{|c|c|c|c|c|c|}
\hline & & Frequência & Porcentagem & $\begin{array}{c}\text { Porcentagem } \\
\text { válida }\end{array}$ & $\begin{array}{l}\text { Porcentagem } \\
\text { acumulada }\end{array}$ \\
\hline \multirow{7}{*}{ Válido } & Máximo & 4 & 2,0 & 2,0 & 2,0 \\
\hline & Alto & 72 & 36,4 & 36,4 & 38,4 \\
\hline & Regular & 78 & 39,4 & 39,4 & 77,8 \\
\hline & Baixo & 26 & 13,1 & 13,1 & 90,9 \\
\hline & Mínimo & 10 & 5,1 & 5,1 & 96,0 \\
\hline & Não aplicável & 8 & 4,0 & 4,0 & 100,0 \\
\hline & Total & 198 & 100,0 & 100,0 & \\
\hline
\end{tabular}

Q24. Qualificação

\begin{tabular}{|c|c|c|c|c|c|}
\hline & & Frequência & Porcentagem & $\begin{array}{c}\text { Porcentagem } \\
\text { válida }\end{array}$ & $\begin{array}{c}\text { Porcentagem } \\
\text { acumulada }\end{array}$ \\
\hline \multirow{7}{*}{ Válido } & Muito Bem & 55 & 27,8 & 27,8 & 27,8 \\
\hline & Bem & 95 & 48,0 & 48,0 & 75,8 \\
\hline & Razoavelmente & 27 & 13,6 & 13,6 & 89,4 \\
\hline & Mal & 12 & 6,1 & 6,1 & 95,5 \\
\hline & Muito mal & 1 & 0,5 & 0,5 & 96,0 \\
\hline & Não aplicável & 8 & 4,0 & 4,0 & 100,0 \\
\hline & Total & 198 & 100,0 & 100,0 & \\
\hline
\end{tabular}

Q25. Conteúdo da documentação

\begin{tabular}{|c|c|c|c|c|c|}
\hline & & Frequência & Porcentagem & $\begin{array}{l}\text { Porcentagem } \\
\text { válida }\end{array}$ & $\begin{array}{c}\text { Porcentagem } \\
\text { acumulada }\end{array}$ \\
\hline \multirow{7}{*}{ Válido } & Muito Boa & 27 & 13,6 & 13,6 & 13,6 \\
\hline & Boa & 86 & 43,4 & 43,4 & 57,1 \\
\hline & Razoável & 53 & 26,8 & 26,8 & 83,8 \\
\hline & Ruim & 16 & 8,1 & 8,1 & 91,9 \\
\hline & Muito ruim & 6 & 3,0 & 3,0 & 94,9 \\
\hline & Não aplicável & 10 & 5,1 & 5,1 & 100,0 \\
\hline & Total & 198 & 100,0 & 100,0 & \\
\hline
\end{tabular}


Q26. Disponibilidade da documentação

\begin{tabular}{|c|c|c|c|c|c|}
\hline & & Frequência & Porcentagem & $\begin{array}{l}\text { Porcentagem } \\
\text { válida }\end{array}$ & $\begin{array}{c}\text { Porcentagem } \\
\text { acumulada }\end{array}$ \\
\hline \multirow{7}{*}{ Válido } & Sempre & 53 & 26,8 & 26,8 & 26,8 \\
\hline & Geralmente & 83 & 41,9 & 41,9 & 68,7 \\
\hline & Às Vezes & 33 & 16,7 & 16,7 & 85,4 \\
\hline & Raramente & 13 & 6,6 & 6,6 & 91,9 \\
\hline & Nunca & 4 & 2,0 & 2,0 & 93,9 \\
\hline & Não aplicável & 12 & 6,1 & 6,1 & 100,0 \\
\hline & Total & 198 & 100,0 & 100,0 & \\
\hline
\end{tabular}

Q27. Entendimento da documentação

\begin{tabular}{|l|c|c|c|c|}
\hline & Frequência & Porcentagem & $\begin{array}{c}\text { Porcentagem } \\
\text { válida }\end{array}$ & $\begin{array}{c}\text { Porcentagem } \\
\text { acumulada }\end{array}$ \\
\hline Muito Alto & 39 & 19,7 & 19,7 & 19,7 \\
Alto & 102 & 51,5 & 51,5 & 71,2 \\
Razoável & 34 & 17,2 & 17,2 & 88,4 \\
Válido & 6 & 3,0 & 3,0 & 91,4 \\
Baixo & 4 & 2,0 & 2,0 & 93,4 \\
Muito baixo & 13 & 6,6 & 6,6 & 100,0 \\
Não aplicável & 198 & 100,0 & 100,0 & \\
$\quad$ Total & & & & \\
\hline
\end{tabular}

Q28. Problemas na documentação

\begin{tabular}{|c|c|c|c|c|c|}
\hline & & Frequência & Porcentagem & $\begin{array}{l}\text { Porcentagem } \\
\text { válida }\end{array}$ & $\begin{array}{c}\text { Porcentagem } \\
\text { acumulada }\end{array}$ \\
\hline \multirow{7}{*}{ Válido } & Muito Boa & 31 & 15,7 & 15,7 & 15,7 \\
\hline & Boa & 91 & 46,0 & 46,0 & 61,6 \\
\hline & Razoável & 42 & 21,2 & 21,2 & 82,8 \\
\hline & Ruim & 13 & 6,6 & 6,6 & 89,4 \\
\hline & Muito ruim & 4 & 2,0 & 2,0 & 91,4 \\
\hline & Não aplicável & 17 & 8,6 & 8,6 & 100,0 \\
\hline & Total & 198 & 100,0 & 100,0 & \\
\hline
\end{tabular}

Q29. Atualização da documentação

\begin{tabular}{|l|c|c|c|c|}
\hline & Frequência & Porcentagem & $\begin{array}{c}\text { Porcentagem } \\
\text { válida }\end{array}$ & $\begin{array}{c}\text { Porcentagem } \\
\text { acumulada }\end{array}$ \\
\hline Muito Boa & 23 & 11,6 & 11,6 & 11,6 \\
Boa & 80 & 40,4 & 40,4 & 52,0 \\
Razoável & 53 & 26,8 & 26,8 & 78,8 \\
Válido & 20 & 10,1 & 10,1 & 88,9 \\
Ruim & 8 & 4,0 & 4,0 & 92,9 \\
Muito ruim & 14 & 7,1 & 7,1 & 100,0 \\
Não aplicável & 198 & 100,0 & 100,0 & \\
Total & & & & \\
\hline
\end{tabular}


Q30. Exequibilidade do processo

\begin{tabular}{|cl|c|c|c|c|}
\hline & Frequência & Porcentagem & $\begin{array}{c}\text { Porcentagem } \\
\text { válida }\end{array}$ & $\begin{array}{c}\text { Porcentagem } \\
\text { acumulada }\end{array}$ \\
\hline \multirow{6}{*}{ Válido } & Extremamente fácil & 13 & 6,6 & 6,7 & 6,7 \\
& Muito fácil & 70 & 35,4 & 35,9 & 42,6 \\
& Razoavelmente fácil & 75 & 37,9 & 38,5 & 81,0 \\
& Difícil & 19 & 9,6 & 9,7 & 90,8 \\
& Muito difícil & 1 & 0,5 & 0,5 & 91,3 \\
& Não aplicável & 17 & 8,6 & 8,7 & 100,0 \\
Ausente & Total & 195 & 98,5 & 100,0 & \\
& Sistema & 3 & 1,5 & & \\
\hline
\end{tabular}

Q31. Carga de trabalho

\begin{tabular}{|c|c|c|c|c|c|}
\hline & & Frequência & Porcentagem & $\begin{array}{l}\text { Porcentagem } \\
\text { válida }\end{array}$ & $\begin{array}{c}\text { Porcentagem } \\
\text { acumulada }\end{array}$ \\
\hline \multirow{5}{*}{ Válido } & Extremamente equilibrada & 11 & 5,6 & 5,8 & 5,8 \\
\hline & Muito equilibrada & 85 & 42,9 & 44,7 & 50,5 \\
\hline & Moderadamente equilibrada & 65 & 32,8 & 34,2 & 84,7 \\
\hline & Pouco equilibrada & 19 & 9,6 & 10,0 & 94,7 \\
\hline & Nem um pouco equilibrada & 10 & 5,1 & 5,3 & 100,0 \\
\hline \multirow{3}{*}{ Ausente } & Total & 190 & 96,0 & 100,0 & \\
\hline & Sistema & 8 & 4,0 & & \\
\hline & Total & 198 & 100,0 & & \\
\hline
\end{tabular}

Q32. Temperatura do ambiente

\begin{tabular}{|c|c|c|c|c|c|}
\hline & & Frequência & Porcentagem & $\begin{array}{l}\text { Porcentagem } \\
\text { válida }\end{array}$ & $\begin{array}{c}\text { Porcentagem } \\
\text { acumulada }\end{array}$ \\
\hline \multirow{5}{*}{ Válido } & Muito bom & 34 & 17,2 & 18,2 & 18,2 \\
\hline & Bom & 109 & 55,1 & 58,3 & 76,5 \\
\hline & Razoável & 25 & 12,6 & 13,4 & 89,8 \\
\hline & Ruim & 15 & 7,6 & 8,0 & 97,9 \\
\hline & Muito ruim & 4 & 2,0 & 2,1 & 100,0 \\
\hline \multirow{3}{*}{ Ausente } & Total & 187 & 94,4 & 100,0 & \\
\hline & Sistema & 11 & 5,6 & & \\
\hline & Total & 198 & 100,0 & & \\
\hline
\end{tabular}

Q33. Luminosidade do ambiente

\begin{tabular}{|cl|c|c|c|c|}
\hline \multirow{6}{*}{ Válido } & Frequência & Porcentagem & $\begin{array}{c}\text { Porcentagem } \\
\text { válida }\end{array}$ & $\begin{array}{c}\text { Porcentagem } \\
\text { acumulada }\end{array}$ \\
\hline \multirow{6}{*}{ Muito bom } & 46 & 23,2 & 24,6 & 24,6 \\
& Bom & 108 & 54,5 & 57,8 & 82,4 \\
& Razoável & 26 & 13,1 & 13,9 & 96,3 \\
& Ruim & 5 & 2,5 & 2,7 & 98,9 \\
& Muito ruim & 2 & 1,0 & 1,1 & 100,0 \\
& Total & 187 & 94,4 & 100,0 & \\
Ausente & Sistema & 11 & 5,6 & & \\
\multicolumn{2}{|c|}{ Total } & 198 & 100,0 & & \\
\hline
\end{tabular}


Q34. Qualidade do Ar

\begin{tabular}{|cl|c|c|c|c|}
\hline & Frequência & Porcentagem & $\begin{array}{c}\text { Porcentagem } \\
\text { válida }\end{array}$ & $\begin{array}{c}\text { Porcentagem } \\
\text { acumulada }\end{array}$ \\
\hline \multirow{6}{*}{ Válido } & Ótima & 47 & 23,7 & 25,1 & 25,1 \\
& Boa & 90 & 45,5 & 48,1 & 73,3 \\
& Regular & 37 & 18,7 & 19,8 & 93,0 \\
& Ruim & 7 & 3,5 & 3,7 & 96,8 \\
& Muito ruim & 3 & 1,5 & 1,6 & 98,4 \\
& Não aplicável & 3 & 1,5 & 1,6 & 100,0 \\
& $\quad$ Total & 187 & 94,4 & 100,0 & \\
Ausente & Sistema & 11 & 5,6 & & \\
& Total & 198 & 100,0 & & \\
\hline
\end{tabular}

Q35. Ruídos no ambiente

\begin{tabular}{|cl|c|c|c|c|}
\hline & Frequência & Porcentagem & $\begin{array}{c}\text { Porcentagem } \\
\text { válida }\end{array}$ & $\begin{array}{c}\text { Porcentagem } \\
\text { acumulada }\end{array}$ \\
\hline \multirow{6}{*}{ Válido } & Muito bom & 31 & 15,7 & 16,6 & 16,6 \\
& Bom & 82 & 41,4 & 43,9 & 60,4 \\
& Razoável & 45 & 22,7 & 24,1 & 84,5 \\
& Ruim & 19 & 9,6 & 10,2 & 94,7 \\
& Muito ruim & 8 & 4,0 & 4,3 & 98,9 \\
& Não aplicável & 2 & 1,0 & 1,1 & 100,0 \\
& Total & 187 & 94,4 & 100,0 & \\
Ausente & Sistema & 11 & 5,6 & & \\
& Total & 198 & 100,0 & & \\
\hline
\end{tabular}

Q36. Pressão do tempo

\begin{tabular}{|cl|c|c|c|c|}
\hline & Frequência & Porcentagem & $\begin{array}{c}\text { Porcentagem } \\
\text { válida }\end{array}$ & $\begin{array}{c}\text { Porcentagem } \\
\text { acumulada }\end{array}$ \\
\hline \multirow{6}{*}{ Válido } & Muito maior & 3 & 1,5 & 1,6 & 1,6 \\
& Maior & 32 & 16,2 & 17,1 & 18,7 \\
& Equivalente & 119 & 60,1 & 63,6 & 82,4 \\
& Menor & 21 & 10,6 & 11,2 & 93,6 \\
& Muito menor & 6 & 3,0 & 3,2 & 96,8 \\
& Não aplicável & 6 & 3,0 & 3,2 & 100,0 \\
Ausente & Total & 187 & 94,4 & 100,0 & \\
& Sistema & 11 & 5,6 & & \\
& Total & 198 & 100,0 & & \\
\hline
\end{tabular}

Q37. Ergonomia no trabalho

\begin{tabular}{|cl|c|c|c|c|}
\hline & Frequência & Porcentagem & $\begin{array}{c}\text { Porcentagem } \\
\text { válida }\end{array}$ & $\begin{array}{c}\text { Porcentagem } \\
\text { acumulada }\end{array}$ \\
\hline \multirow{6}{*}{ Válido } & Muito Boa & 29 & 14,6 & 15,5 & 15,5 \\
& Boa & 78 & 39,4 & 41,7 & 57,2 \\
& Razoável & 48 & 24,2 & 25,7 & 82,9 \\
& Ruim & 13 & 6,6 & 7,0 & 89,8 \\
& Muito ruim & 9 & 4,5 & 4,8 & 94,7 \\
& Não aplicável & 10 & 5,1 & 5,3 & 100,0 \\
& Total & 187 & 94,4 & 100,0 & \\
Ausente & Sistema & 11 & 5,6 & & \\
& Total & 198 & 100,0 & & \\
\hline
\end{tabular}


Q38. Limpeza do ambiente

\begin{tabular}{|cl|c|c|c|c|}
\hline & Frequência & Porcentagem & $\begin{array}{c}\text { Porcentagem } \\
\text { válida }\end{array}$ & $\begin{array}{c}\text { Porcentagem } \\
\text { acumulada }\end{array}$ \\
\hline \multirow{6}{*}{ Válido } & Ótimas & 36 & 18,2 & 19,4 & 19,4 \\
& Boas & 104 & 52,5 & 55,9 & 75,3 \\
& Razoáveis & 41 & 20,7 & 22,0 & 97,3 \\
& Ruins & 3 & 1,5 & 1,6 & 98,9 \\
& Muito ruins & 2 & 1,0 & 1,1 & 100,0 \\
& Total & 186 & 93,9 & 100,0 & \\
Ausente & Sistema & 12 & 6,1 & & \\
& Total & 198 & 100,0 & & \\
\hline
\end{tabular}

Q39. Estado dos Sistemas de segurança

\begin{tabular}{|cl|c|c|c|c|}
\hline & Frequência & Porcentagem & $\begin{array}{c}\text { Porcentagem } \\
\text { válida }\end{array}$ & $\begin{array}{c}\text { Porcentagem } \\
\text { acumulada }\end{array}$ \\
\hline \multirow{6}{*}{ Válido } & Ótimo & 14 & 7,1 & 7,5 & 7,5 \\
& Bom & 66 & 33,3 & 35,5 & 43,0 \\
& Razoável & 64 & 32,3 & 34,4 & 77,4 \\
& Ruim & 21 & 10,6 & 11,3 & 88,7 \\
& Muito ruim & 10 & 5,1 & 5,4 & 94,1 \\
& Não aplicável & 11 & 5,6 & 5,9 & 100,0 \\
Ausente & Total & 186 & 93,9 & 100,0 & \\
& Sistema & 12 & 6,1 & & \\
& Total & 198 & 100,0 & & \\
\hline
\end{tabular}

Q40. Estresse no trabalho

\begin{tabular}{|c|c|c|c|c|c|}
\hline & & Frequência & Porcentagem & $\begin{array}{c}\text { Porcentagem } \\
\text { válida }\end{array}$ & $\begin{array}{c}\text { Porcentagem } \\
\text { acumulada }\end{array}$ \\
\hline \multirow{6}{*}{ Válido } & Nem um pouco estressante & 21 & 10.6 & 11.3 & 11.3 \\
\hline & Pouco estressante & 62 & 31.3 & 33.3 & 44.6 \\
\hline & Razoavelmente estressante & 78 & 39.4 & 41.9 & 86.6 \\
\hline & Muito estressante & 19 & 9.6 & 10.2 & 96.8 \\
\hline & Extremamente estressante & 2 & 1.0 & 1.1 & 97.8 \\
\hline & Não aplicável & 4 & 2.0 & 2.2 & 100.0 \\
\hline \multirow{3}{*}{ Ausente } & Total & 186 & 93.9 & 100.0 & \\
\hline & Sistema & 12 & 6.1 & & \\
\hline & Total & 198 & 100.0 & & \\
\hline
\end{tabular}

Q41. Demanda de horas extras

\begin{tabular}{|ll|c|c|c|c|}
\hline & Frequência & Porcentagem & $\begin{array}{c}\text { Porcentagem } \\
\text { válida }\end{array}$ & $\begin{array}{c}\text { Porcentagem } \\
\text { acumulada }\end{array}$ \\
\hline \multirow{6}{*}{ Válido } & Nunca & 23 & 11,6 & 12,4 & 12,4 \\
& Raramente & 34 & 17,2 & 18,3 & 30,6 \\
& De vez em quando & 37 & 18,7 & 19,9 & 50,5 \\
& Geralmente & 14 & 7,1 & 7,5 & 58,1 \\
& Sempre & 13 & 6,6 & 7,0 & 65,1 \\
& Não aplicável & 65 & 32,8 & 34,9 & 100,0 \\
& Total & 186 & 93,9 & 100,0 & \\
Ausente & Sistema & 12 & 6,1 & & \\
& Total & 198 & 100,0 & & \\
\hline
\end{tabular}


Q42. Satisfação no trabalho

\begin{tabular}{|cl|c|c|c|c|}
\hline & Frequência & Porcentagem & $\begin{array}{c}\text { Porcentagem } \\
\text { válida }\end{array}$ & $\begin{array}{c}\text { Porcentagem } \\
\text { acumulada }\end{array}$ \\
\hline \multirow{6}{*}{ Válido } & Máximo & 9 & 4,5 & 4,9 & 4,9 \\
& Alto & 65 & 32,8 & 35,1 & 40,0 \\
& Moderado & 71 & 35,9 & 38,4 & 78,4 \\
& Baixo & 24 & 12,1 & 13,0 & 91,4 \\
& Mínimo & 14 & 7,1 & 7,6 & 98,9 \\
& Não aplicável & 2 & 1,0 & 1,1 & 100,0 \\
& Total & 185 & 93,4 & 100,0 & \\
Ausente & Sistema & 13 & 6,6 & & \\
& Total & 198 & 100,0 & & \\
\hline
\end{tabular}

Q43. Lições aprendidas

\begin{tabular}{|c|c|c|c|c|c|}
\hline & & Frequência & Porcentagem & $\begin{array}{l}\text { Porcentagem } \\
\text { válida }\end{array}$ & $\begin{array}{l}\text { Porcentagem } \\
\text { acumulada }\end{array}$ \\
\hline \multirow{6}{*}{ Válido } & Consideração total & 12 & 6,1 & 6,5 & 6,5 \\
\hline & Bastante consideração & 65 & 32,8 & 35,1 & 41,6 \\
\hline & Consideração moderada & 49 & 24,7 & 26,5 & 68,1 \\
\hline & Pouca consideração & 28 & 14,1 & 15,1 & 83,2 \\
\hline & Nenhuma consideração & 12 & 6,1 & 6,5 & 89,7 \\
\hline & Não aplicável & 19 & 9,6 & 10,3 & 100,0 \\
\hline \multirow{3}{*}{ Ausente } & Total & 185 & 93,4 & 100,0 & \\
\hline & Sistema & 13 & 6,6 & & \\
\hline & Total & 198 & 100,0 & & \\
\hline
\end{tabular}

Q44. Análise de acidentes

\begin{tabular}{|cl|c|c|c|c|}
\hline \multirow{6}{*}{ Válido } & Frequência & Porcentagem & $\begin{array}{c}\text { Porcentagem } \\
\text { válida }\end{array}$ & $\begin{array}{c}\text { Porcentagem } \\
\text { acumulada }\end{array}$ \\
\hline & Extrema importância & 36 & 18,2 & 19,5 & 19,5 \\
& Muita importância & 65 & 32,8 & 35,1 & 54,6 \\
& Importância moderada & 41 & 20,7 & 22,2 & 76,8 \\
& Pouca importância & 23 & 11,6 & 12,4 & 89,2 \\
& Nenhuma importância & 2 & 1,0 & 1,1 & 90,3 \\
& Não aplicável & 18 & 9,1 & 9,7 & 100,0 \\
Ausente & Total & 185 & 93,4 & 100,0 & \\
& Sistema & 13 & 6,6 & & \\
& Total & 198 & 100,0 & & \\
\hline
\end{tabular}

Q45. Ações corretivas

\begin{tabular}{|c|c|c|c|c|c|}
\hline & & Frequência & Porcentagem & $\begin{array}{c}\text { Porcentagem } \\
\text { válida }\end{array}$ & $\begin{array}{l}\text { Porcentagem } \\
\text { acumulada }\end{array}$ \\
\hline \multirow{6}{*}{ Válido } & Extremamente eficazes & 8 & 4,0 & 4,3 & 4,3 \\
\hline & Muito eficazes & 39 & 19,7 & 21,1 & 25,4 \\
\hline & Razoavelmente eficazes & 83 & 41,9 & 44,9 & 70,3 \\
\hline & Pouco eficazes & 29 & 14,6 & 15,7 & 85,9 \\
\hline & Ineficazes & 3 & 1,5 & 1,6 & 87,6 \\
\hline & Não aplicável & 23 & 11,6 & 12,4 & 100,0 \\
\hline \multirow{3}{*}{ Ausente } & Total & 185 & 93,4 & 100,0 & \\
\hline & Sistema & 13 & 6,6 & & \\
\hline & Total & 198 & 100,0 & & \\
\hline
\end{tabular}


Q46. Divulgação das causas dos acidentes

\begin{tabular}{|cl|c|c|c|c|}
\hline & Frequência & Porcentagem & $\begin{array}{c}\text { Porcentagem } \\
\text { válida }\end{array}$ & $\begin{array}{c}\text { Porcentagem } \\
\text { acumulada }\end{array}$ \\
\hline \multirow{6}{*}{ Válido } & Extremamente transparente & 13 & 6,6 & 7,0 & 7,0 \\
& Muito transparente & 45 & 22,7 & 24,3 & 31,4 \\
& Razoavelmente transparente & 57 & 28,8 & 30,8 & 62,2 \\
& Pouco transparente & 45 & 22,7 & 24,3 & 86,5 \\
& Não transparente & 13 & 6,6 & 7,0 & 93,5 \\
& Não aplicável & 12 & 6,1 & 6,5 & 100,0 \\
\multirow{2}{*}{ Ausente } & Total & 185 & 93,4 & 100,0 & \\
& Sistema & 13 & 6,6 & & \\
\hline
\end{tabular}

Q47. Avaliações externas (receptividade)

\begin{tabular}{|c|c|c|c|c|c|}
\hline & & Frequência & Porcentagem & $\begin{array}{c}\text { Porcentagem } \\
\text { válida }\end{array}$ & $\begin{array}{c}\text { Porcentagem } \\
\text { acumulada }\end{array}$ \\
\hline \multirow{6}{*}{ Válido } & Extremamente receptiva & 9 & 4,5 & 5,0 & 5,0 \\
\hline & Muito receptiva & 58 & 29,3 & 32,0 & 37,0 \\
\hline & Razoavelmente receptiva & 54 & 27,3 & 29,8 & 66,9 \\
\hline & Pouco receptiva & 17 & 8,6 & 9,4 & 76,2 \\
\hline & Muito pouco receptiva & 8 & 4,0 & 4,4 & 80,7 \\
\hline & Não aplicável & 35 & 17,7 & 19,3 & 100,0 \\
\hline \multirow{3}{*}{ Ausente } & Total & 181 & 91,4 & 100,0 & \\
\hline & Sistema & 17 & 8,6 & & \\
\hline & Total & 198 & 100,0 & & \\
\hline
\end{tabular}

Q48. Avaliações internas (frequência)

\begin{tabular}{|cl|c|c|c|c|}
\hline & Frequência & Porcentagem & $\begin{array}{c}\text { Porcentagem } \\
\text { válida }\end{array}$ & $\begin{array}{c}\text { Porcentagem } \\
\text { acumulada }\end{array}$ \\
\hline \multirow{6}{*}{ Válido } & Sempre ocorrem & 20 & 10,1 & 11,0 & 11,0 \\
& Geralmente ocorrem & 33 & 16,7 & 18,2 & 29,3 \\
& Às vezes ocorrem & 61 & 30,8 & 33,7 & 63,0 \\
& Raramente ocorrem & 43 & 21,7 & 23,8 & 86,7 \\
& Nunca ocorrem & 13 & 6,6 & 7,2 & 93,9 \\
& Não aplicável & 11 & 5,6 & 6,1 & 100,0 \\
& Total & 181 & 91,4 & 100,0 & \\
Ausente & Sistema & 17 & 8,6 & & \\
& Total & 198 & 100,0 & & \\
\hline
\end{tabular}

Q49. Divulgação dos resultados das avaliações

\begin{tabular}{|cl|c|c|c|c|}
\hline & Frequência & Porcentagem & $\begin{array}{c}\text { Porcentagem } \\
\text { válida }\end{array}$ & $\begin{array}{c}\text { Porcentagem } \\
\text { acumulada }\end{array}$ \\
\hline \multirow{6}{*}{ Válido } & Muito bem divulgados & 5 & 2,5 & 2,8 & 2,8 \\
& Bem divulgados & 26 & 13,1 & 14,4 & 17,1 \\
& Razoavelmente divulgados & 43 & 21,7 & 23,8 & 40,9 \\
& Mal divulgados & 28 & 14,1 & 15,5 & 56,4 \\
& Muito mal divulgados & 18 & 9,1 & 9,9 & 66,3 \\
& Não aplicável & 61 & 30,8 & 33,7 & 100,0 \\
\multirow{2}{*}{ Ausente } & Total & 181 & 91,4 & 100,0 & \\
& Sistema & 17 & 8,6 & & \\
\hline
\end{tabular}

